\author{
Universidade de São Paulo \\ Instituto de Física
}

\title{
Absorção da Radiação por Aerossóis na Amazônia
}

\section{Bruna Amorim Holanda}

Orientador: Prof. Dr. Paulo Eduardo Artaxo Netto

Dissertação de mestrado apresentada ao Instituto de Física para a obtenção do título de Mestre em Ciências

Banca Examinadora:

Prof. Dr. Paulo Eduardo Artaxo Netto (IF-USP)

Profa. Dra. Maria de Fátima Andrade (IAG-USP)

Prof. Dr. Eduardo Landulfo (IPEN-USP) 


\section{FICHA CATALOGRÁFICA \\ Preparada pelo Serviço de Biblioteca e Informação do Instituto de Física da Universidade de São Paulo}

Holanda, Bruna Amorim

Absorção da radiação por aerossóis na Amazônia. S São Paulo, 2015.

Dissertação (Mestrado) - Universidade de São Paulo. Instituto de Física. Depto. de Física Aplicada.

Orientador: Prof. Dr. Paulo Eduardo Artaxo Netto

Área de Concentração: Física

Unitermos: 1. Mudança climática; 2. Sensoriamento remoto; 3. Aerossol; 4. Radiação atmosférica.

USP/IF/SBI-128/2015 
Aos meus pais, pelo reconhecido esforço e dedicação.

Às minhas irmãs.

Ao meu noivo Daniel. 


\section{AGRADECIMENTOS}

Ao Professor Paulo Artaxo, pela orientação, respeito e confiança depositada em mim. Por ter contribuído de todas as maneiras para o imenso aprendizado que obtive ao longo do mestrado.

Ao Joel, pela amizade, incentivo e pelas muitas horas que se dedicou a me ensinar e discutir resultados, sempre com muita paciência e bom humor. Por sempre me incentivar a ir mais longe.

Às queridas Samara e Elisa, pela amizade, por todas as discussões científicas, dicas e empenho para que eu realizasse um bom trabalho.

À Luciana pela atenção, paciência e ajuda inestimável no processamento, análise de dados e interpretação dos resultados.

Ao Henrique e ao Alexandre pela atenção e por todos os ensinamentos.

À Andrea e Simara pela convivência e valiosas conversas do dia-a-dia.

Aos técnicos Alcides, Fernando, Fabinho, Ana pelas explicações sobre instrumentação e por garantirem a qualidade das medidas.

A todos os meus queridos amigos do LFA (Boris, Rafael, Diego, Alex, Marina, Clarice, André, Nathalia e Theo) por fazerem do ambiente de trabalho um lugar especial, divertido e agradável.

À Clarice, pela amizade, pela revisão do texto e pelas palavras de motivação nos momentos mais difíceis.

Ao CNPq pelo apoio financeiro concedido para o desenvolvimento deste trabalho.

Ao Glauber e à Simone pela incrível disposição em ajudar.

Aos amigos de Quântica (Juliana, Leonardo e Júlio) pelas muitas horas de estudo e ajuda mútua. Agradeço especialmente à Ju pela ajuda na finalização da dissertação.

Aos colegas da graduação, especialmente à Tha e ao Sell pela presença em todos os momentos e pelos diversos happy hour nos fins de semana.

À Dalva e ao Alberto por todos os cafezinhos no final do dia, pela agradável companhia e muitas risadas.

Às minhas irmãs Thaís e Amanda, pelo apoio, torcida e incentivo.

Ao Daniel, pelo carinho, paciência e por estar sempre ao meu lado superando todos os desafios.

Aos meus pais Maria e Amaro, pelo amor incondicional, apoio e dedicação em todos os momentos. 


\section{RESUMO}

Neste estudo foi feita uma detalhada caracterização das propriedades óticas de partículas de aerossóis biogênicos, de poluição urbana e de queimadas na bacia Amazônia. Foram utilizadas diferentes abordagens, incluindo medidas in-situ e por sensoriamento remoto em várias localidades. Radiômetros solares da rede AERONET e instrumentos de medida de absorção (Aetalômetros e MAAP) e espalhamento (Nefelômetros) foram utilizados no experimento GoAmazon2014/5 que estudou o efeito das emissões urbanas de Manaus nas propriedades de aerossóis. Em regiões impactadas pela queima de biomassa, a forçante radiativa foi quantificada através de medidas da AERONET, separando as contribuições de carbono orgânico (OC) e elementar (EC). Com base apenas nas propriedades óticas dos aerossóis, foi feita uma análise qualitativa dos tipos de aerossóis dominantes durante a queima de biomassa na Amazônia, avaliando seus impactos no balanço radiativo. O OC emitido nas queimadas tem forte efeito de resfriamento no topo da atmosfera, com uma forçante radiativa de $-53 \pm 17$ $\mathrm{W} / \mathrm{m}^{2}$. O EC é altamente absorvedor e, apesar de estar presente em menor quantidade que o OC, apresenta um forte efeito na forçante radiativa no topo da atmosfera, tornando-a significativamente menos negativa, com efeitos de até $-12 \pm 9 \mathrm{~W} / \mathrm{m}^{2}$.

As propriedades de absorção e espalhamento associadas com as emissões urbanas da cidade de Manaus foram analisadas. Uma significativa diferença na componente de absorção da profundidade ótica foi observada entre dois sítios localizados vento acima e vento abaixo da pluma urbana. O efeito da absorção é notável principalmente na estação chuvosa, mas também pode ser observado com as plumas de queimadas na estação seca. A partir de medidas in-situ, foi observado que o albedo de espalhamento simples (SSA) médio diminui de 0,92 \pm 0,06 antes de Manaus para 0,83 \pm 0,11 na região impactada pela pluma urbana durante a estação chuvosa.

Medidas in-situ do coeficiente de absorção do particulado $\mathrm{PM}_{10}$ foram realizadas em paralelo com o $\mathrm{PM}_{2.5}$ durante a estação chuvosa na reserva $\mathrm{ZF}$ 2, para análise da absorção de partículas grossas biogênicas. Em condições de dominância do particulado biogênico, a absorção em $880 \mathrm{~nm}$ do $\mathrm{PM}_{10}$ é cerca de $10 \%$ superior à absorção do $\mathrm{PM}_{2.5}$ no mesmo comprimento de onda, inferindo a absorção da radiação por partículas biogênicas na moda grossa. 


\begin{abstract}
In this study, a detailed characterization of aerosol optical properties for the biogenic, urban pollution and biomass burning aerosols was performed in the Amazon basin. A number of different approaches were used, including in-situ and remote sensing measurements in several locations. As part of the GoAmazon2014/5 experiment, solar radiometers from AERONET Network and in-situ instruments measuring absorption (Aethalometers and MAAP) and scattering coefficients (Nephelometers) were used to assess the effect of Manaus urban emissions on the aerosol properties. In regions heavily affected by the biomass burning events, the radiative forcing retrieved by AERONET was quantified, separating the contributions of organic carbon (OC) and elemental (EC). Based exclusively on the aerosol optical properties, a qualitative analysis of the dominant aerosol types was performed in the Amazon, assessing its impact on the radiative balance. The OC emitted from biomass burn has strong cooling effect at the top of the atmosphere, presenting an instantaneous radiative forcing of $-53 \pm 17 \mathrm{~W} / \mathrm{m}^{2}$. The EC is highly absorbing and, despite its lower concentration compared to the OC, showed a strong effect on the instantaneous radiative forcing at the top of the atmosphere, making it significantly less negative, with an effect up to $-12 \pm 9 \mathrm{~W} / \mathrm{m}^{2}$.

The absorption and scattering properties associated with the urban emissions from the Manaus city were analyzed. A significant difference on the absorption optical depth was observed between two sites located upwind and downwind of the urban plume, respectively. The effect of absorption is particularly remarkable in the rainy season, but can also be observed with the biomass burning plumes during the dry season. In-situ measurements showed that the averaged single scattering albedo (SSA) decreased from $0.92 \pm 0.06$ upwind to $0.83 \pm 0.11$ downwind of Manaus urban plume during the wet season.

In-situ measurements of the spectral absorption coefficient of PM10 cut size were performed in parallel with the PM2.5 during the wet season at ZF2 reserve in order to study the light absorption by biogenic coarse particles. In atmospheric conditions with the dominance of biogenic particles, the PM10 absorption at $880 \mathrm{~nm}$ is up to $10 \%$ higher than the PM2.5 absorption at the same wavelength, inferring the absorption of radiation by biogenic particles in the coarse mode.
\end{abstract}




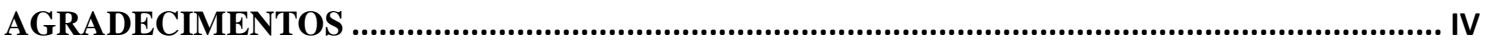

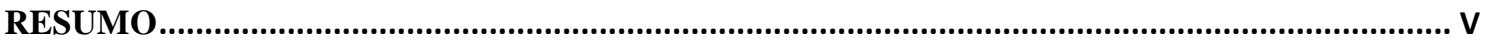

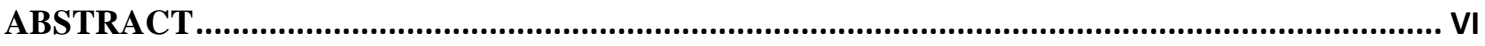

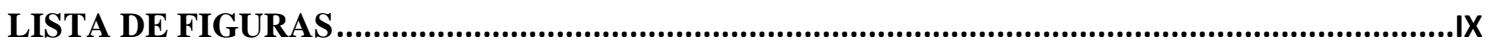

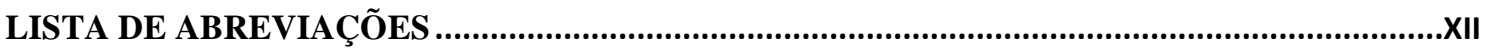

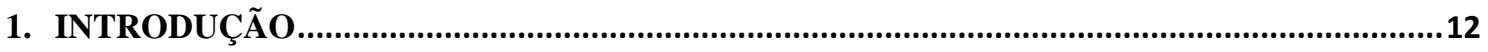

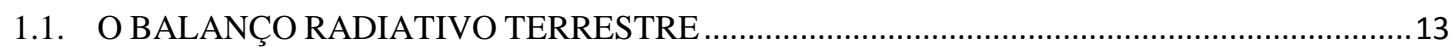

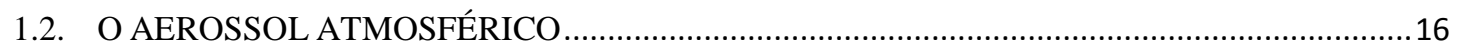

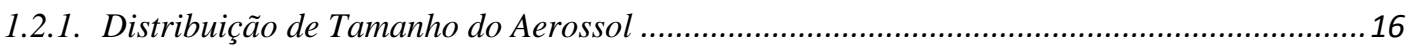

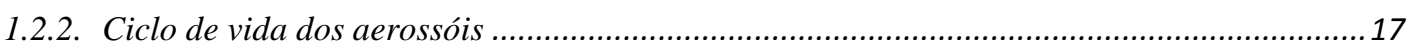

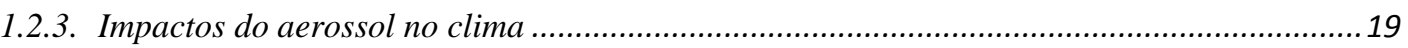

1.2.4. A componente orgânica do aerossol........................................................................................20

1.2.5. O Black Carbon e a absorção de radiação..........................................................................2 21

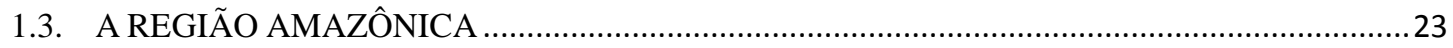

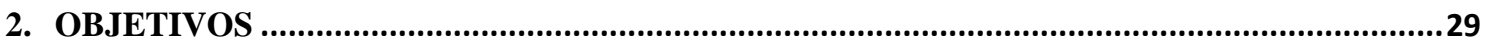

3. FUNDAMENTOS DA INTERAÇÃO ENTRE AEROSSÓIS E RADIAÇÃO ..............................30

3.1. TRANSFERÊNCIA RADIATIVA NA ATMOSFERA …………..............................................

3.2. ABSORÇÃO E ESPALHAMENTO DE RADIAÇÃO POR PARTÍCULAS DE AEROSSOL E

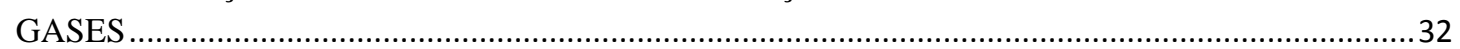

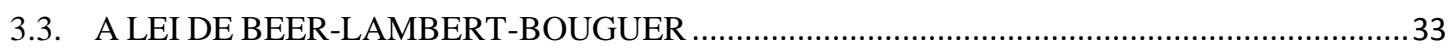

3.4. PROPRIEDADES INTENSIVAS E EXTENSIVAS DO AEROSSOL ATMOSFÉRICO .............34

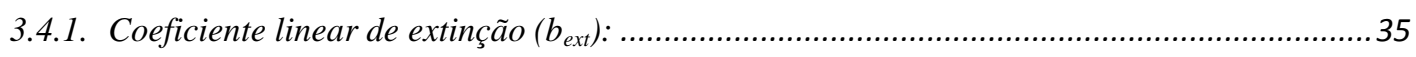

3.4.2. Espessura ótica de extinção $($ Sext $)$ :

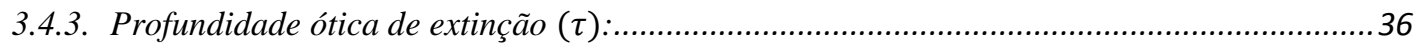

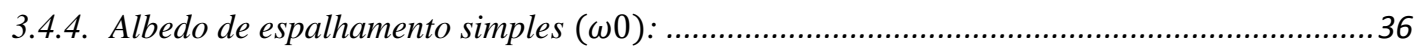

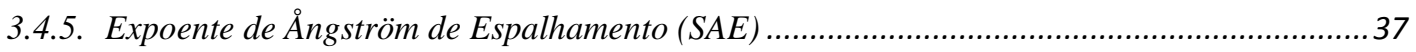

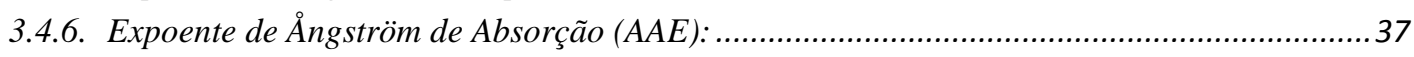

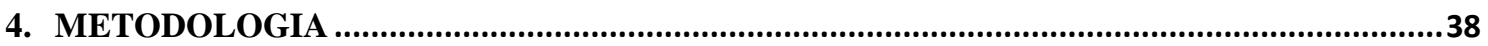

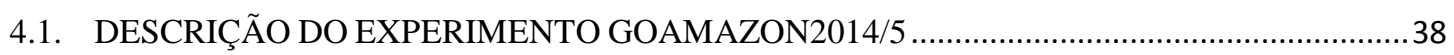

4.2. SENSORIAMENTO REMOTO DA ATMOSFERA - A REDE AERONET ……………….......42

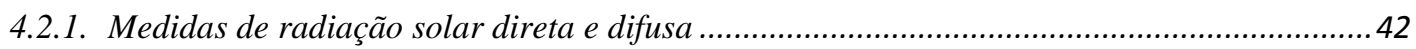

4.2.2. Forçante Radiativa do Aerossol como produtos da AERONET …………………………....... 44

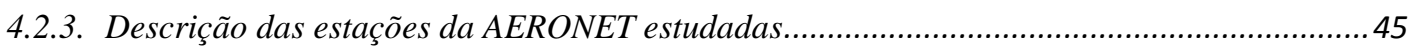

4.3. MEDIDAS DE ESPALHAMENTO E ABSORÇÃO ESPECTRAIS IN-SITU .............................45

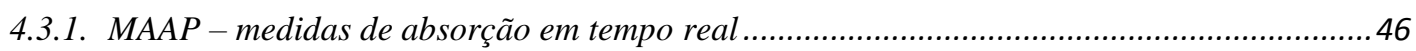

4.3.2. A medida da absorção espectral de aerossóis com Aetalômetro ...........................................47

4.3.3. A medida do espalhamento espectral com Nefelômetros.................................................... 48

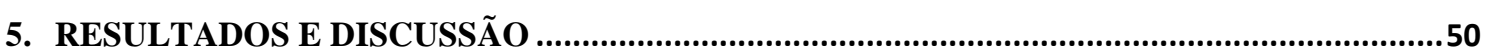

5.1. MEDIDAS DAS PROPRIEDADES ÓTICAS DE AEROSSÓIS NA AMAZÔNIA ATRAVÉS

DA REDE DE FOTÔMETROS SOLARES DA AERONET ..............................................................50

5.2. INFLUÊNCIA DA PLUMA DE MANAUS SOBRE AS PROPRIEDADES ÓTICAS DO AEROSSOL NO CONTEXTO DO EXPERIMENTO GOAMAZON2014/5 .......................................61 
5.2.1. Medidas por sensoriamento remoto durante o experimento GoAmazon2014/5.

5.2.2. Medidas in-situ durante o experimento GoAmazon 2014/5..................................................67

5.3. CONTRIBUIÇÃO DE PARTÍCULAS BIOGÊNICAS NA MODA GROSSA PARA A ABSORÇÃO DE RADIAÇÃO NA AMAZÔNIA CENTRAL ......................................................74

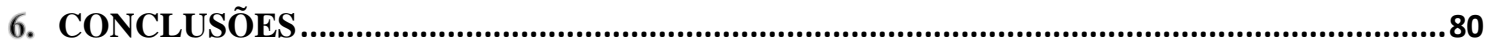

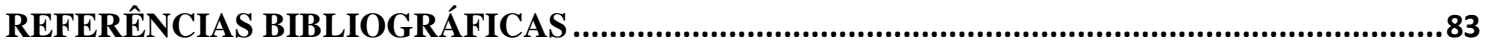

APÊNDICE A - RESUMOS PUBLICADOS EM ANAIS DE CONGRESSOS ..............................91 


\section{LISTA DE FIGURAS}

FIGURA 1 - BALANÇO ENERGÉTICO MÉDIO GLOBAL SOB AS CONDIÇÕES CLIMÁTICAS ATUAIS. OS NÚMEROS REPRESENTAM A MAGNITUDE DOS FLUXOS DE ENERGIA INDIVIDUAIS EM W/M², AJUSTADOS DENTRO DE SUA INCERTEZA PARA FECHAR O BALANÇO DE ENERGIA. (FIGURA ADAPTADA DE (WILD ET AL. 2013)). 13

FIGURA 2 - MÉDIA GLOBAL DA FORÇANTE RADIATIVA DEVIDO A ATIVIDADES NATURAIS E ANTRÓPICAS DESDE 1750 (IPCC, 2013).

FIGURA 3- DISTRIBUIÇÃO DE TAMANHO DAS PARTÍCULAS DE AEROSSOL E PROCESSOS ASSOCIADOS À PRODUÇÃO E TRANSFORMAÇÃO DE PARTÍCULAS (SEINFELD \& PANDIS 2006).

FIGURA 4 - CICLO DE VIDA DE AEROSSÓIS E NUVENS. OBSERVA-SE FORTES VÍNCULOS ENTRE RADIAÇÃO, NUVENS E AEROSSÓIS QUE SÃO PARTICULARMENTE INTENSOS NA REGIÃO AMAZÔNICA.

FIGURA 5- DESENHO ESQUEMÁTICO DAS FONTES PRIMÁRIAS DE EMISSÃO DE BLACK CARBON (BOND ET AL. 2013)

FIGURA 6- DESCRIÇÃO DOS FLUXOS DE ÁGUA, ENERGIA E PARTíCULAS ENTRE A BIOSFERA E A ATMOSFERA, MOSTRANDO O FORTE ACOPLAMENTO ENTRE OS DOIS (BARTH ET AL. 2005)

FIGURA 7- (A) DESMATAMENTO NA AMAZÔNIA LEGAL ATÉ 2010. AS ÁREAS EM ROSA REPRESENTAM ÁREAS DESMATADAS; EM VERDE, FLORESTAS; EM AMARELO, FORMAÇÃO NÃO FLORESTAL. (HTTP://WWW.IMAZON.ORG.BR) (B)TAXA DE DESMATAMENTO NA AMAZÔNIA LEGAL CALCULADA POR IMAGEM DE SATÉLITE (INPE, 2015).

FIGURA 8- ESTATÍSTICAS MENSAIS PARA OS COEFICIENTES DE ESPALHAMENTO (550 NM) E ABSORÇÃO (637NM) NAS LOCALIDADES DE PORTO VELHO E AMAZÔNIA CENTRAL, ENTRE 2009 E 2012. OS CÍRCULOS REPRESENTAM OS VALORES MEDIANOS E AS BARRAS REPRESENTAM OS PERCENTIS 10 E 90. (ADAPTADA DE ARTAXO ET AL. (2013)).

FIGURA 9 - IRRADIÂNCIA SOLAR ESPECTRAL NO TOPO DA ATMOSFERA E NA SUPERFÍCIE AO NÍVEL DO MAR. A LINHA TRACEJADA REPRESENTA A CURVA CORRESPONDENTE DE CORPO NEGRO A UMA TEMPERATURA MÉDIA EQUIVALENTE A 6.000K. AS REGIÕES HACHURADAS REPRESENTAM AS ABSORÇÕES MOLECULARES NA ATMOSFERA (COMO POR EXEMPLO, OZÔNIO, VAPOR DE ÁGUA E DiÓXIDO DE CARBONO). FIGURA ADAPTADA DE SEINFELD E PANDIS, 1998.

FIGURA 10 - (A) CURVAS NORMALIZADAS DE RADIÂNCIA DE CORPO NEGRO PARA TEMPERATURAS DA ORDEM DAS TEMPERATURAS MÉDIAS DO SOL E DA TERRA. SÃO INDICADAS TAMBÉM AS PRINCIPAIS BANDAS DE ABSORÇÃO GASOSA E A ABSORBÂNCIA ATMOSFÉRICA PARA COMPRIMENTOS DE ONDA ENTRE 0,1 E $100 \mu \mathrm{M}$ : (B) ENTRE O TOPO DA ATMOSFERA E UMA ALTITUDE DE $11 \mathrm{KM}$; (C) ENTRE O TOPO DA ATMOSFERA E O NÍVEL DO SOlO [ADAPTADA DE WALlACE E HOBBS, 1977].

FIGURA 11 - RELAÇÃO ENTRE RAIO DAS PARTÍCULAS, COMPRIMENTO DE ONDA E REGIME DE ESPALHAMENTO

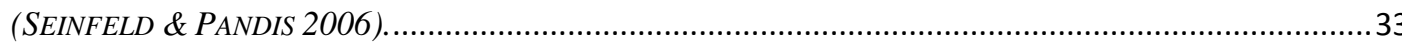

FIGURA 12 - ESQUEMA SIMPLIFICADO PARA EXPLICAÇÃO DA LEI DE BEER-LAMBERT-BOUGUER. ...............34

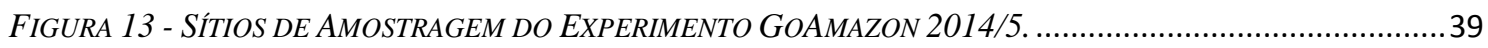

FIGURA 14- ROSA DOS VENTOS PARA A (A) ESTAÇÃO SECA (15 JUN - 30 NOV) E (B) ESTAÇÃO CHUVOSA (1 DEZ - 14 JUN) COM BASE EM MÉDIAS DE MEIA HORA DE VELOCIDADE E DIREÇÃO DO VENTO, MEDIDAS A 81 M AGL PARA O PERÍODO DE 18 DE OUTUBRO DE 2012 A 23 DE JULHO DE 2014 ..........................40

FIGURA 15 - MEDIDAS DE RADIAÇÃO DIFUSA DOS FOTÔMETROS SOLARES DA AERONET (SENA 2013)....43 FIGURA 16 - DESENHO ESQUEMÁTICO DO PRINCÍPIO DE FUNCIONAMENTO DO MAAP. SIMULTANEAMENTE À MEDIDA DE ABSORÇÃO EM UM FILTRO DE FIBRA DE VIDRO, O ESPALHAMENTO ÓTICO É DETERMINADO E DESCONTADO ATRAVÉS DE UM ALGORITMO DESENVOLVIDO PARA O INSTRUMENTO.

FIGURA 17 - PRINCÍPIO dE FUNCIONAMENTO dO AETALÔMETRO MODELO AE33, COM DOIS FEIXES DE REFERÊNCIA DE MEDIDAS PARA CÁLCULOS DE CORREÇÕES PARA EFEITO DE FILTER LOADING. 48 
FIGURA 18 - DIAGRAMA INTERNO DO NEFELÔMETRO TSI-3563. NO CANTO DIREITO DA FIGURA ESTÃO REPRESENTADOS O INLET E O ANTEPARO NO QUAL É OBSERVADO O ESPALHAMENTO DE LUZ DEVIDO À PRESENÇA DE PARTÍCULAS NO INTERIOR DA CÂMARA VOLUMÉTRICA. NO CANTO ESQUERDO ESTÃO REPRESENTADOS OS TRÊS TUBOS FOTOMULTIPLICADORES (AZUL, VERDE, VERMELHO) (RIZZO 2006).

FIGURA 19 - MEDIDAS DA PROFUNDIDADE ÓTICA EM 500 NM PARA DIFERENTES REGIÕES DA AMAZÔNIA DESDE 2000, UTILIZANDO OS FOTÔMETROS SOLARES DA AERONET

FIGURA 20 - NÚMERO DE FOCOS DE INCÊNDIO DETECTADOS POR IMAGENS DE SATÉLITE (INPE,2015). OS PONTOS VERDES E VERMELHOS REPRESENTAM AS MÉDIAS DA PROFUNDIDADE ÓTICA DE AEROSSÓIS EM 500 NM CALCULADAS DURANTE A ESTAÇÃO SECA EM ALTA FLORESTA E CUIABÁ, RESPECTIVAMENTE, UTILIZANDO OS FOTÔMETROS SOLARES DA AERONET.

FIGURA 21 - VARIAÇÃO INTERANUAL TÍPICA DA PROFUNDIDADE ÓPTICA DE ABSORÇÃO E DE ESPALHAMENTO EM ALTA FLORESTA, REPRESENTANDO A MÉDIA DIÁRIA DE TODOS OS DADOS OBTIDOS AO LONGO DE 15 ANOS DE MEDIDAS (2000-2014). A BANDA SOMBREADA REPRESENTA A ESTAÇÃO SECA (AGOSTO-OUTUBRO).

FigURA 22 - (A) DISTRIBUIÇÃO VOLUMÉTRICA DE TAMANHO PARA O SÍTIO DE ALTA FLORESTA, REPRESENTANDO A MÉDIA SEMANAL DE TODOS OS DADOS OBTIDOS AO LONGO DE 15 ANOS (20002014); (B) FRAÇÃO DA MODA FINA DA AOD ${ }_{675 \mathrm{NM}}$ (FMF) OBTIDA PELO PRODUTO DE INVERSÃO.........54

FIGURA 23 - PROFUNDIDADE ÓTICA DE ABSORÇÃO ESPECTRAL MÉDIA EM FUNÇÃO DO COMPRIMENTO DE ONDA EM ESCALA LOGARÍTMICA PARA OS INTERVALOS DA FRAÇÃO DE MODA FINA DA AOD $675_{\mathrm{NM}}$ EM ALTA FLORESTA AO LONGO DE 15 ANOS DE MEDIDAS. TAMBÉM ESTÁ INDICADO O COEFICIENTE ÅNGSTRÖM DE ABSORÇÃO (AAE) MÉDIO PARA CADA INTERVALO DE FMF.

FIGURA 24 - MATRIZ ÅNGSTRÖM COM MEDIDAS DE FOTOMETRIA SOLAR EM ALTA FLORESTA (DADOS COM NÍVEL 2.0) PARA AS ESTAÇÕES SECA E CHUVOSA......

FIGURA 25 - MATRIZ ÅNGSTRÖM COM TODAS AS MEDIDAS DE ALTA FLORESTA TOMADAS AO LONGO DE 15 ANOS. AS CORES REPRESENTAM A FORÇANTE RADIATIVA NO TOPO DA ATMOSFERA. ........................59

FIGURA 26 - SERIE TEMPORAL DA PROFUNDIDADE ÓTICA DAS ESTAÇÕES MANAUS-EMBRAPA E ARMMANACAPURU DA AERONET, LOCALIZADAS VENTO ACIMA E VENTO ABAIXO DA CIDADE DE MANAUS, RESPECTIVAMENTE. OS PONTOS REPRESENTAM MÉDIAS HORÁRIAS DE TODOS OS DADOS NÍVEL 1.5 DISPONÍVEIS DURANTE O EXPERIMENTO GOAMAZON2014/5, NO PERÍODO DE JANEIRO DE 2014 A SETEMBRO DE 2015.

FIGURA 27 - PROFUNDIDADE ÓTICA MÉDIA $\left(\mathrm{AOD}_{675 \mathrm{NM}}\right)$ PARA AS ESTAÇÕES CHUVOSA E SECA MEDIDAS COM OS FOTÔMETROS SOLARES DA AERONET NOS SITES EMBRAPA E MANACAPURU DURANTE O EXPERIMENTO GOAMAZON2014/5 (MEDIDAS DE JANEIRO DE 2014 A SETEMBRO DE 2015). TAMBÉM ESTÁ INDICADA A VARIABILIDADE DA DISTRIBUIÇÃO DAS MEDIDAS.....

FIGURA 28 - MÉDIA DAS DISTRIBUIÇÕES DE TAMANHO VOLUMÉTRICAS DERIVADAS DE OBSERVAÇÕES DURANTE A ESTAÇÃO CHUVOSA (FEVEREIRO-JUNHO) E OS MESES DE QUEIMADAS (AGOSTOOUTUBRO) NOS SÍTIOS DA EMBRAPA E MANACAPURU. TAMBÉM INDICADA ESTÁ A FRAÇÃO DA MODA FINA (FMF) PARA CADA ESTAÇÃO DO ANO E CADA LOCAL.

FIGURA 29 - PROFUNDIDADE ÓTICA DE ABSORÇÃO MÉDIA (675NM) PARA AS ESTAÇÕES CHUVOSA E SECA MEDIDAS COM OS FOTÔMETROS SOLARES DA AERONET NOS SITES EMBRAPA E MANACAPURU DURANTE O EXPERIMENTO GOAMAZON2014/5. AS BARRAS DE ERRO REPRESENTAM O DESVIO PADRÃO.

FIGURA 30 - FORÇANTE RADIATIVA NO TOPO DA ATMOSFERA MÉDIA PARA AS ESTAÇÕES CHUVOSA E SECA MEDIDAS COM OS FOTÔMETROS SOLARES DA AERONET NOS SITES EMBRAPA E MANACAPURU DURANTE O EXPERIMENTO GOAMAZON2014/5. O DESVIO PADRÃO TAMBÉM ESTÁ INDICADO NA FIGURA.

FIGURA 31 - SÉRIE TEMPORAL DO COEFICIENTE DE ABSORÇÃO EM 880 NM (À ESQUERDA) E COEFICIENTE DE ESPALHAMENTO EM 450 NM (À DIREITA) PARA OS SÍTIOS TOA E T3 DO GOAMAZON2014/5. FOI UTILIZADO CORTE DE TAMANHO PMIO ATÉ 5 DE MAIO DE 2014 E A PARTIR DESTA DATA FOI UTILIZADO CORTE PMI. 
FigURA 32 - HiSTOGRAMA DOS VALORES DE ALBEDO SIMPLES OBTIDOS PARA AS ESTAÇÕES ATTO (T0A) E MANACAPURU (T3) A PARTIR DE MEDIDAS IN-SITU UTILIZANDO AETALÔMETROS E NEFELÔMETROS DURANTE A ESTAÇÃO SECA E CHUVOSA DE 2014

FIGURA 33 - COMPOSIÇÃO QUíMICA DE AEROSSOL FINO NA TORRE ATTO, PARA A ESTAÇÃO CHUVOSA DE 2014, ESTAÇÃO SECA DE 2014 E ESTAÇÃO CHUVOSA DE 2015, RESPECTIVAMENTE, MEDIDOS COM O Aerosol Chemical Speciation Monitor (ACSM). Compilação de Samara Carbone, 2015.. 70

FIGURA 34 - CICLO DIURNO MÉDIO DO EXPOENTE ÅNGSTRÖM DE ABSORÇÃO CALCULADO EM MANACAPURU PARA AS ESTAÇÕES CHUVOSA E SECA DE 2014. AS BARRAS INFERIORES E SUPERIORES REPRESENTAM O PRIMEIRO E TERCEIRO QUARTIS, RESPECTIVAMENTE. A ÁREA SOMBREADA REPRESENTA O HORÁRIO DIURNO.

FIGURA 35 - CICLO DIURNO MÉDIO DO EXPOENTE ÅNGSTRÖM DE ESPALHAMENTO CALCULADO EM MANACAPURU PARA AS ESTAÇÕES CHUVOSA E SECA DE 2014. AS BARRAS INFERIORES E SUPERIORES REPRESENTAM O PRIMEIRO E TERCEIRO QUARTIS, RESPECTIVAMENTE. A ÁREA SOMBREADA REPRESENTA O HORÁRIO DIURNO.

FIGURA 36 - DESENHO ESQUEMÁTICO DO ARRANJO EXPERIMENTAL NA RESERVA ECOLÓGICA ZF2 _............75

FIGURA 37 - COMPARAÇÃO ENTRE OS COEFICIENTES DE ABSORÇÃO MEDIDOS PELO AE33 E MAAP NO SÍTIO EXPERIMENTAL DA ZF2, PARA OS CORTES DE TAMANHO PM $10 \mathrm{E} \mathrm{PM}_{2.5}$

FigURA 38 - SÉRIE TEMPORAL DOS COEFICIENTES DE ABSORÇÃO DO PARTICULADO PM ${ }_{10}$ E $^{\text {PM }} 2.5$, MEDIDOS PELO AETALÔMETRO AE33 NO SÍTIO EXPERIMENTAL DA ZF2 ………………………………….....76

FIGURA 39 - VARIAÇÃO DIURNA DAS CONCENTRAÇÕES DE PARTÍCULAS FINAS (0,25-2,5 $\mu \mathrm{M})$ E GROSSAS (2,510 $\mu$ M) MEDIDAS PELO OPC GRIMM NA RESERVA ECOLÓGICA ZF2 DURANTE O EXPERIMENTO. A ÁREA SOMBREADA REPRESENTA O HORÁRIO DIURNO.

FIGURA 40 - REGRESS ÃO LINEAR ENTRE OS COEFICIENTES DE ABSORÇÃO DOS PARTICULADOS PM10 E PM2.5, MEDIDOS PELO AE33 NA ZF2.

FIGURA 41 - RAZÃO ENTRE OS COEFICIENTES DE ABSORÇÃO DO PM ${ }_{10}$ E PM $_{2.5}$ MEDIDOS PELO AE33 COMO FUNÇÃO DO VALOR MÁXIMO DE ABSORÇÃO UTILIZADO NA REGRESSÃO PARA OS COMPRIMENTOS DE ONDA 470 E 880 NM. 


\section{LISTA DE ABREVIAÇÕES}

AAE - Absorption Ångström Exponent

AAOD - Absorption Aerosol Optical Depth

AERONET - Aerosol Robotic Network

AOD - Aerosol Optical Depth

BC - Black Carbon

BOA - Bottom of Atmosphere

BrC - Brown Carbon

CCN - Cloud Condensation Nuclei

EC - Elemental Carbon

FMF - Fine Mode Fraction

GAME - Global Atmospheric Model

MAAP - MultiAngle Absorption Photometry

OC - Organic Carbon

OPC - Optical Particle Counter

SAE - Scattering Ångström Exponent

SAOD - Scattering Aerosol Optical Depth

SSA - Single Scattering Albedo

TOA - Top of Atmosphere 


\section{INTRODUÇÃO}

Praticamente toda a energia que chega a Terra provém do Sol e, a princípio, toda a radiação solar recebida pela Terra deve ser reemitida de volta para o espaço para garantir o equilíbrio radiativo. Desde a revolução industrial, as atividades humanas têm contribuído significativamente para o aumento da concentração de aerossóis e gases de efeito estufa como dióxido de carbono $\left(\mathrm{CO}_{2}\right)$, metano $\left(\mathrm{CH}_{4}\right)$ e oxido nitroso $\left(\mathrm{N}_{2} \mathrm{O}\right)$ na atmosfera. A emissão de gases e partículas tem causado uma perturbação no fluxo radiativo na atmosfera terrestre, tendo como resultado principal o aumento da temperatura média global observada nos últimos anos (Forster et al., 2007). Diversos fatores, como por exemplo, o uso de combustíveis fósseis, desflorestamento e a crescente urbanização, têm modificado a composição atmosférica, impactando o balanço radiativo terrestre (Kiehl \& Trenberth 1997; Trenberth et al. 2009). O impacto humano sobre o clima está excedendo em muito as alterações decorrentes de processos naturais, tais como mudanças solares, erupções vulcânicas e mudanças na órbita terrestre (Boucher et al., 2013). Nos últimos anos, várias evidências das mudanças climáticas têm sido observadas, como o derretimento parcial das calotas polares e glaciais e consequente aumento do nível dos oceanos, intensificação de catástrofes naturais, entre outras alterações bem documentadas. Apesar dos grandes avanços das pesquisas em mudanças climáticas, as consequências destas modificações para o clima futuro ainda são bastante incertas (Steffen et al. 2015).

A queima de biomassa é uma importante fonte de gases e partículas atmosféricas (Andreae \& Merlet 2001). A Amazônia é a maior floresta tropical do mundo e está sujeita a uma das maiores taxas de desmatamento (Artaxo 2001). Cerca de $80 \%$ da atividade de queima global está ocorrendo nos trópicos e um terço disto ocorre na América do Sul. Em condições meteorológicas adequadas, as características químicas, físicas e óticas dos aerossóis podem ser muito diferentes das médias globais ou regionais. Estas características, por sua vez, são fortemente influenciadas por perturbações locais e regionais, como por exemplo, as emissões florestais, incêndios, poeira mineral, sal marinho, etc., levando a uma maior heterogeneidade espacial e temporal. 


\subsection{O BALANÇO RADIATIVO TERRESTRE}

A radiação solar é a principal fonte de energia que governa o clima terrestre. A quantidade de energia solar média incidente sobre o planeta Terra por segundo, por unidade de área é de aproximadamente $340 \mathrm{~W} / \mathrm{m}^{2}$ (Figura 1). Cerca de $30 \%$ da radiação solar incidente no topo da atmosfera é refletida de volta para o espaço por nuvens, gases e partículas $\left(100 \mathrm{~W} / \mathrm{m}^{2}\right)$ e pela superfície terrestre $\left(24 \mathrm{~W} / \mathrm{m}^{2}\right)$, e uma fração menor (79 $\mathrm{W} / \mathrm{m}^{2}$ ) é absorvida diretamente na atmosfera. Metade da radiação solar é absorvida pela superfície terrestre e cerca de $20 \%$ é absorvido pela atmosfera, totalizando aproximadamente $240 \mathrm{~W} / \mathrm{m}^{2}$ de absorção de radiação de ondas curtas pelo sistema Terra-atmosfera. A superfície terrestre, por sua vez, transfere a maior parte desta radiação para a atmosfera na forma de emissão de radiação de ondas longas. As nuvens, partículas e gases atmosféricos reirradiam a energia de ondas longas para o espaço e para a superfície terrestre. Aproximadamente a mesma quantidade de energia solar absorvida pela Terra é reirradiada de volta para o espaço, mantendo o equilíbrio do balanço radiativo terrestre (Trenberth et al. 2009).

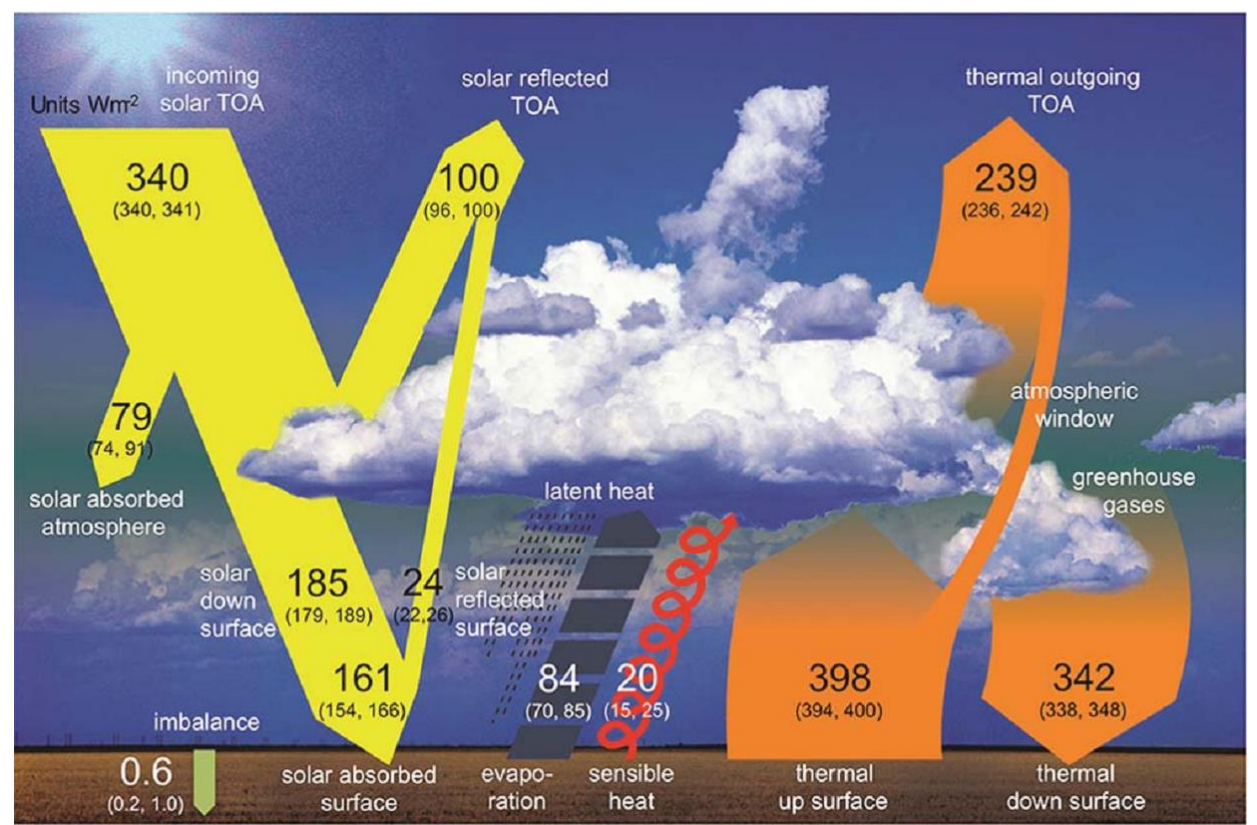

Figura 1 - Balanço energético médio global sob as condições climáticas atuais. Os números representam a magnitude dos fluxos de energia individuais em $\mathrm{W} / \mathrm{m}^{2}$, ajustados dentro de sua incerteza para fechar o balanço de energia. (Figura adaptada de (Wild et al. 2013)).

O balanço radiativo terrestre pode ser perturbado através de diversos fatores que podem ser naturais ou antrópicos. Os fatores naturais que causam alterações na quantidade de radiação solar que chega à Terra são as mudanças na órbita terrestre, atividade solar (manchas solares) e erupções vulcânicas. Dentre os fatores antrópicos, 
está o aumento da concentração de gases de efeito estufa na atmosfera, que é responsável pela diminuição na quantidade de radiação térmica que é reemitida de volta para o espaço. Além disso, mudanças na cobertura de nuvens e na concentração de aerossóis podem alterar a quantidade de radiação solar que chega à superfície. Estes fatores podem alterar o clima tanto direta quanto indiretamente, através de diversos mecanismos de retroalimentação (feedbacks) (Boucher et al., 2013). Um feedback climático é um processo interno que amplifica ou atenua a resposta do clima a uma forçante inicial.

A forçante radiativa é uma mudança imposta no balanço radiativo da Terra. Ela é medida pela alteração no fluxo por radiação líquida em algum nível na atmosfera, que ocorre em resposta a uma perturbação. De acordo com a definição adotada pelo $5^{\circ}$ Relatório de Avaliação do Painel Intergovernamental de Mudanças Climáticas (do inglês, IPCC), a forçante radiativa é definida como a diferença na irradiância líquida na tropopausa entre um estado de referência e um estado perturbado por um agente climático externo. O IPCC adota o início da revolução industrial (considerado 1750) como estado de referência (Myhre et al. 2013). Forçantes radiativas positivas indicam um efeito líquido de aquecimento do sistema Terra-atmosfera e forçantes negativas indicam efeitos de resfriamento.

Os aerossóis têm um papel fundamental no balanço de radiação global e regional (Andreae \& Rosenfeld 2008). A Figura 2 apresenta as estimativas das forçantes radiativas para 2011 em relação a 1750 para os principais agentes causadores das mudanças climáticas, de acordo com o $5^{\circ}$ relatório do IPCC. É possível observar que as forçantes radiativas dos aerossóis (exceto black carbon) e da mudança de albedo de superfície contribuem para um resfriamento do sistema, enquanto que os gases de efeito estufa causam o aquecimento. 


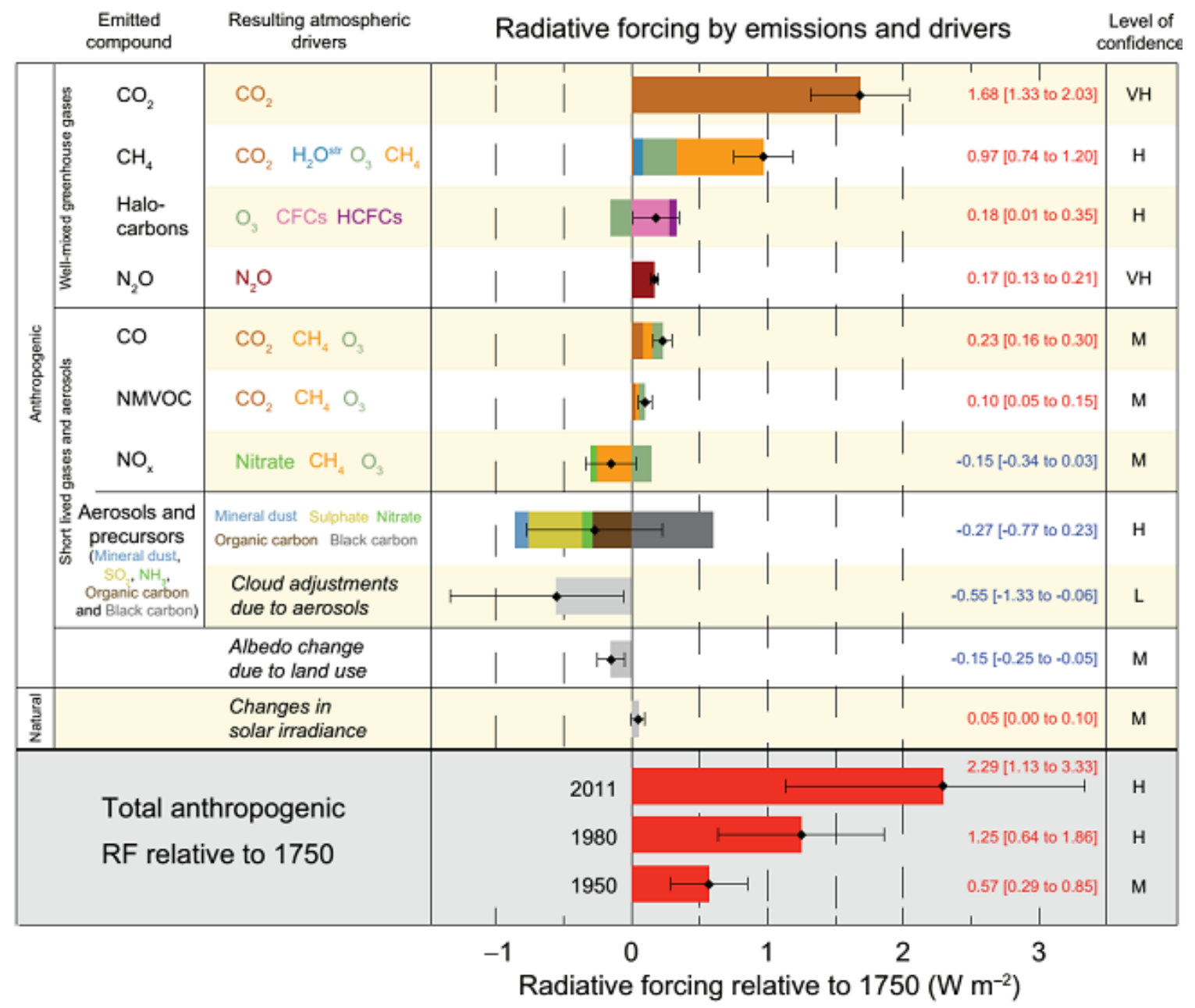

Figura 2 - Média global da forçante radiativa devido a atividades naturais e antrópicas desde 1750 (IPCC, 2013).

Os aerossóis atmosféricos em geral resfriam o sistema climático e, consequentemente, se opõem ao aquecimento dos gases de efeito estufa $\left(+1,68 \mathrm{~W} / \mathrm{m}^{2}\right)$ (IPCC, 2013). Os aerossóis de origem antrópica (principalmente sulfatos, nitratos, carbono orgânico, poeira mineral e black carbon), por exemplo, produzem em conjunto um efeito de resfriamento, com uma forçante radiativa direta a nível global de -0,27 (0,77 a 0,23) W/m2 (IPCC, 2013). Ao mesmo tempo, eles causam um efeito indireto, associado com mudança do albedo de nuvem, de $-0,55(-1,33$ a $-0,06) \mathrm{W} / \mathrm{m}^{2}$. Os efeitos locais dos aerossóis, entretanto, podem ser muito maiores e chegar a centenas de $\mathrm{W} / \mathrm{m}^{2}$ em regiões próximas das fontes de emissão (García et al. 2012). Estes valores indicam claramente que as incertezas na quantificação do papel dos aerossóis no balanço radiativo ainda são bastante significativas e dominam as incertezas globais. Neste contexto, o acompanhamento de longo prazo dos diferentes tipos de aerossóis é crucial para melhorar o entendimento da forçante radiativa e parâmetros climáticos. 


\subsection{O AEROSSOL ATMOSFÉRICO}

O aerossol atmosférico é composto por um conjunto de partículas sólidas ou líquidas em suspensão na atmosfera, de diferentes tamanhos, formas, composições químicas e propriedades físicas (Seinfeld \& Pandis 2006), sendo originado tanto por fontes naturais quanto antrópicas. As principais fontes naturais são erupções vulcânicas, incêndios naturais, ressuspensão de poeira do solo e emissões biogênicas (Seinfeld \& Pandis 2006). Entre as fontes antrópicas encontramos agricultura, queima de biomassa e queima de combustíveis fósseis como os contribuintes mais importantes (Andreae \& Merlet 2001).

As partículas podem ser denominadas aerossóis primários, caso sejam introduzidas na atmosfera diretamente a partir da fonte emissora, ou aerossóis secundários, caso sejam formados na atmosfera a partir de transformações físicas e químicas de gases precursores, e podem ser removidas por processos de deposição seca (como difusão e sedimentação), ou deposição úmida (Charlson, R. J. and Heintzenberg 1995). Exemplos de partículas de aerossol biogênico primário (PBA) incluem pólen, bactérias, fungos e fragmentos de plantas e animais. Exemplos de componentes de aerossol orgânico secundário (SOA) são moléculas de baixa volatilidade resultantes das reações de $\mathrm{O}_{3}$ e radical $\mathrm{OH}$ com compostos orgânicos voláteis biogênicos (BVOCS), como isopreno e terpeno (Surratt et al. 2010; Allan et al. 2014).

\subsubsection{Distribuição de Tamanho do Aerossol}

O tamanho dos aerossóis varia de poucos nanômetros até centenas de micrometros de diâmetro e são classificados de acordo com seu diâmetro (Dp), como mostrado na Figura 3. Partículas com diâmetros maiores que 2,5 $\mu \mathrm{m}$ são classificadas como partículas grossas, tendo como exemplo os aerossóis marinhos, poeira de solo, emissões vulcânicas e partículas de origem biogênica. Aquelas com diâmetro menor do que 2,5 $\mu \mathrm{m}$ são chamadas de partículas finas, que incluem normalmente a maior parte do número total de partículas. As partículas da moda fina podem ainda ser subdivididas em outras três classes de tamanho: moda de nucleação ( $\mathrm{Dp}<30 \mathrm{~nm}$ ); moda de Aitken $(30<\mathrm{Dp}<\sim 120 \mathrm{~nm})$ e moda de acumulação $(\sim 80<\mathrm{Dp}<\sim 2500 \mathrm{~nm})$. 


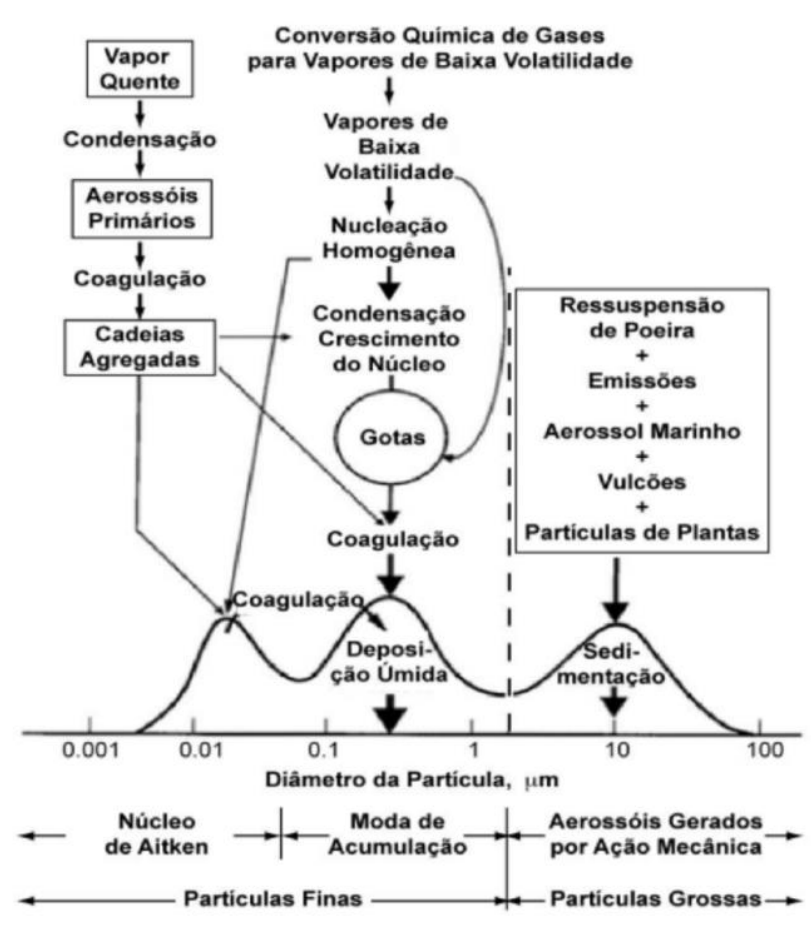

Figura 3- Distribuição de tamanho das partículas de aerossol e processos associados à produção e transformação de partículas (Seinfeld \& Pandis 2006).

\subsubsection{Ciclo de vida dos aerossóis}

O aerossol tem um ciclo atmosférico próprio, envolvendo sua emissão, transformação e deposição. O tempo de residência na atmosfera é da ordem de um dia a duas semanas na troposfera, e cerca de um ano na estratosfera (Seinfeld \& Pandis 2006). Os processos naturais e antrópicos de emissão de partículas lançam na atmosfera grandes quantidades de aerossóis que sofrem transformações em suas propriedades físico-químicas. Após lançadas na atmosfera, as partículas de aerossóis interagem com o ambiente que as circunda e entre si por meio de uma série de processos físico-químicos, tais como: condensação, coagulação, nucleação, ativação, deposição e oxidação. Estes processos são importantes porque eles afetam as propriedades óticas e de nucleação de nuvens do aerossol. O ciclo de vida das nuvens, por sua vez, está relacionado à precipitação e ao balanço radiativo, além de ser influenciado pelas propriedades de superfície e termodinâmicas da atmosfera como um todo (Figura 4). 


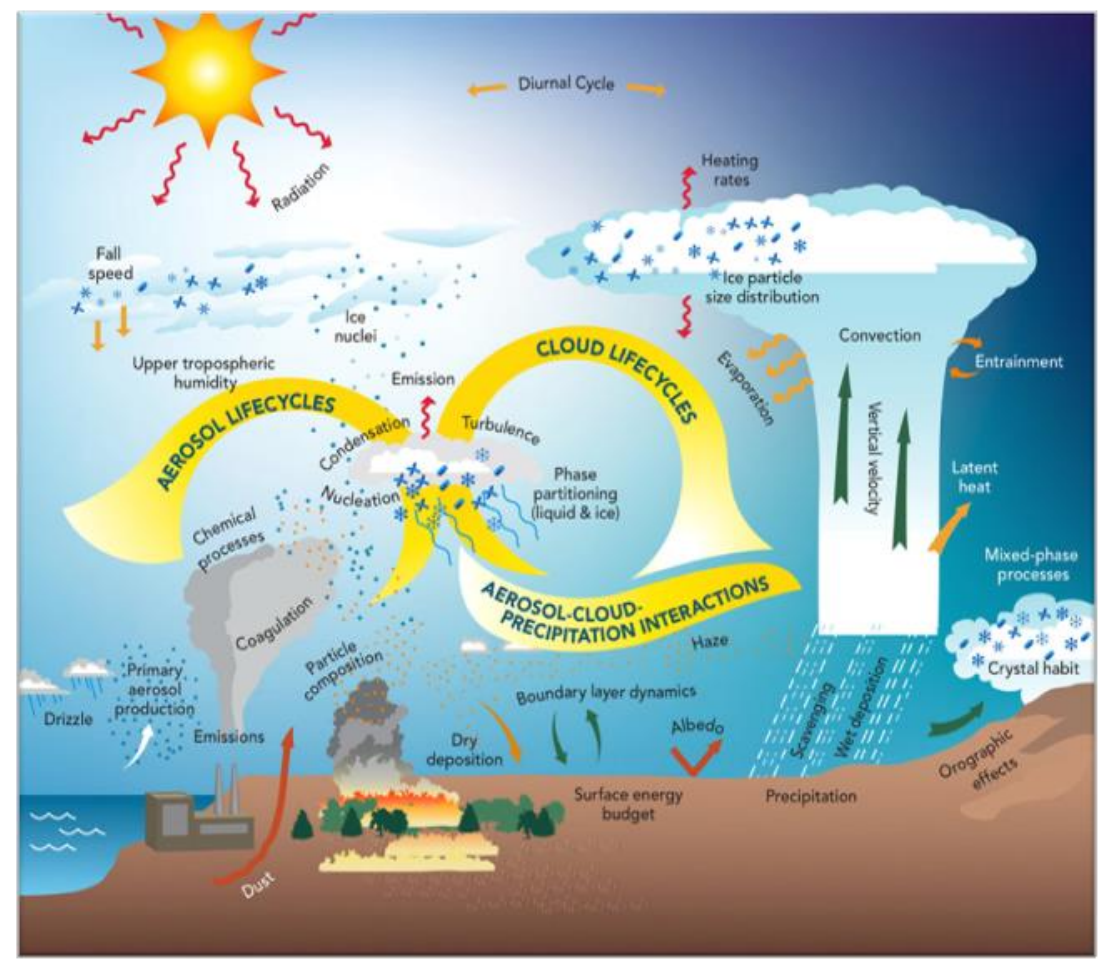

Figura 4 - Ciclo de vida de aerossóis e nuvens. Observa-se fortes vínculos entre radiação, nuvens e aerossóis que são particularmente intensos na região Amazônica.

Em algumas regiões do globo, o processo de formação de novas partículas por agrupamento de moléculas pode desempenhar um papel importante na manutenção do número de partículas (Kulmala et al. 2013). Partículas recém-formadas têm aproximadamente alguns nanômetros de tamanho e podem crescer rapidamente, mesmo ao longo de um único dia, até alcançar tamanhos nos quais podem interagir mais fortemente com a radiação solar ou servir como núcleos de condensação de nuvens (CCN) (Heald et al. 2010).

A chamada formação de aerossol secundário, ou seja, o processo de condensação de vapores sobre a superfície de aerossóis provoca o aumento do diâmetro médio das distribuições de tamanho. Outro processo que provoca o aumento do diâmetro de uma população de aerossóis é denominado coagulação, e consiste na união de duas ou mais partículas para formar uma partícula maior. Este processo gera um contínuo decréscimo na concentração numérica de partículas, associado a um aumento no diâmetro médio das distribuições. O tempo característico para a coagulação decorrente do movimento browniano é superior a 1 hora (Wexler et al. 1994). Tanto a condensação quanto a coagulação ocorrem comumente na atmosfera e durante o processamento de aerossóis no interior de nuvens. A nucleação de partículas ocorre pela transferência de massa de compostos gasosos de baixa pressão de vapor para a fase de 
partícula. Se a concentração de uma determinada espécie é menor do que a respectiva saturação, a substância permanece na fase gasosa. Porém, se a concentração de saturação for superada, a espécie é condensada na superfície do material particulado disponível, até que o equilíbrio entre as fases de gás e aerossol seja restaurado (Pandis et al. 1992).

A remoção de aerossóis da atmosfera dá-se pelos processos de deposição seca e úmida. A deposição seca pode ocorrer por sedimentação e impactação (processos eficientes para partículas da moda grossa) ou por difusão turbulenta (eficiente para a moda de nucleação) (Wesely \& Hicks 2000; Gallagher et al. 2002). Já a deposição úmida ocorre pela incorporação de aerossóis por gotículas de nuvens e pela remoção de partículas através da precipitação (eficiente para as modas grossa e de acumulação) (Williams et al. 1997; Laakso 2003).

\subsubsection{Impactos do aerossol no clima}

Os aerossóis afetam o balanço radiativo da Terra tanto diretamente, pelo espalhamento e absorção da radiação solar (Charlson et al. 1992; Kiehl \& Briegleb 1993), quanto indiretamente, através da sua ação como núcleos de condensação de nuvens (Andreae 2002; Andreae et al. 2004; Kaufman et al. 2005), tendo sido identificados como uma das maiores fontes de incerteza na interpretação do clima da Terra em escala global e regional (IPCC, 2013). A magnitude da forçante radiativa (medida em $\mathrm{W} / \mathrm{m}^{2}$ ) em um determinado tempo e local depende da quantidade de radiação emitida de volta para o espaço que, por sua vez, depende do tamanho, abundância e das propriedades óticas do aerossol. A interação da radiação com os aerossóis depende significativamente do tamanho da partícula, sendo maior o efeito quando o tamanho da partícula possui a mesma ordem de grandeza que o comprimento de onda da radiação incidente. Devido ao seu tamanho, as partículas da moda de acumulação são as que interagem mais eficientemente com a radiação solar.

Através do efeito de espalhamento dos aerossóis, grande parte da radiação solar incidente muda de direção e é enviada de volta para o espaço, resultando no resfriamento do sistema e, portanto, em uma forçante negativa. Por outro lado, quando a radiação é absorvida pelas partículas, sua energia é convertida em calor, causando o aquecimento da região onde a partícula se encontra e resultando em uma forçante positiva. Além disso, se as partículas consistem de uma mistura de material puramente espalhador, como o sulfato de amônia, e parcialmente absorvedor, como a fuligem, o 
efeito de resfriamento ou aquecimento depende da maneira em que as duas substâncias estão misturadas em uma população de partículas.

O efeito indireto do aerossol sobre o clima é causado pela formação de nuvens. Todas as gotículas de nuvens são formadas pela água que se condensa em uma partícula de aerossol. Ao alterar o tamanho, concentração e composição química dos aerossóis, a quantidade de nuvens, assim como suas propriedades óticas é alterada consequentemente (Ramanathan et al. 2001). Um elevado número de partículas de aerossol resulta em uma maior quantidade de gotículas de nuvens, porém em tamanhos menores. Gotas menores resultam em nuvens mais brilhantes que refletem mais radiação solar de volta para o espaço, e, proporcionalmente, reduzem a quantidade de radiação solar que alcança a superfície terrestre, apresentando um efeito de resfriamento sobre o clima (Twomey 1977; Twomey 1974). O segundo efeito indireto é também um resultado das pequenas gotículas de nuvens que atrasa precipitação e, assim, aumenta a vida útil das nuvens (Albrecht 1989). No entanto, como visto na Figura 2, a incerteza atribuída ao efeito albedo de nuvem ainda é bastante alta.

\subsubsection{A componente orgânica do aerossol}

Os aerossóis são constituídos de muitos compostos diferentes, dependendo da sua origem. Segundo o último relatório do IPCC, os principais constituintes do aerossol atmosférico são espécies inorgânicas (ex.: sulfatos, nitratos, sal marinho), espécies orgânicas (espécies carbonáceas em geral, exceto BC), black carbon (tipo de material carbonáceo absorvedor de luz) e espécies minerais (principalmente poeira do solo e emissões vulcânicas) (Boucher et al., 2013).

O carbono é um componente muito importante para o material particulado atmosférico, e é em geral o elemento majoritário. Na natureza o ciclo do carbono é um dos ciclos biogeoquímicos mais importantes e está presente na forma de substâncias orgânicas e inorgânicas. Estes compostos são importantes devido a sua ocorrência nas modas grossa e fina do aerossol atmosférico, possuir propriedades de absorção e de espalhamento de radiação.

O OC é componente das moléculas orgânicas no aerossol carbonáceo e pouco absorvedor de luz na região do visível pela presença de compostos que, na maioria, são considerados incolores, por exemplo, hidrocarbonetos. Entretanto, OC pode ser dividido em duas partes quando consideradas suas propriedades óticas: a fração que não apresenta absorção de luz no visível e a fração absorvedora de luz, denominada brown 
carbon (BrC). $\mathrm{O} \mathrm{BrC}$ é encontrado tanto em áreas urbanas quanto em queima de biomassa e absorve radiação preferencialmente no comprimento do UV.

Geralmente, OC constitui entre 10 a $50 \%$ da concentração em massa orgânica atmosférica, dependendo da fonte (Seinfeld \& Pandis 2006). Durante eventos de queimada na Amazônia, a contribuição dos aerossóis orgânicos na massa do aerossol fino chega a mais de $90 \%$ (Brito et al. 2014). A composição do carbono orgânico do aerossol atmosférico é bastante complexa por causa da mistura de inúmeros compostos orgânicos diferentes.

\subsubsection{O Black Carbon e a absorção de radiação}

Apesar de black carbon (BC) ser um dos principais componentes atmosféricos que influencia as mudanças climáticas e a qualidade do ar, não há acordo sobre a terminologia que considera todos os aspectos de propriedades específicas, definições, métodos de medição, e incertezas relacionadas. Muitas vezes, é definido pelos cientistas baseando-se no método de medida (Petzold et al. 2013). O termo Black Carbon Equivalente (EBC) deve ser usado ao invés de BC para os dados derivados a partir de métodos por absorção ótica, juntamente com os respectivos coeficientes de absorção de massa (MAC), para a conversão do coeficiente de absorção de luz em concentração de massa. Além disso, o termo Carbono Elementar (EC) deve ser utilizado ao invés de BC para medidas derivadas de métodos termo-óticos. Outro termo utilizado atualmente é o Black Carbon Refratário (rBC) que deve substituir o termo black carbon para medidas com métodos baseados em incandescência induzida por laser (por exemplo, o instrumento SP2) (Petzold et al. 2013).

O BC é caracterizado pelas seguintes propriedades distintas: (1) absorve radiação na região do visível, com um valor de MAC acima de $5 \mathrm{~m}^{2} / \mathrm{g}$ a um comprimento de onda $\lambda=550 \mathrm{~nm}$ para partículas recém produzidas; (2) é refratário, com uma temperatura de volatilização perto de $4000 \mathrm{~K}$; (3) é insolúvel em água, em solventes orgânicos, incluindo metanol e acetona, e nos outros componentes do aerossol atmosférico; (4) consiste de agregados de pequenas esférulas de carbono de $<10 \mathrm{~nm}$ a cerca de $50 \mathrm{~nm}$ de diâmetro; e (5) contém uma grande fração de átomos de carbono (sp2) do tipo grafite (Petzold et al. 2013).

$\mathrm{O}$ BC é formado pela queima incompleta de biomassa ou combustíveis fósseis. Uma grande variedade de fontes de combustão, tanto natural como antrópica, emite BC diretamente na atmosfera. As maiores fontes globais são as queimadas de florestas e 
savanas, queima de combustíveis fósseis e diesel. Uma vez emitido, o BC é transportado em escala regional e continental, sendo removido da atmosfera por deposição seca e úmida, resultando em um tempo de vida médio de aproximadamente uma semana. Na Figura 5 é possível observar as principais fontes de emissão do BC e seus impactos no meio ambiente.

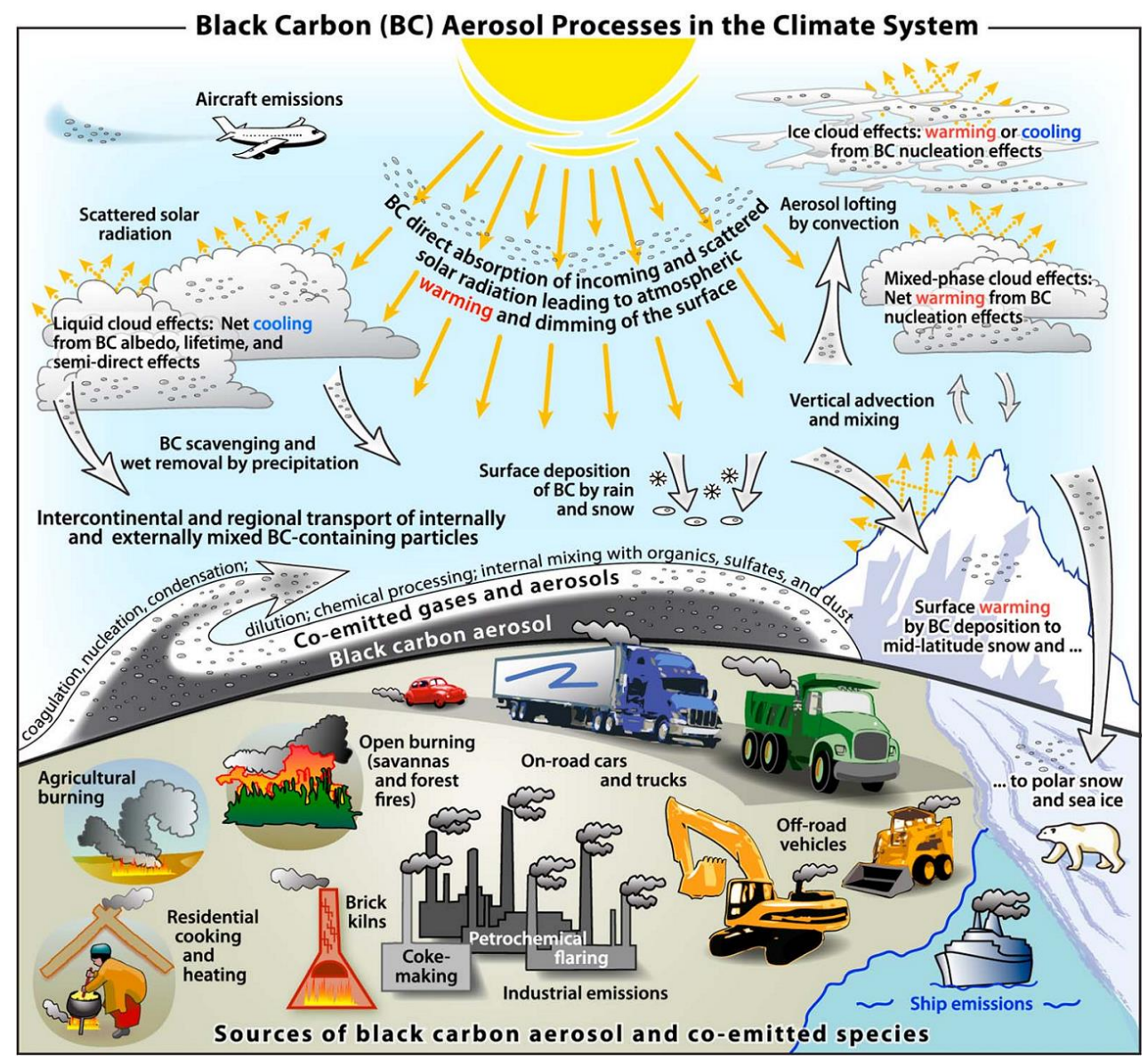

Figura 5- Desenho esquemático das fontes primárias de emissão de black carbon (Bond et al. 2013)

A extinção da radiação solar devido a partículas de aerossol é causada principalmente por partículas carbonáceas (EC e OC) e poeira mineral. No entanto, as propriedades de absorção são fortemente dependentes do estado de mistura das partículas (Bond \& Bergstrom 2006; Schnaiter et al. 2005). Além disso, vários trabalhos recentes observaram absorção por aerossóis biogênicos naturais (Schafer et al. 2008; Rizzo et al. 2011). Devido às formas e composição intrínseca, as partículas biogênicas podem absorver quantidades significativas de radiação visível (Andreae \& Gelencsér 2006; Després et al. 2012).

Segundo o $5^{\circ}$ Relatório de Avaliação do IPCC (AR5), a forçante radiativa direta do $\mathrm{BC}$ na atmosférica é de $+0,6 \mathrm{~W} / \mathrm{m}^{2}$. Isto implica que o $\mathrm{BC}$ é o maior responsável pelo aquecimento global depois do $\mathrm{CO}_{2}$ (IPCC, 2013), reforçando ainda mais o conceito 
de controle de $\mathrm{BC}$ como uma estratégia eficaz de mitigação do clima. A estimativa do AR5 é baseada em dois estudos: a avaliação do Aerocom II (Myhre et al. 2013) e o estudo de Bond et al. (2013), que estimou a forçante radiativa do BC em $+1,1$ (0,17$2,10) \mathrm{W} / \mathrm{m}^{2}$. Estes valores indicam claramente incertezas significativas nas estimativas da forçante radiativa do $\mathrm{BC}$ e confirmam a necessidade de estudar suas propriedades radiativas a fim de quantificar adequadamente seus efeitos no balanço radiativo.

A forçante radiativa direta do $\mathrm{BC}$ sozinho é mais incerta do que a forçante radiativa direta total do conjunto de aerossóis. Isto ocorre porque o seu efeito pode ser confundido com outras espécies absorvedoras de radiação, como os orgânicos e poeira mineral. Embora as fontes de poeira mineral possam ser isoladas geograficamente das fontes de BC, os aerossóis orgânicos são tipicamente co-emitidos com BC. O estudo da absorção de radiação do aerossol pelas diferentes espécies químicas é, portanto, essencial tanto para limitar as grandes incertezas na estimativa da forçante radiativa do BC (Forster et al., 2007) quanto para controlar as emissões com políticas públicas.

\subsection{A REGIÃO AMAZÔNICA}

A Amazônia brasileira se estende ao longo de cerca de 5,5 milhões de $\mathrm{km}^{2}$, correspondendo a $61 \%$ da área do Brasil. Durante o período chuvoso, a região apresenta uma das menores concentrações de aerossóis em regiões continentais (Artaxo et al. 2013; Andreae et al. 2015). Este grande ecossistema desempenha um papel crucial na regulação do clima global e regional e do ciclo hidrológico, alimentando a circulação atmosférica global, o transporte de calor e umidade para áreas continentais (Davidson \& Artaxo 2004; Boers et al. 2014). A região possui um forte ciclo hidrológico que é mantido por emissões de grande quantidade de vapor de água, bem como núcleos de condensação de nuvens (CCN) produzidos a partir de emissões florestais, sendo um importante local de convecção profunda.

Devido a sua localização tropical e seu intenso metabolismo, a floresta amazônica exerce um papel importante como fonte natural de gases traço, aerossóis e vapor de água para atmosfera global (Andreae \& Crutzen, 1997; Andreae, 2002; Artaxo et al., 2006; Silva Dias et al., 2004; Martin et al., 2010b; Andreae et al., 2012). A biosfera e a atmosfera estão intrinsecamente relacionadas. As emissões de gases traços e de aerossóis orgânicos primários pela biosfera terrestre regulam as características atmosféricas, que por sua vez influenciam diversos processos biológicos responsáveis 
por estas emissões. A troca de gases traço e aerossóis biogênicos entre a superfície terrestre e a atmosfera são controladas pela produção e consumo desses compostos pela vegetação, incluindo atividade microbiótica, processos químicos e transporte por fluxos turbulentos (Rizzo, 2006). Ao serem emitidos pelas plantas ou formados na atmosfera, os aerossóis naturais, primários e secundários, também interagem diretamente com a radiação solar através da absorção e do espalhamento de luz, influenciando o balanço de energia na superfície e as taxas de reações fotoquímicas na troposfera. A relação entre a biosfera e a atmosfera da Amazônia está ilustrada na Figura 6, onde processos que regulam os fluxos de energia gases traços e aerossóis para a atmosfera estão explicitados.

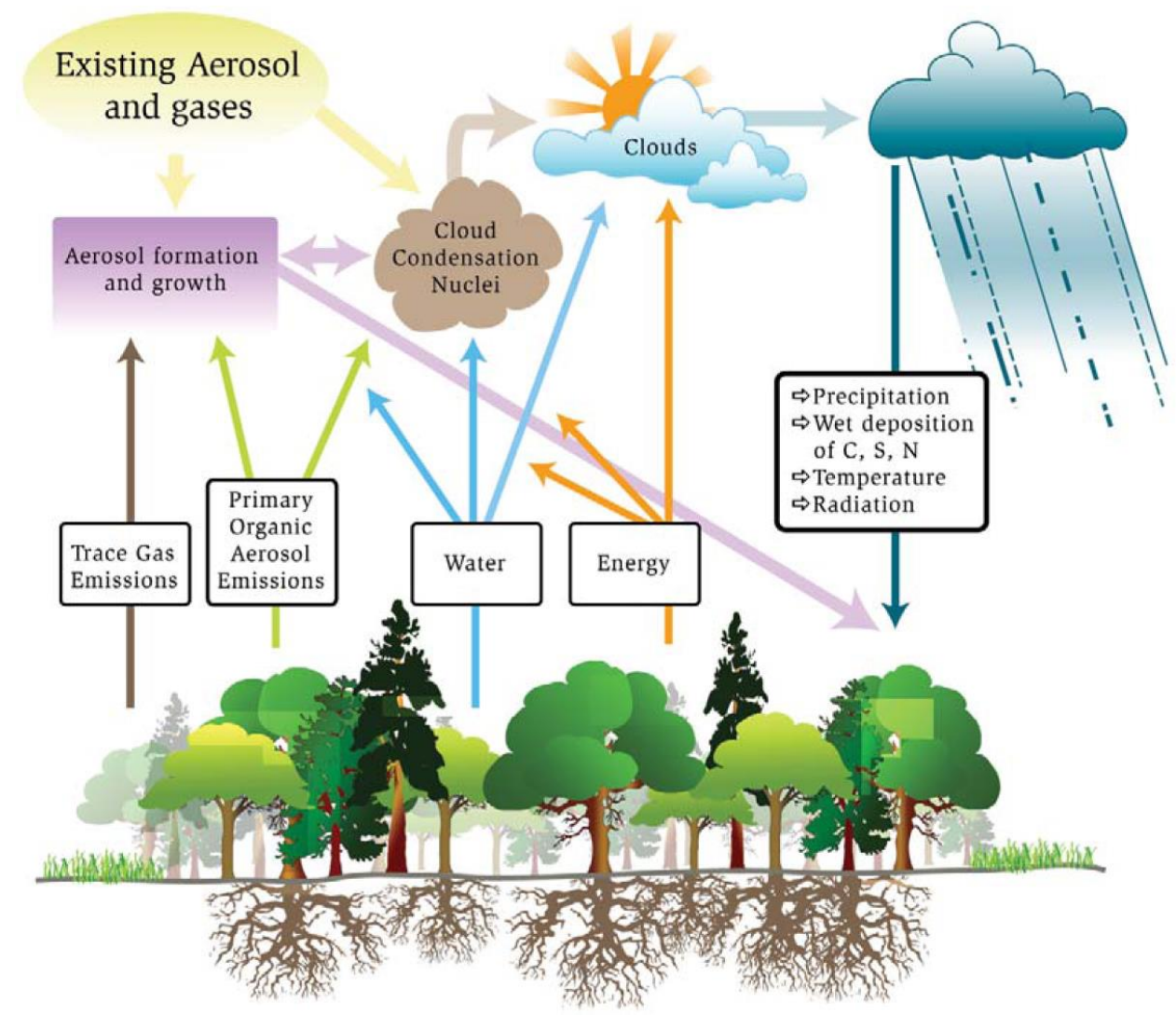

Figura 6- Descrição dos fluxos de água, energia e partículas entre a biosfera e a atmosfera, mostrando o forte acoplamento entre os dois (Barth et al. 2005).

As atividades humanas na Amazônia nos últimos 50 anos têm tido um impacto significativo sobre uma parte considerável da região (Davidson et al. 2012). Recentemente duas fortes secas, em 2005 e 2010, receberam especial atenção como potenciais indicadores de aumento de extremos climáticos na Amazônia (Gatti et al. 2014). As queimadas são a principal causa das alterações na composição da atmosfera amazônica, sendo responsáveis por um significativo aumento na concentração de gases 
e partículas. Como consequência dessas mudanças, uma grande quantidade de poluentes é adicionada às emissões biogênicas naturais com impactos no balanço radiativo tanto em escala local como regional (Artaxo et al. 2013; Sena et al. 2013).

Durante as décadas de 70 e 80, a ocupação da Amazônia Legal foi incentivada por políticas governamentais de incentivos para projetos agropecuários e reforma agrária, gerando uma intensa migração para diversos Estados da região Norte do país (Becker, 2001). Atualmente, os desmatamentos em várias regiões da Amazônia são impulsionados pela pecuária de média e grande escala, pela produção e exportação de grãos, e pela exploração madeireira (Soares-Filho et al., 2004). A área desflorestada acumulada na Amazônia legal até o ano de 2014 foi de aproximadamente 408 mil km² segundo dados do Programa de Monitoramento do Desflorestamento na Amazônia Legal (PRODES) do Instituto Nacional de Pesquisas Espaciais (INPE, 2015). O mapa do desflorestamento na região amazônica até o ano de 2010 é mostrado na Figura 7a. O desmatamento não é distribuído homogeneamente, e sim concentrado ao longo do denominado "Arco do Desflorestamento", área que se estende do sudeste do estado do Maranhão, ao norte do Tocantins, sul do Pará, norte de Mato Grosso, Rondônia, sul do Amazonas e sudeste do estado do Acre. É também nessa área onde se encontra o maior número de focos de queima de biomassa. A Figura $7 \mathrm{~b}$ mostra a taxa de desflorestamento da Amazônia legal nos últimos 20 anos. Recentemente foi observado um forte declínio das taxas anuais de desmatamento na Amazônia brasileira de $27.800 \mathrm{~km}^{2} \mathrm{yr}^{-1}$ em 2004 para $4.900 \mathrm{~km}^{2} \mathrm{yr}^{-1}$ em 2014, conforme estimativas do PRODES. Os indicadores de queimadas não seguem, entretanto, a mesma tendência de queda do desflorestamento, sugerindo que atualmente há uma transição da localização de queimadas da região de floresta para a região de cerrado (Ten Hoeve et al. 2012). 
a)

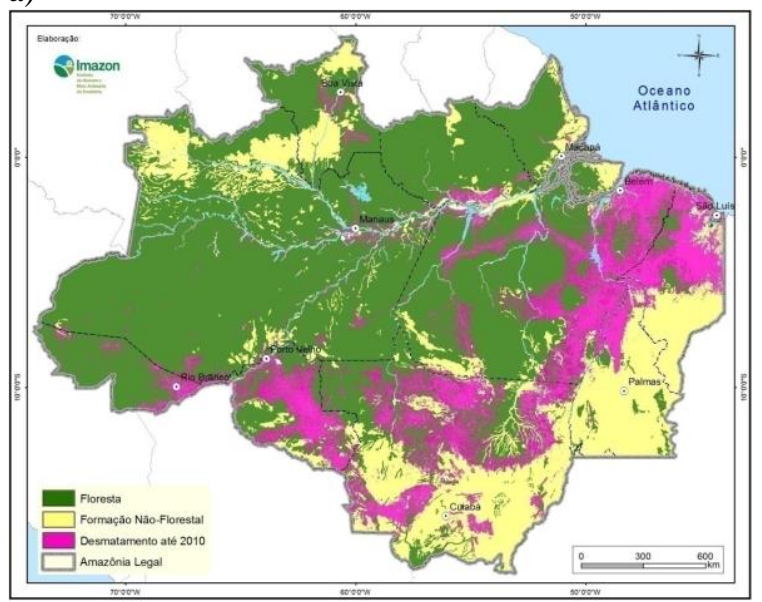

b)

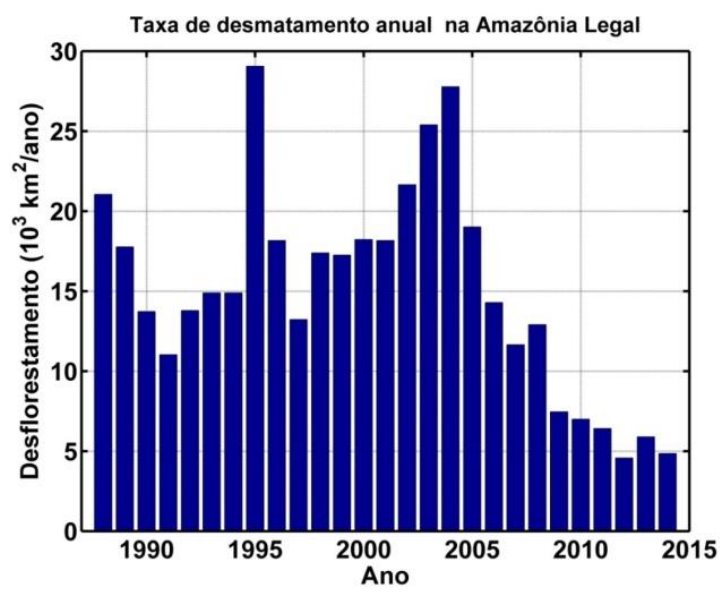

Figura 7- (a) Desmatamento na Amazônia legal até 2010. As áreas em rosa representam áreas desmatadas; em verde, florestas; em amarelo, formação não florestal. (http://www.imazon.org.br)

(b)Taxa de desmatamento na Amazônia legal calculada por imagem de satélite (INPE, 2015).

$\mathrm{Na}$ época chuvosa, massas de ar atravessam milhares de quilômetros de floresta sem impacto significativo de emissões antrópicas. Esta estação é caracterizada por baixas concentrações em número de partículas (cerca de 300 partículas por $\mathrm{cm}^{3}$ ), sendo predominantemente de matéria orgânica (Artaxo et al. 2013; Andreae et al. 2015). Também nesta temporada, episódios de transporte de longas distâncias podem trazer para a região grandes quantidades de poeira saariana, queimadas da África e aerossóis marinhos do Atlântico (Talbot et al. 1990; Baars et al. 2011). As baixas concentrações de aerossóis na estação chuvosa, o alto nível de vapor de água e intenso nível de radiação solar tornam a região amazônica sensível à concentração de aerossóis, onde pequenas alterações podem levar a importantes impactos no desenvolvimento de nuvens (Andreae et al. 2004; Chang et al. 2015).

Este cenário muda drasticamente durante a estação seca, quando a queima de biomassa resulta na adição de grandes quantidades de aerossóis de poluição, que variam entre de 15000 a 30000 partículas $/ \mathrm{cm}^{3}$ (Artaxo et al. 2013). Este aumento é acompanhado por uma alteração significativa na distribuição de tamanho de partícula, uma vez que a maior parte das partículas emitidas durante eventos de queimada pertencem à moda fina (Dubovik et al. 2002; Eck et al. 2003; Schafer et al. 2008; Sena \& Artaxo 2015). 
Os efeitos destas partículas de aerossol no balanço radiativo e clima regional da Amazônia são muito significativos (Sena et al. 2013). A influência dos aerossóis no clima pode ser tanto direta, pela absorção e espalhamento da radiação solar, quanto indireta, pela mudança nas propriedades microfísicas de nuvens. O conhecimento das propriedades de absorção e espalhamento é importante para que se possam quantificar os efeitos do aerossol no balanço radiativo (Sena et al., 2013).

A Figura 8 mostra as médias mensais do coeficiente de espalhamento (550nm) e absorção (637nm) em Porto Velho (PVH) e na torre TT34 da ZF2, entre 2009 e 2012 (Artaxo et al., 2013).

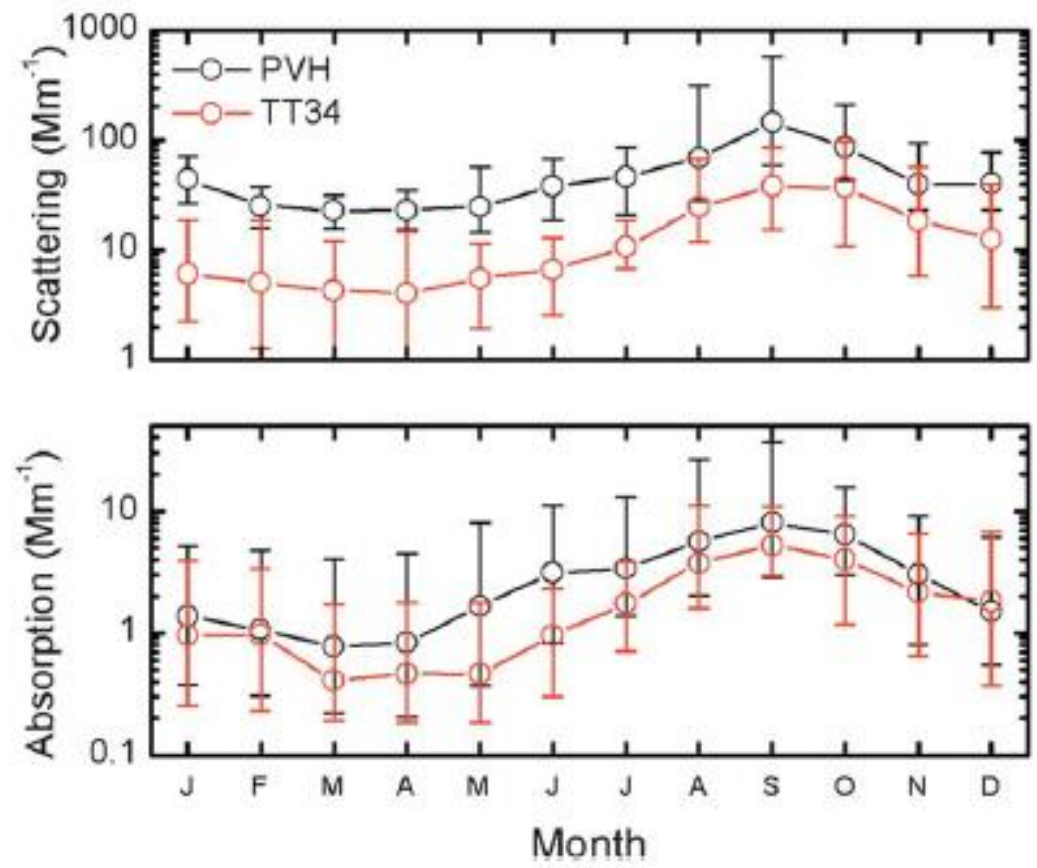

Figura 8- Estatísticas mensais para os coeficientes de espalhamento (550 nm) e absorção (637nm) nas localidades de Porto Velho e Amazônia central, entre 2009 e 2012. Os círculos representam os valores medianos e as barras representam os percentis 10 e 90. (Adaptada de Artaxo et al. (2013)).

É observado um aumento por um fator 10 no coeficiente de espalhamento em comparação com o sítio TT34 em ambas as estações. Essa grande diferença é um indicativo de que as mudanças de uso do solo no sul da Amazônia estão aumentando significativamente a carga regional de aerossóis, mesmo na estação chuvosa, quando a queima de biomassa é reduzida em consequência dos altos índices de precipitação. No que diz respeito à absorção, a diferença entre Porto Velho (PVH) e Amazônia central é muito menor durante todo o ano. Em janeiro e Fevereiro (estação chuvosa em ambos os locais), o coeficiente de absorção é de aproximadamente $1,0 \mathrm{Mm}^{-1}$. Uma vez que praticamente não há focos de queimada nesse período, a absorção observada é então 
majoritariamente atribuída ao chamado brown carbon (Andreae et al., 2006; Artaxo et al., 2013), que ocorre devido à presença de partículas biogênicas absorvedoras de radiação solar (Rizzo et al., 2011; 2013).

Os aerossóis de queimadas podem ser transportados por longas distâncias e, consequentemente, exercer um impacto em grande escala sobre o balanço radiativo em toda a Bacia Amazônica. Utilizando dados de satélite, Sena et al. (2013) avaliou o impacto dos aerossóis de queimadas no balanço radiativo sobre a região amazônica. As médias diárias da forçante radiativa direta de aerossóis de queimadas no topo da atmosfera para o período de 2000 a 2009 obtidas por duas metodologias distintas foram de $-8,2 \pm 2,1 \mathrm{~W} / \mathrm{m}^{2}$ e $-5,2 \pm 2,6 \mathrm{~W} / \mathrm{m}^{2}$. Além disso, as distribuições espaciais e temporais da forçante radiativa direta de aerossóis sobre a região amazônica apresentam grande variabilidade, indicando que o impacto dos aerossóis é mais pronunciado sobre a Amazônia Central e Ocidental. Para altas concentrações de aerossóis (profundidade óptica em $550 \mathrm{~nm}>1$ ) a média diária da forçante radiativa no topo da atmosfera pode atingir valores de até $-30 \mathrm{~W} / \mathrm{m}^{2}$ localmente. Além disso, a variabilidade da forçante radiativa durante a estação de queimadas também é bastante alta. Para o ano 2007, por exemplo, a forçante radiativa média variou cerca de $12 \mathrm{~W} / \mathrm{m}^{2}$, do início para o final da estação de queimadas (Sena et al.,2013). Estes resultados indicam a importância de obter a forçante radiativa direta em alta resolução espacial e temporal, para uma avaliação correta de seus efeitos no ecossistema (Davidson et al., 2012). 


\section{OBJETIVOS}

Existem muitas questões em aberto em relação à absorção de radiação solar por aerossóis, bem como no papel do espalhamento por aerossóis orgânicos. Este trabalho visa investigar a absorção de radiação pelos diferentes tipos de aerossol que compõem a atmosfera amazônica, bem como sua influência no balanço radiativo regional. Para isto, será feita uma caracterização das propriedades óticas dos aerossóis biogênicos, das partículas emitidas em queimadas e da poluição urbana associadas à cidade de Manaus na região da Amazônia. A caracterização de cada uma das componentes nos processos de espalhamento e absorção da radiação será feita a partir de medidas in-situ e por sensoriamento remoto. Com isto, propõe-se responder as seguintes questões:

i. Em condições naturais, como se constituem as propriedades óticas das partículas de aerossol biogênico nas emissões diretas?

ii. Quais são as características de absorção e espalhamento de partículas de aerossóis emitidos em queimadas na Amazônia Central?

iii. Como as emissões urbanas de Manaus influenciam nas propriedades óticas do aerossol na região central da Amazônia?

Para responder a primeira pergunta, medidas da concentração numérica de partículas em diferentes intervalos de tamanho, utilizando um OPC, e do coeficiente de absorção do $\mathrm{PM}_{10}$ e $\mathrm{PM}_{2.5}$, utilizando Aetalômetros, serão analisadas na reserva ecológica da ZF2, na Amazônia central. A segunda pergunta será respondida com base em análises de propriedades óticas integradas na coluna atmosférica, obtidas pelo fotômetro solar CIMEL da AERONET ao longo de 15 anos de medidas em Alta Floresta. Este sítio de amostragem está localizado no sul da Amazônia, em uma região fortemente impactada pela queima de biomassa. Finalmente, para avaliar o impacto das emissões de Manaus nas propriedades óticas do aerossol correspondente à terceira pergunta, parâmetros como absorção, espalhamento e sua dependência espectral serão utilizados como indicadores da presença da pluma urbana no sítio experimental T3, localizado vento abaixo da cidade. O impacto da pluma urbana será avaliado a partir da comparação entre as medidas realizadas no T3 com medidas similares realizadas no T0e e T0a, geralmente com pouca influência da cidade de Manaus. 


\section{FUNDAMENTOS DA INTERAÇÃO ENTRE AEROSSÓIS E RADIAÇÃO}

Neste capítulo são descritos brevemente os conceitos fundamentais das interações das partículas de aerossóis com a radiação, transferência radiativa na atmosfera e propriedades óticas dos aerossóis. Estes conceitos serão utilizados amplamente ao longo deste trabalho.

\subsection{TRANSFERÊNCIA RADIATIVA NA ATMOSFERA}

A radiação eletromagnética se propaga em forma de onda e é caracterizada pelo seu comprimento de onda $(\lambda)$ e frequência $(v)$, sendo estas duas grandezas inversamente proporcionais $(\lambda=c / v)$, onde c é a velocidade da luz no vácuo $(\sim 3$. $\left.10^{8} \mathrm{~m} / \mathrm{s}^{2}\right)$. O espectro eletromagnético é dividido em várias regiões: raios gama e raios-X (comprimentos de onda muito pequenos e altamente energéticos); região ultravioleta $(0,010 \mu \mathrm{m}$ a $0,40 \mu \mathrm{m})$; região visível $(0,40 \mu \mathrm{m}$ e $0,70 \mu \mathrm{m})$; região infravermelha $(0,70 \mu \mathrm{m}$ a $100 \mu \mathrm{m})$; região de micro-ondas $(1 \mathrm{~mm}$ a $1 \mathrm{~m})$; e ondas de rádio (maiores do que $1 \mathrm{~m}$ ). A região infravermelha ainda é subdividida em dois intervalos: infravermelho próximo $(0,7 \mu \mathrm{m}$ a $3,5 \mu \mathrm{m})$, e infravermelho térmico $(3,5 \mu \mathrm{m}$ a $100 \mu \mathrm{m})$.

O Sol emite radiação eletromagnética como um corpo negro de temperatura aproximada de $6000 \mathrm{~K}$, nas regiões do ultravioleta, do visível, e do infravermelho próximo, sendo que o pico de energia ocorre no espectro visível, próximo a $0,5 \mu \mathrm{m}$. A radiância solar espectral $B_{\lambda}(T)$ de um corpo negro a temperatura $T[K]$ é descrita pela função de Planck:

$$
B_{\lambda}(T)=\frac{2 h c^{2}}{\lambda^{5}\left(\exp \left(\frac{h c}{\lambda k T}\right)-1\right)}\left[W m^{-2} s r^{-1} \mu m^{-1}\right]
$$

onde $h$ é a constante de Planck $\left(6,626 \cdot 10^{-34} \mathrm{~J} \cdot s\right)$, e $k$ é a constante de Boltzmann $\left(1,381 \cdot 10^{-23} J \cdot K^{-1}\right)$. Considerando a radiação emitida pelo corpo negro como isotrópica, ou seja, igualmente distribuída em todas as direções, a irradiância $F_{B \lambda}$ é equivalente a $\pi B_{\lambda}$ dada pela integral da radiância no ângulo sólido $d \Omega=\sin \theta d \theta d \phi$ em um hemisfério:

$$
F_{B \lambda}(T)=\int_{0}^{2 \pi} \int_{0}^{\pi / 2} B_{\lambda} \cos \theta d \Omega=\frac{2 \pi h c^{2}}{\lambda^{5}\left(\exp \left(\frac{h c}{k \lambda T}\right)-1\right)}\left[W m^{-2} \mu m^{-1}\right]
$$


A Figura 9 mostra o espectro da irradiância solar da forma como chega ao topo da atmosfera terrestre.

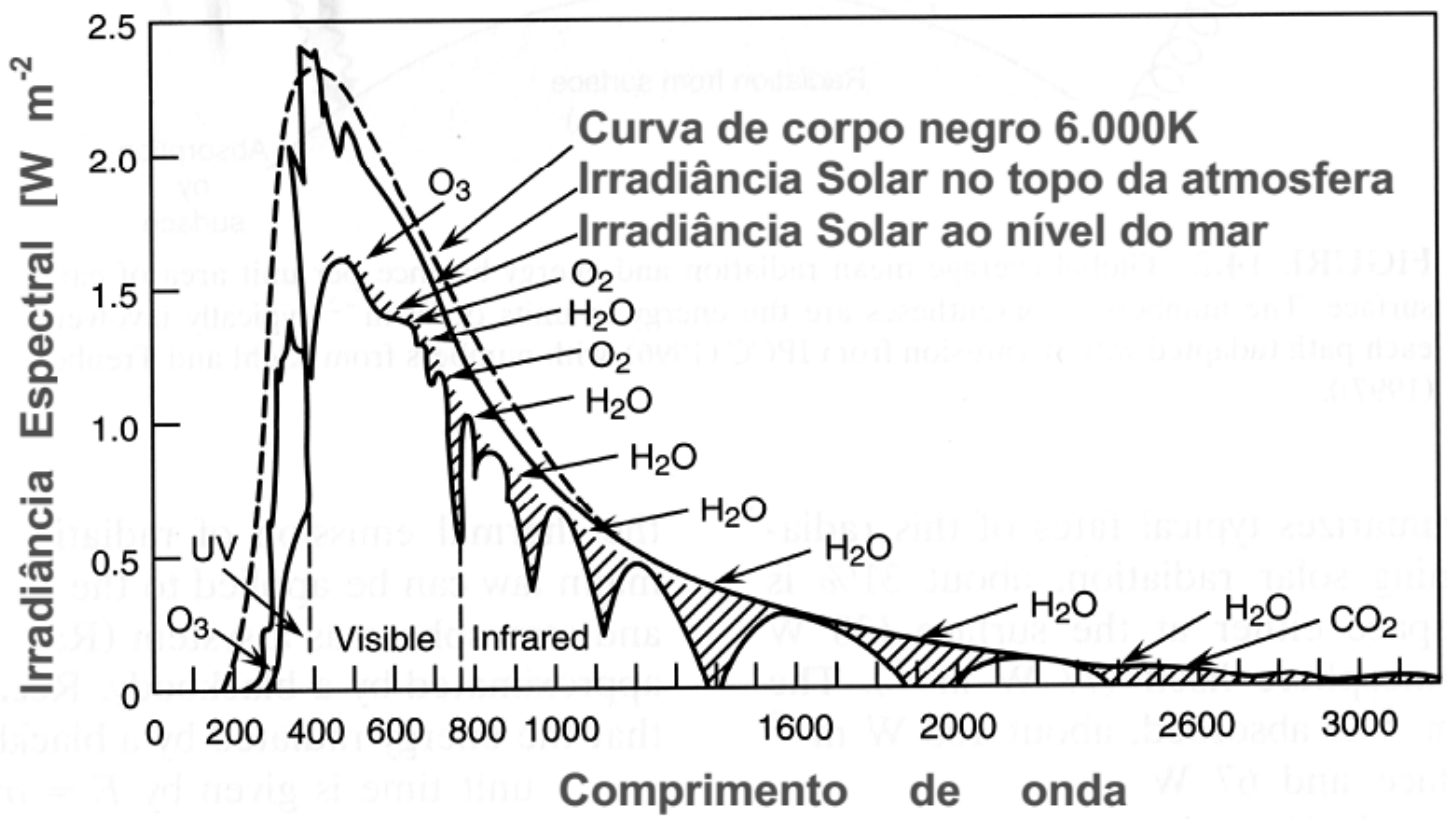

Figura 9 - Irradiância solar espectral no topo da atmosfera e na superfície ao nível do mar. A linha tracejada representa a curva correspondente de corpo negro a uma temperatura média equivalente a $6.000 \mathrm{~K}$. As regiões hachuradas representam as absorções moleculares na atmosfera (como por exemplo, ozônio, vapor de água e dióxido de carbono). Figura adaptada de Seinfeld e Pandis, 1998.

A Terra também emite radiação como um corpo negro, porém com temperatura bem menor, por volta de $250 \mathrm{~K}$, emitindo em comprimento de ondas maiores, a partir de $4 \mu \mathrm{m}$, sendo que o seu pico de energia é próximo a $15 \mu \mathrm{m}$, na região do infravermelho térmico (Figura 10a).

Quando o espectro solar no topo da atmosfera é comparado com o espectro solar na superfície terrestre nota-se uma diminuição da energia incidente na superfície em alguns comprimentos de onda. Em determinados intervalos, denominadas bandas de absorção, vários gases e partículas presentes na atmosfera absorvem a radiação solar em seu caminho à superfície. Os comprimentos de onda onde os constituintes da atmosfera permitem a transmissão de radiação são denominados "janelas atmosféricas". O oxigênio $\left(\mathrm{O}_{2}\right)$ e o ozônio $\left(\mathrm{O}_{3}\right)$ absorvem praticamente toda a radiação solar de comprimentos de onda inferiores a $0,3 \mu \mathrm{m}$, sendo que o ozônio presente na estratosfera também absorve na região visível do espectro (Figura 10b). Já o vapor d'água $\left(\mathrm{H}_{2} \mathrm{O}\right)$ e o dióxido de carbono $\left(\mathrm{CO}_{2}\right)$ afetam principalmente a radiação infravermelha terrestre (Figura 10c), sendo os principais responsáveis pelo aumento do efeito estufa. Ainda nesta figura, nota-se que existem pequenas janelas no espectro, destacando-se o 
intervalo entre 0,3 e $0,8 \mu \mathrm{m}$ no qual quase toda a radiação é transmitida. A maioria dos instrumentos de sensoriamento remoto trabalha nas janelas atmosféricas.
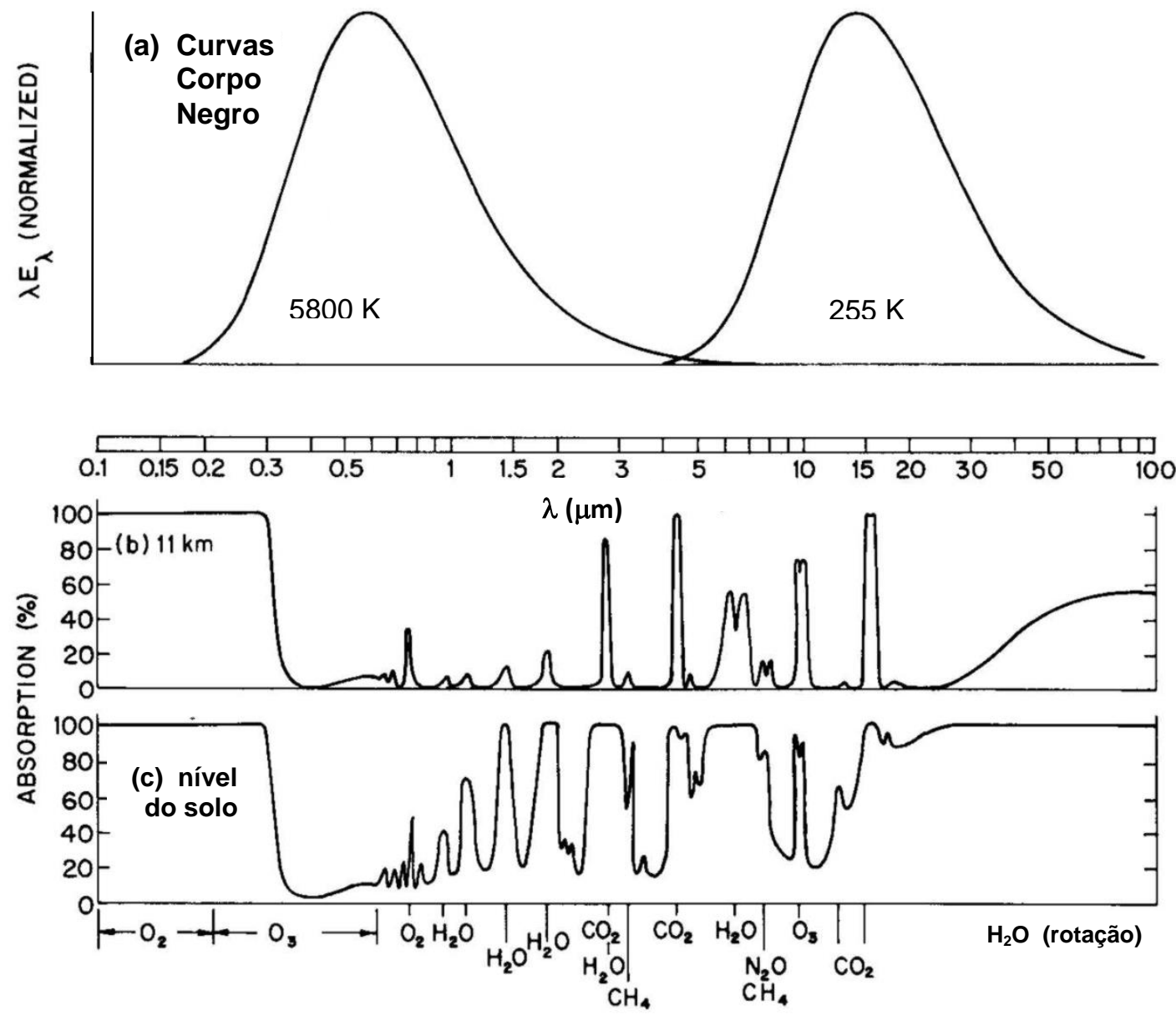

Figura 10 - (a) Curvas normalizadas de radiância de corpo negro para temperaturas da ordem das temperaturas médias do Sol e da Terra. São indicadas também as principais bandas de absorção gasosa e a absorbância atmosférica para comprimentos de onda entre 0,1 e $100 \mu \mathrm{m}$ : (b) entre o topo da atmosfera e uma altitude de $11 \mathrm{~km}$; (c) entre o topo da atmosfera e o nível do solo [Adaptada de Wallace e Hobbs, 1977].

\subsection{ABSORÇÃO E ESPALHAMENTO DE RADIAÇÃO POR PARTÍCULAS} DE AEROSSOL E GASES

O espalhamento e a absorção são processos físicos fundamentais associados à luz e sua interação com a matéria, sendo as principais causas de atenuação da radiação na atmosfera. Quando um feixe de luz atravessa um meio material, os fótons incidentes causam um deslocamento de cargas elétricas das partículas que, por sua vez, emitem radiação eletromagnética (Seinfeld e Pandis, 2006). As cargas elétricas oscilantes irradiam energia em todas as direções (espalhamento) e pode converter uma parte da radiação incidente em energia térmica (absorção). 
O espalhamento varia em função de um termo físico denominado parâmetro de tamanho $(x)$, que é a razão entre o tamanho da partícula e o comprimento de onda incidente. Para partículas esféricas $x$ é definido por (Liou, 2002):

$$
x=\frac{2 \pi r}{\lambda}
$$

onde $r$ é o raio da partícula e $\lambda$ é o comprimento de luz incidente. Se $x<<1$, o regime de espalhamento é Rayleigh (espalhamento por moléculas ou partículas atmosféricas pequenas em relação ao $\lambda$ incidente); se $x \cong 1$, o espalhamento é determinado pela teoria de Mie (espalhamento por partículas esféricas homogêneas de tamanho próximo ao $\lambda$ incidente); e, finalmente, se $x>>1$, o espalhamento é regido pelas leis da ótica geométrica (espalhamento por partículas atmosféricas grandes em relação ao $\lambda$ incidente). Estes diferentes regimes de espalhamento são ilustrados na

Figura 11, em função do raio da partícula e do comprimento de onda da radiação incidente.

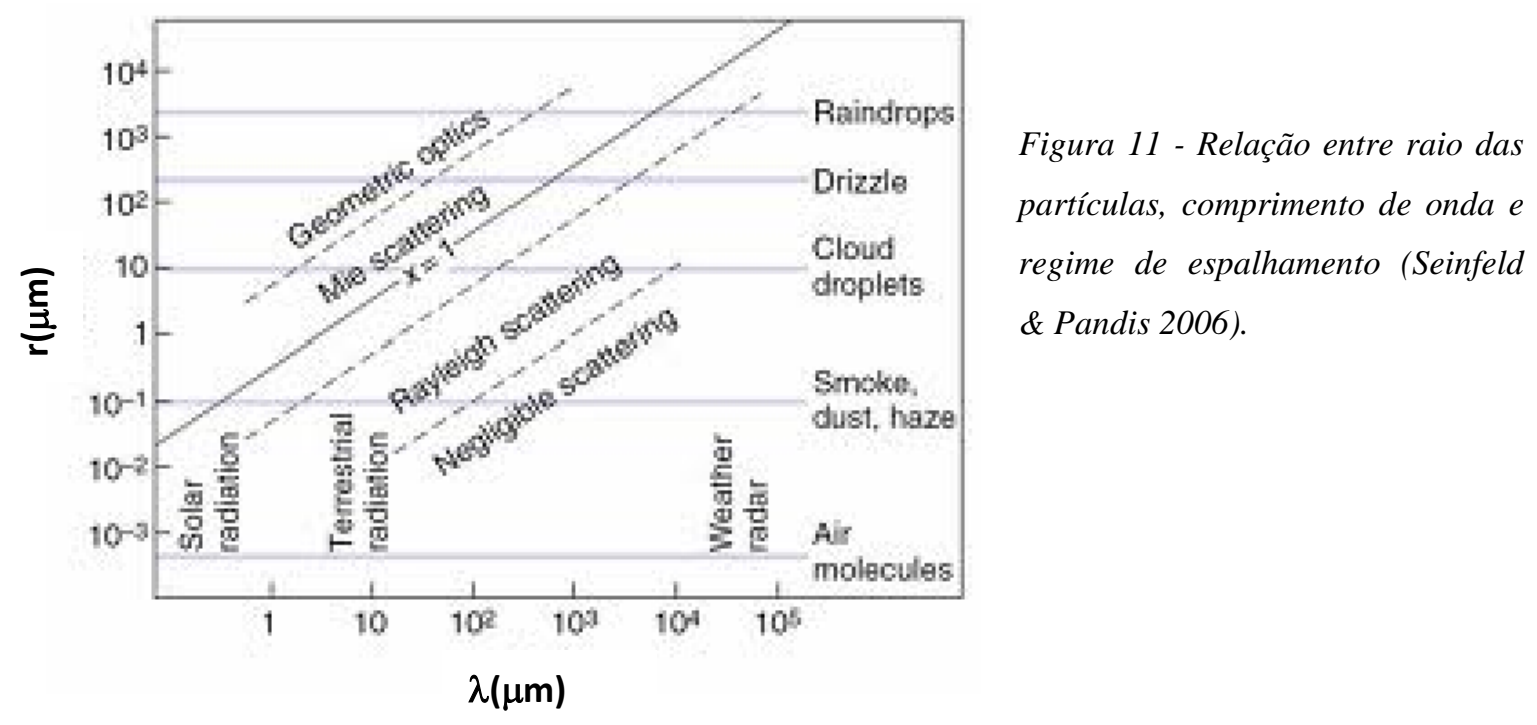

\subsection{A LEI DE BEER-LAMBERT-BOUGUER}

A lei de Beer-Lambert-Bouguer descreve a atenuação da radiação eletromagnética ao atravessar um meio homogêneo. Ao atravessar um meio material de volume $d V=d A d s$, a radiação pode interagir através de diferentes processos. O feixe direto pode ser atenuado por absorção de fótons pelo meio material ou espalhamento de fótons para outras direções. 


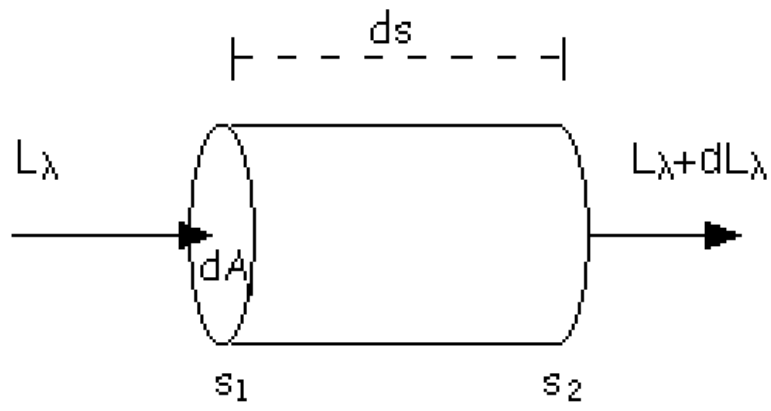

Figura 12 - Esquema simplificado para explicação da lei de Beer-Lambert-Bouguer.

Supondo a ausência de emissão de radiação difusa produzida pelo espalhamento múltiplo, a intensidade da radiação (radiância espectral $L_{\lambda},\left[W \cdot m^{-2} \cdot s r^{-1} \cdot \mu m^{-1}\right]$ ) que emerge em $s_{2}$ sofre uma redução $\left(d L_{\lambda}\right)$ em relação ao que entra em $s_{1}$ devido às interações do feixe com a matéria contida neste volume de ar:

$$
d L_{\lambda}=-b_{\text {ext }} L_{\lambda} d s
$$

onde a constante de proporcionalidade $b_{\text {ext }}(\lambda, s)$ é o coeficiente linear de extinção do meio.

Integrando-se (4) entre $s_{1}$ e $s_{2}$, tem-se que:

$$
L_{\lambda}\left(s_{2}\right)=L_{\lambda}\left(s_{1}\right) \exp \left(-\int_{s 1}^{s 2} b_{e x t, \lambda} d s\right)
$$

O expoente da equação 5 é denominado espessura ótica do meio material $\left(\delta_{\lambda}\right)$ :

$$
L_{\lambda}\left(s_{2}\right)=L_{\lambda}\left(s_{1}\right) \exp \left(-\delta_{\lambda}\right)
$$

A equação 6 é conhecida como a Lei de extinção de Beer-Lambert-Bouguer, que mostra que a intensidade da radiação decai exponencialmente ao longo do caminho ótico percorrido.

\subsection{PROPRIEDADES INTENSIVAS E EXTENSIVAS DO AEROSSOL ATMOSFÉRICO}

As partículas de aerossol tem um efeito direto no sistema climático através do espalhamento e da absorção da radiação. Ambos os processos removem energia de um feixe de radiação que atravessa um meio, causando a atenuação do feixe (extinção). Neste trabalho foram realizadas medidas tanto do coeficiente de espalhamento quanto de absorção de radiação. 
As propriedades intensivas do aerossol são aquelas que não dependem da concentração de partículas e estão associadas com as suas propriedades intrínsecas. Neste estudo, algumas propriedades intensivas dos aerossóis foram calculadas, como: expoente Ångström de espalhamento (SAE) e absorção (AAE) e albedo de espalhamento simples $\left(\omega_{0}\right)$. Essas variáveis são úteis na obtenção de informações adicionais sobre a natureza física e química das partículas de aerossol medidas nos sítios experimentais.

\subsubsection{Coeficiente linear de extinção $\left(b_{\text {ext }}\right)$ :}

O coeficiente de extinção em um dado comprimento de onda $\lambda$ de uma camada atmosférica contendo várias partículas é um parâmetro definido como:

$$
b_{\text {ext }}=C_{\text {ext }} N
$$

onde $N$ é a concentração numérica das partículas ou moléculas $\left(\mathrm{m}^{-3}\right)$ e $\mathrm{C}_{\mathrm{ext}}$ é a seção de choque de extinção de uma única partícula, em unidades de $\mathrm{m}^{2}$. A seção de choque de extinção representa a área efetiva de uma única partícula. A absorção e espalhamento ocorrem simultaneamente na atmosfera porque todas as moléculas e partículas tanto absorvem quanto espalham a radiação (Seinfeld \& Pandis 2006). Logo, o coeficiente de extinção é a soma dos coeficientes de absorção $\left(b_{a b s}\right)$ e de espalhamento $\left(b_{e s p}\right)$.

\subsubsection{Espessura ótica de extinção $\left(\delta_{\text {ext }}\right)$ :}

A espessura ótica de extinção em um determinado comprimento de onda $\lambda$ é definida como a integração do coeficiente linear de extinção $b_{\text {ext }}(\lambda)$, ao longo de um caminho $d s$, e representa a quantidade de partículas em toda a coluna atmosférica responsáveis pela extinção da radiação solar no comprimento de onda $\lambda$ ao longo do caminho óptico $d s$ :

$$
\delta_{\text {ext }}(\lambda)=\int_{s 1}^{s 2} b_{\text {ext }}(\lambda) d s
$$

Esta grandeza pode ser decomposta nas componentes de absorção e espalhamento da seguinte forma:

$$
\delta_{\text {ext }}(\lambda)=\delta_{\text {esp }}(\lambda)+\delta_{a b s}(\lambda)
$$




\subsubsection{Profundidade ótica de extinção $(\tau)$ :}

A espessura ótica medida na vertical é definida como profundidade ótica de extinção $\tau$ (ou AOD) em um determinado comprimento de onda $\lambda$ :

$$
\tau(\lambda)=\cos \theta \delta(\lambda)
$$

onde $\theta$ é o ângulo zenital solar (ângulo formado entre a vertical e o sol). Analogamente a equação 9:

$$
\tau_{\text {ext }}(\lambda)=\tau_{\text {esp }}(\lambda)+\tau_{a b s}(\lambda)
$$

Neste trabalho, a profundidade óptica será referida como AOD (do inglês, Aerosol Optical Depth). As profundidades ópticas de absorção e espalhamento serão referidas como AAOD e SAOD, respectivamente.

\subsubsection{Albedo de espalhamento simples $\left(\omega_{0}\right)$ :}

O albedo de espalhamento simples de um determinado comprimento de onda $\lambda$ é definido como a razão entre o coeficiente de espalhamento e o coeficiente de extinção. Ele é interpretado como a fração do feixe incidente que é espalhada pela matéria numa parcela de ar, sendo que o restante é absorvido pela matéria:

$$
\omega_{0}=\frac{b_{e s p}}{b_{e x t}}=1-\frac{b_{a b s}}{b_{e x t}}
$$

$\mathrm{Na}$ coluna atmosférica o $\omega_{0}$ é calculado utilizando os valores de $\tau_{\text {esp }}$ e $\tau_{a b s}$ no lugar de $b_{e s p}$ e $b_{a b s}$ da equação 12 , respectivamente.

Valores de $\omega_{0}$ próximos de 1 indicam partículas de aerossol puramente espalhadoras (e.g. sulfato de amônia), enquanto que baixos valores de $\omega_{0}(0,1-0,6)$ indicam a predominância de aerossóis absorvedores (e.g. black carbon). Neste trabalho, o albedo de espalhamento simples será referido como SSA (do inglês, Single Scattering Albedo). 


\subsubsection{Expoente de Ångström de Espalhamento (SAE)}

O coeficiente Ångström de espalhamento (SAE) representa a dependência espectral do coeficiente de espalhamento $\left(b_{\mathrm{esp}}\right)$ ou da espessura ótica de espalhamento $\left(\tau_{\text {esp }}\right)$. Uma vez que estas grandezas decrescem monotonicamente com o comprimento de onda, aproxima-se esta dependência pela lei de potência (Ångström, 1929):

$$
\sigma_{S}(\lambda)=B \cdot \lambda^{-S A E}
$$

onde B é uma constante denominada de coeficiente de turbidez.

Os expoentes Ångström de espalhamento tem relação com o tamanho médio da população de partículas. Para uma distribuição de tamanho "monomodal", SAE maiores que 2 indicam a predominância de partículas finas, geralmente associadas à poluição urbana ou queima de biomassa. Por outro lado, SAE próximos de 1 indicam a presença de partículas na moda grossa, tipicamente associadas ao sal marinho e poeira mineral (Schuster et al., 2006).

\subsubsection{Expoente de Ångström de Absorção (AAE):}

O coeficiente Ångström de absorção (AAE) representa a dependência espectral do coeficiente de absorção $b_{a b s}$ e, portanto, seu cálculo é feito a partir da medida do $b_{a b s}$ em diversos comprimentos de onda. O AAE é calculado de maneira semelhante ao Ångström de espalhamento (SAE), descrito no subitem anterior. Este parâmetro ótico está relacionado com as propriedades físicas e químicas do aerossol (Rizzo et al., 2011). $\mathrm{O}$ BC tipicamente segue uma dependência espectral $\lambda_{-1}$, obtendo-se uma AAE de 1 (Bergstrom et al. 2002), enquanto o carbono orgânico em aerossóis de queima de biomassa e poeiras minerais contribuem para a absorção de luz no ultravioleta e regiões espectrais do UV, resultando em um AAE maior que a unidade (Kirchstetter 2004). Valores de AAE maiores que 1,5 tem sido observados para aerossóis de poeira mineral (Bergstrom et al. 2007; Russell et al. 2010). 


\section{METODOLOGIA}

Para atingir os objetivos propostos neste trabalho, foram feitas observações das propriedades óticas do aerossol em diversas regiões da bacia Amazônica. Pela primeira vez foi feita uma caracterização da profundidade ótica espectral de absorção e espalhamento dos aerossóis urbanos e de queimadas obtida pelos fotômetros solares da AERONET nesta região. Medidas dos coeficientes de espalhamento e absorção espectrais in-situ também foram realizadas em diversas regiões durante o experimento GoAmazon2014/5. Os locais de estudo envolveram tanto regiões preservadas quanto regiões impactadas pelas atividades antrópicas na Amazônia. As regiões de estudo bem como a instrumentação utilizada serão descritas detalhadamente a seguir.

\subsection{DESCRIÇÃO DO EXPERIMENTO GOAMAZON2014/5}

O experimento GoAmazon2014/5 procura entender como o ciclo de vida de aerossóis e nuvens é influenciado pelos poluentes da cidade de Manaus em meio a floresta tropical. Em janeiro de 2014 o experimento foi iniciado, colocando em operação diversas estações a diferentes distâncias vento acima e vento abaixo da cidade de Manaus.

Manaus é uma cidade que possui 2 milhões de habitantes e uma frota veicular de aproximadamente 700 mil veículos, cercada por milhares de quilômetros de floresta, criando uma área urbana isolada dentro da Bacia Amazônica. É grande o suficiente para ter um efeito de ilha de calor urbana de até $3{ }^{\circ} \mathrm{C}$ em relação à floresta circundante (de Souza \& dos Santos Alvalá 2014). A região vento abaixo de Manaus irá alternar entre um ambiente muito limpo e um ambiente com forte influência da pluma de poluição da cidade, com o número de partículas e concentrações em massa sendo da ordem de 10 a 100 vezes maior durante a presença da pluma (Kuhn et al. 2010). O estudo dos processos atmosféricos nessa região é importante para avaliações regionais e globais de mudanças climáticas. Portanto, um conjunto detalhado de medidas de propriedades óticas do aerossol foi realizado em 4 regiões diferentes, seguido de estudos detalhados de transporte meteorológico.

Três sítios de amostragem do experimento foram localizados vento acima da pluma Manaus: ATTO (T0a), ZF2 (T0z) e EMBRAPA (T0e); e um site localizado vento abaixo da pluma: Manacapuru (T3). 
Em todos os sites, um grande conjunto de medições foi realizado: medidas das propriedades óticas do aerossol, como espalhamento e absorção espectral da luz; distribuição de tamanho; composição química; componentes orgânicos e inorgânicos; $\mathrm{CCN}$; profundidade ótica, entre outras medidas. $\mathrm{O}$ enorme conjunto de dados coletados representa um novo marco para o estudo do clima e da qualidade do ar na Amazônia. A cidade de Manaus e os sítios de investigação são mostrados na Figura 13. As coordenadas de latitude e longitude de cada local são listadas na Tabela 1.

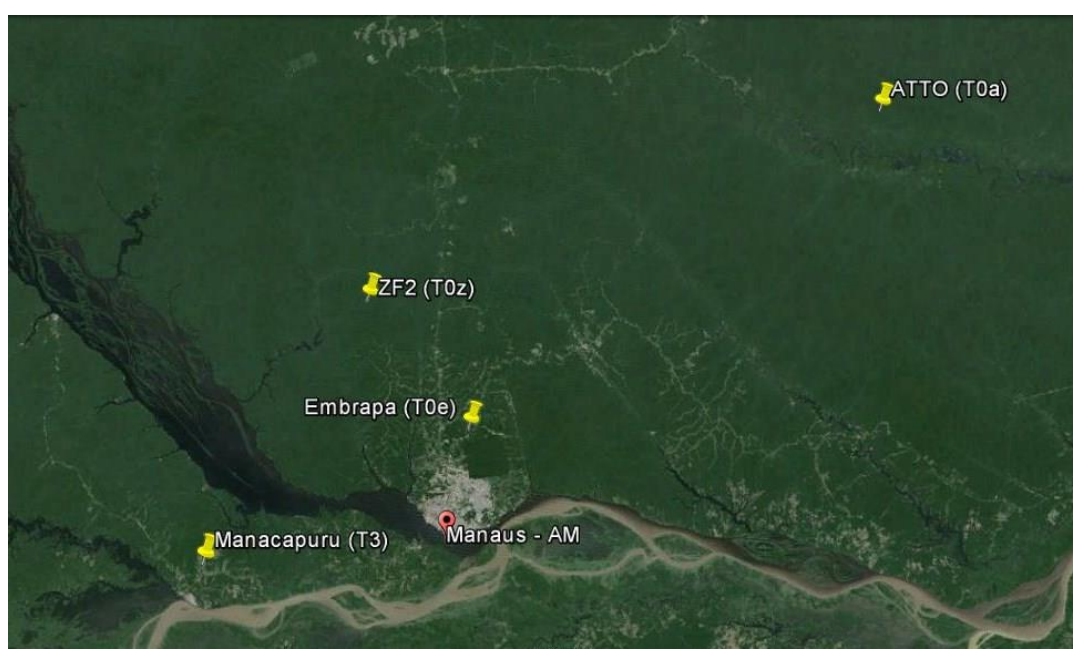

Figura 13 - Sítios de Amostragem do Experimento GoAmazon $2014 / 5$.

Tabela 1: Coordenadas de cada sítio observacional do experimento GoAmazon2014/5.

\begin{tabular}{|c|c|c|c|c|c|}
\hline \multirow{2}{*}{ Sítio } & & \multicolumn{2}{|c|}{ Localização } & \multirow{2}{*}{$\begin{array}{l}\text { Dist. do T1 } \\
\text { (km) }\end{array}$} & \multirow{2}{*}{ Descrição do site } \\
\hline & & Lat. $\left({ }^{\circ} \mathbf{N}\right)$ & Long. $\left({ }^{\circ} \mathbf{L}\right)$ & & \\
\hline T0a & ATTO & $-2.1466^{\circ}$ & $-59.0050^{\circ}$ & 151.4 & $\begin{array}{c}\text { Floresta } 160 \mathrm{~km} \text { vento } \\
\text { acima de Manaus }\end{array}$ \\
\hline T0e & EMBRAPA & $-2.8942^{\circ}$ & $-59.9718^{\circ}$ & 22.5 & $\begin{array}{c}\text { Pasto a } 25 \mathrm{~km} \text { norte de } \\
\text { Manaus }\end{array}$ \\
\hline T0z & ZF2 & $-2.5946^{\circ}$ & $-60.2093^{\circ}$ & 60.9 & $\begin{array}{l}\text { Floresta a } 60 \mathrm{~km} \text { norte de } \\
\text { Manaus }\end{array}$ \\
\hline T3 & Manacapuru & $-3.2133^{\circ}$ & $-60.5987^{\circ}$ & 69.4 & $\begin{array}{c}\text { Pasto } 60 \mathrm{~km} \text { vento abaixo } \\
\text { de Manaus }\end{array}$ \\
\hline
\end{tabular}

O site T0a é o Amazonian Tall Tower Observatory (ATTO) e fica a cerca de 160 $\mathrm{km}$ ao Norte de Manaus. Vento acima deste sítio, no sentido do vento dominante (nordeste a leste), grandes áreas cobertas por florestas não perturbadas se estendem por centenas de quilômetros. À nordeste, o local com densa atividade humana mais próximo fica na região costeira das Guianas e do Estado do Amapá, há cerca de $1100 \mathrm{~km}$ de 
distância. À sudeste, os estados densamente povoados do nordeste brasileiro ficam a distâncias superiores a $1000 \mathrm{~km}$. A origem das massas de ar na estação ATTO muda ao longo do ano, conforme a Zona de Convergência Intertropical (ZCIT) sofre mudanças sazonais sobre a Bacia Amazônica, resultando em grandes diferenças das condições meteorológicas e composição atmosférica (Andreae et al. 2012). Durante a estação chuvosa, massas de ar chegam predominantemente de nordeste ao longo de quilômetros de cobertura de floresta tropical limpa. Durante este período, o transporte de longas distâncias do Atlântico e da África traz episódios de aerossol marinho, areia do Saara, e fumaça de queimadas da África Ocidental. Este padrão muda abruptamente no final de maio quando os ZCIT se deslocam para o norte do ATTO e a estação amostra massas de ar do hemisfério Sul. A rosa dos ventos para estação seca (15 junho - 30 novembro) e estação chuvosa (1 dezembro - 14 junho) estão ilustradas na Figura 14 e indicam a predominância do vento vindo de leste. Uma ligeira mudança de direção do vento em direção a ENE é observado durante a estação chuvosa, enquanto os fluxos são principalmente de leste durante a estação seca.
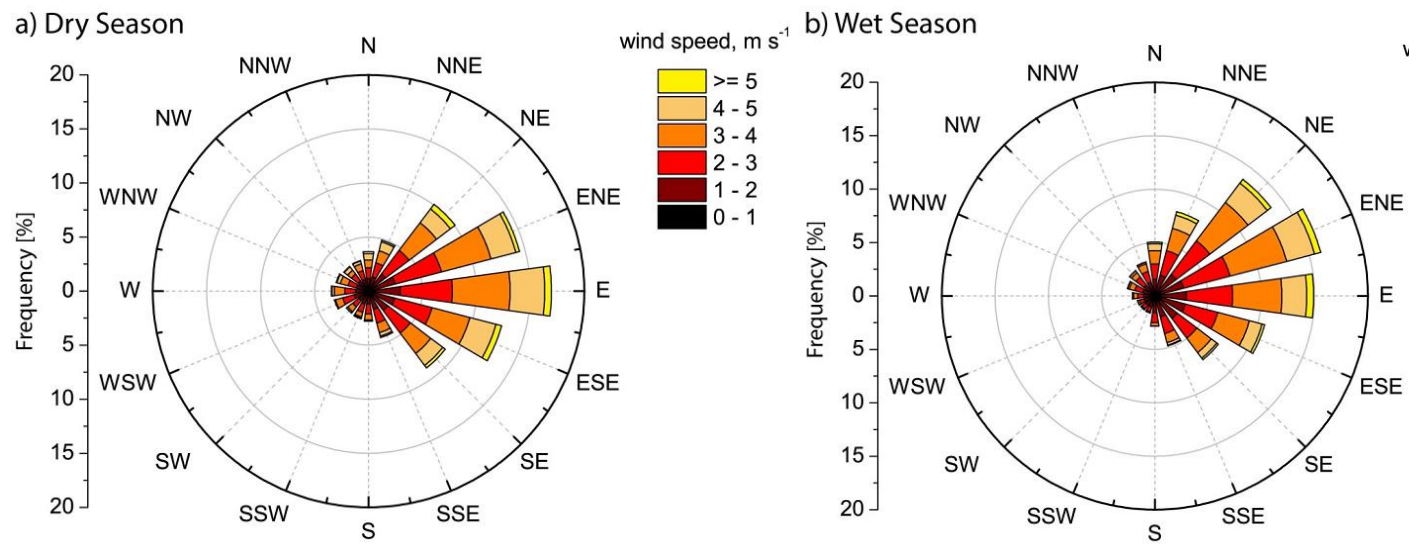

Figura 14- Rosa dos ventos para a (a) estação seca (15 jun - 30 nov) e (b) estação chuvosa (1 dez - 14 jun) com base em médias de meia hora de velocidade e direção do vento, medidas a 81 m agl para o período de 18 de outubro de 2012 a 23 de julho de 2014.

A estação ATTO está em operação desde meados de 2012, realizando medidas contínuas da composição da atmosfera em condições de background, com pouca ou nenhuma influência da pluma de Manaus na região. O Instituto de Física da Universidade de São Paulo (IFUSP) está realizando medidas de absorção, espalhamento, distribuição de tamanho, $\mathrm{CCN}$ e composição química em parceria com o Instituto Max Planck que mede parâmetros similares com outra instrumentação, além de compostos gasosos $\left(\mathrm{O}_{3}, \mathrm{CO}, \mathrm{CH}_{4}, \mathrm{CO}_{2}, \mathrm{~N}_{2} \mathrm{O}\right.$ e outros gases $)$. A torre de $325 \mathrm{~m}$ de altura 
foi inaugurada em agosto de 2015, portanto as medidas foram feitas a partir de uma torre de 80 m muito próxima da torre ATTO.

O sítio T0e, ou EMBRAPA (Empresa Brasileira de Pesquisas Agropecuárias), está localizado cerca de $25 \mathrm{~km}$ ao norte do limite da área metropolitana de Manaus (Barbosa et al. 2014). Este site foi construído para operação do sistema Raman Lidar, que necessita de eletricidade contínua e também Internet de alta qualidade para sua operação. Um fotômetro solar da rede AERONET também foi instalado neste site e está funcionando continuamente desde 2011.

$\mathrm{O}$ site $\mathrm{T} 0 \mathrm{z}$ está na reserva ecológica $\mathrm{ZF} 2$, que tem sido parte central de estudos na Amazônia há mais de 20 anos. Uma das torres da ZF2 (K34) tem sido a peça central do Experimento de Grande Escala da Biosfera-Atmosfera (LBA) desde a sua construção em 1999 (Araújo 2002). A outra torre (TT34) foi estabelecida para o experimento AMAZE em 2008 (Martin et al. 2010). Neste trabalho, medidas de absorção espectral dos particulados PM10 e PM2.5 foram realizadas neste site durante a estação chuvosa.

Todos os locais intitulados T0 estão localizados vento acima da cidade de Manaus, geralmente em condições de atmosfera limpa. No entanto, estes sites podem receber esporadicamente a pluma de poluição de Manaus, transportada pelos ventos locais (Chen et al. 2015).

O sítio T3 está localizado a $70 \mathrm{~km}$ vento abaixo de Manaus, o que representa um tempo de 2 a 6 horas para que a massa de ar vinda de Manaus atinja o site, dependendo da velocidade do vento. O sítio experimental T3 é um local de pastagem situado na estrada que liga Manaus à cidade de Manacapuru. Manacapuru está a $10 \mathrm{~km}$ a sudoeste do T3, o que significa que o sítio experimental T3 não é afetado constantemente pelas emissões de Manacapuru, dados os padrões predominantes do vento. Foram instalados cerca de 19 containers no local, com um amplo conjunto de medidas de propriedades de aerossóis, incluindo absorção e espalhamento espectrais. Um fotômetro solar da AERONET também foi colocado em operação neste site em dezembro de 2013. 


\subsection{SENSORIAMENTO REMOTO DA ATMOSFERA - A REDE AERONET}

\subsubsection{Medidas de radiação solar direta e difusa}

A AERONET (Aerosol Robotic Network) é uma rede de sensoriamento remoto em solo que faz o monitoramento global da profundidade ótica do aerossol (AOD) e de outras propriedades derivadas do algoritmo inversão, como distribuições de tamanho de aerossóis e albedo de espalhamento único, integrados na coluna atmosférica.

Os radiômetros solares, modelo CIMEL Eletronic 318A, são constituídos de sensores aos quais são acoplados colimadores projetados para rejeitar a luz difusa. Os radiômetros automáticos fazem medidas da radiação solar direta com um campo de visão de $1,2^{\circ}$ a cada 15 minutos nos comprimentos de onda (nominais) de 340, 380, 440, 500, 675, 870, 940, and $1020 \mathrm{~nm}$. Estas medidas da extinção solar são utilizadas para calcular a profundidade ótica (AOD) para cada comprimento de onda, exceto o canal de 940nm, que é usado para calcular a coluna de vapor d'água precipitável. A partir do cálculo da extinção da radiação solar, a espessura ótica espectral das partículas de aerossol é calculada de acordo com a lei de Beer-Lambert-Bouguer (equação 6). A profundidade ótica de extinção pode ser dividida em suas várias componentes (extinção por aerossóis, espalhamento molecular e absorção gasosa). A fim de determinar a espessura ótica devida apenas às partículas de aerossóis, a atenuação de radiação solar por outros gases que possam interferir nas medidas são estimadas e removidas.

Além das medidas de radiação solar direta, os fotômetros solares da rede AERONET fazem medidas da radiação solar difusa com o intuito de observar o espalhamento espectral dos aerossóis (Figura 15). Apenas quatro bandas espectrais são utilizadas para as medições da radiação solar difusa (440, 675, 870 e $1020 \mathrm{~nm})$, que são tomadas em intervalos de aproximadamente 1 hora ao longo do dia. As medidas são realizadas no almucantar (varredura do ângulo azimutal com inclinação do instrumento igual ao ângulo zenital solar), e no plano principal (plano vertical no qual o ângulo azimutal é constante). Estas medidas em conjunto com as medidas diretas da AOD são utilizadas para obter a distribuição de tamanho de aerossóis integrado na coluna e índices de refração. Utilizando estas informações microfísica, o albedo simples é calculado. 


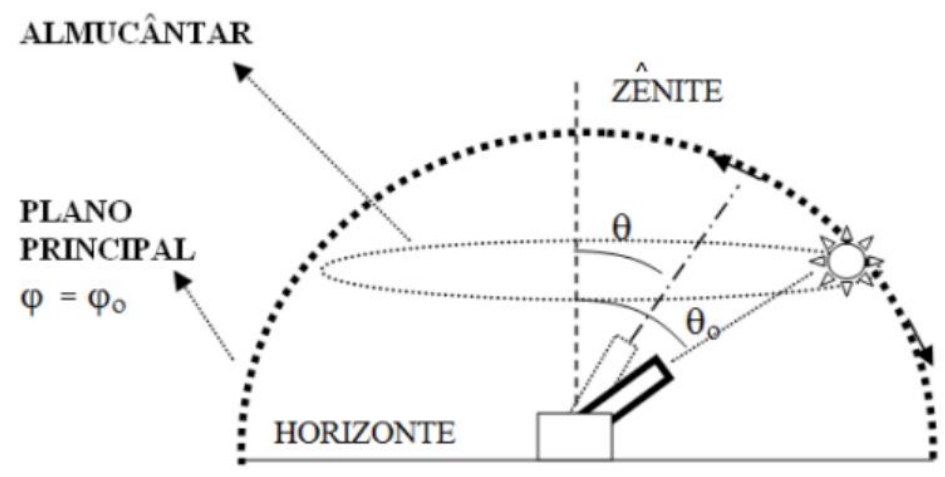

Figura 15 - Medidas de radiação difusa dos fotômetros solares da AERONET (Sena 2013).

Um algoritmo de inversão é utilizado em conjunto com medidas da radiação direta e difusa para calcular diversas propriedades das partículas de aerossol integradas na coluna atmosférica. Esta técnica requer hipóteses adicionais com relação à forma das partículas, interação com a superfície e processos de espalhamento múltiplo. O produto gerado pelo algoritmo de inversão da AERONET fornece a distribuição volumétrica de tamanho de partículas divididas em 22 faixas para o raio da partícula (equidistantes na escala logarítmica) entre 0,05 e $15 \mu \mathrm{m}$ e o índice de refração complexo espectral para os comprimentos de onda correspondentes às medidas de radiância celeste. A distribuição de tamanho e o índice de refração complexo, obtidos pelo instrumento, determinam a função de fase para 83 ângulos de espalhamento, o albedo simples e o fator de assimetria para cada banda espectral. Todos os parâmetros são calculados apenas quando o ângulo zenital solar for maior do que $50^{\circ}$.

No código de inversão utilizado pela rede AERONET, as partículas de aerossol estão particionadas em duas componentes: esféricas e não esféricas. A componente esférica é modelada por um conjunto de esferas polidispersas (que possuem diferentes tamanhos) e homogêneas (é assumido um mesmo índice de refração complexo para todas as partículas de todos os tamanhos). As propriedades são calculadas pela teoria Mie pelo método de ordenadas discretas descrito em Nakajima \& Tanaka 1988. A componente não esférica é tratada como uma mistura de partículas esferoidais polidispersas, homogêneas, orientadas aleatoriamente. O método utilizado para calcular essas partículas é baseado no modelo de mistura de formatos de esferóides polidispersos aleatoriamente orientados descrito em detalhes por (Dubovik et al. 2002; Dubovik et al. 2006). 
A AERONET segue um protocolo para garantia de qualidade de dados (nível 2.0), onde são eliminados dados contaminados pela presença de nuvens e dados cuja a AOD em $440 \mathrm{~nm}$ seja menor do que 0,4. Esta última condição $(\mathrm{AOD}<0,4)$ não foi aplicada aos dados nível 2.0 utilizados neste trabalho dado que durante a estação chuvosa a AOD permanece abaixo de 0,2 na região Amazônica. Também são aplicadas correções devidas a problemas de calibração e degradação do instrumento (Eck et al. 2010). A incerteza na AOD varia entre 0,01 e 0,02 e depende do comprimento de onda, com os erros mais elevados para o UV (Holben et al. 1998). Para o expoente Ångström, esta incerteza varia de 0,03 a 0,04 (Schuster et al. 2006) e de 0,03 a 0,07 para o SSA (Dubovik et al. 2002).

\subsubsection{Forçante Radiativa do Aerossol como produtos da AERONET}

O algoritmo da AERONET calcula a forçante radiativa direta do aerossol como sendo a diferença entre a irradiância (ou fluxo) global integrada em todo o espectro, com e sem a presença de aerossol, computados no topo da atmosfera (TOA, do inglês Top of Atmosphere) e na superfície (BOA, Bottom of Atmosphere).

$$
\begin{aligned}
& \triangle F_{T O A}=F_{T O A}^{\uparrow 0}-F_{T O A}^{\uparrow} \\
& \triangle F_{B O A}=F_{B O A}^{\downarrow}-F_{B O A}^{\downarrow 0}
\end{aligned}
$$

onde $F$ e $F^{0}$ são as irradiâncias com e sem aerossol, e as setas para cima $\uparrow$ indicam fluxo ascendente, e para baixo $\downarrow$ indicam fluxo descendente. Esta escolha dos sinais implica que valores negativos estão associados a efeito de esfriamento e valores negativos ao aquecimento, tanto na superfície (BOA) quanto no topo da atmosfera (TOA).

As propriedades detalhadas de aerossóis são utilizadas para calcular as irradiâncias ascendentes e descendentes no topo da atmosfera e na superfície na faixa espectral entre 0,2 e 4,0 $\mu \mathrm{m}$ a partir do código de transferência radiativa GAME (Global Atmospheric Model) (Dubuisson et al. 1996). A forçante radiativa de aerossóis também é calculada para a mesma faixa espectral. As simulações utilizam interpolações e extrapolações das propriedades óticas de aerossóis obtidas nos comprimentos de onda das medidas de radiância celeste. 


\subsubsection{Descrição das estações da AERONET estudadas}

Para o estudo dos aerossóis de queimadas, foram feitas análises no sítio de Alta Floresta - MT $\left(9.87134^{\circ} \mathrm{S}, 56.10445^{\circ} \mathrm{O}\right)$. Inicialmente, quando a estação foi instalada, ficava em uma área de transição entre floresta e pastagem. Esta estação está localizada no chamado Arco do Desflorestamento, região que se estende do sudeste do estado do Maranhão, ao norte do Tocantins, sul do Pará, norte do Mato Grosso, Rondônia e sul do Amazonas e sudoeste do estado do Acre. Nesta região se encontra o maior número de focos de queima de biomassa do Brasil. As medidas com fotômetros solares da AERONET estão sendo realizadas continuamente em Alta Floresta desde o ano 2000. A longa série temporal dos dados permite uma boa caracterização dos aerossóis de queimadas nesta região.

Para o estudo de aerossóis provenientes de poluição urbana, foram analisados os sítios ARM-Manacapuru e Manaus-Embrapa da AERONET. Estes sítios experimentais são parte do experimento GoAmazon2014/5 e já foram descritos no subitem anterior. O fotômetro solar da AERONET está em operação no sítio da Embrapa desde 2011, enquanto que o fotômetro do T3 está coletando dados desde dezembro de 2013. As coordenadas de latitude e longitude de cada local onde estão instalados os fotômetros solares da AERONET e o período de funcionamento do instrumento estão listados na Tabela 2.

Tabela 2: Coordenadas de cada sítio de amostragem da AERONET e período de amostragem dos fotômetros solares.

\begin{tabular}{|c|c|c|c|}
\hline & \multicolumn{2}{|c|}{ Localização } & \multirow{2}{*}{ Período de funcionamento } \\
\hline & Lat. $\left({ }^{\circ} \mathbf{N}\right)$ & Long. $\left({ }^{\circ} \mathbf{L}\right)$ & \\
\hline Alta Floresta & $-9.8713^{\circ}$ & $-56.1044^{\circ}$ & $2000-2015$ \\
\hline Manaus-EMBRAPA & $-2.8942^{\circ}$ & $-59.9718^{\circ}$ & 2011-2015 \\
\hline ARM-Manacapuru & $-3.2133^{\circ}$ & $-60.5987^{\circ}$ & 2014-2015 \\
\hline
\end{tabular}

\subsection{MEDIDAS DE ESPALHAMENTO E ABSORÇÃO ESPECTRAIS IN-SITU}

Nesta seção será descrita brevemente a instrumentação utilizada neste trabalho para medir a absorção e espalhamento espectrais de partículas de aerossóis. Devido à alta umidade na região Amazônica, antes de serem amostrados, os aerossóis passaram por um processo de secagem através do sistema de difusão em sílica gel, reduzindo a umidade relativa da amostra de ar para valores abaixo de $40 \%$. Os instrumentos in-situ 
amostraram aerossóis com resolução temporal de 1 minuto e médias de 30 minutos foram calculadas para as análises.

\subsubsection{MAAP - medidas de absorção em tempo real}

Medidas de absorção foram feitas utilizando o fotômetro MAAP (MultiAngle Absorption Photometry - Thermo Inc., Model 5012) (Petzold et al., 2005). O MAAP reporta em tempo real a concentração de black carbon em 637 nm, que é convertida para coeficientes de absorção assumindo um coeficiente mássico de absorção MAC = $6,6 \mathrm{~m}^{2} / \mathrm{g}$. O instrumento mede simultaneamente a atenuação ótica e a reflexão de luz por partículas depositadas em um filtro para vários ângulos de detecção (Petzold et al., 2005). Para fazer a medida exclusiva da absorção, o MAAP realiza o cálculo de transferência radiativa através filtro contendo aerossóis e desconta o espalhamento ótico.

As medidas foram realizadas a cada minuto e uma correção de $5 \%$ foi aplicada aos dados para um ajuste de comprimento de onda (Müller et al. 2011). Foram calculadas médias de 30 minutos, resultando em um limite de detecção de $0,13 \mathrm{Mm}^{-1}$ (Petzold et al. 2005) . A Figura 16 mostra uma ilustração do instrumento e o desenho esquemático de seu funcionamento.

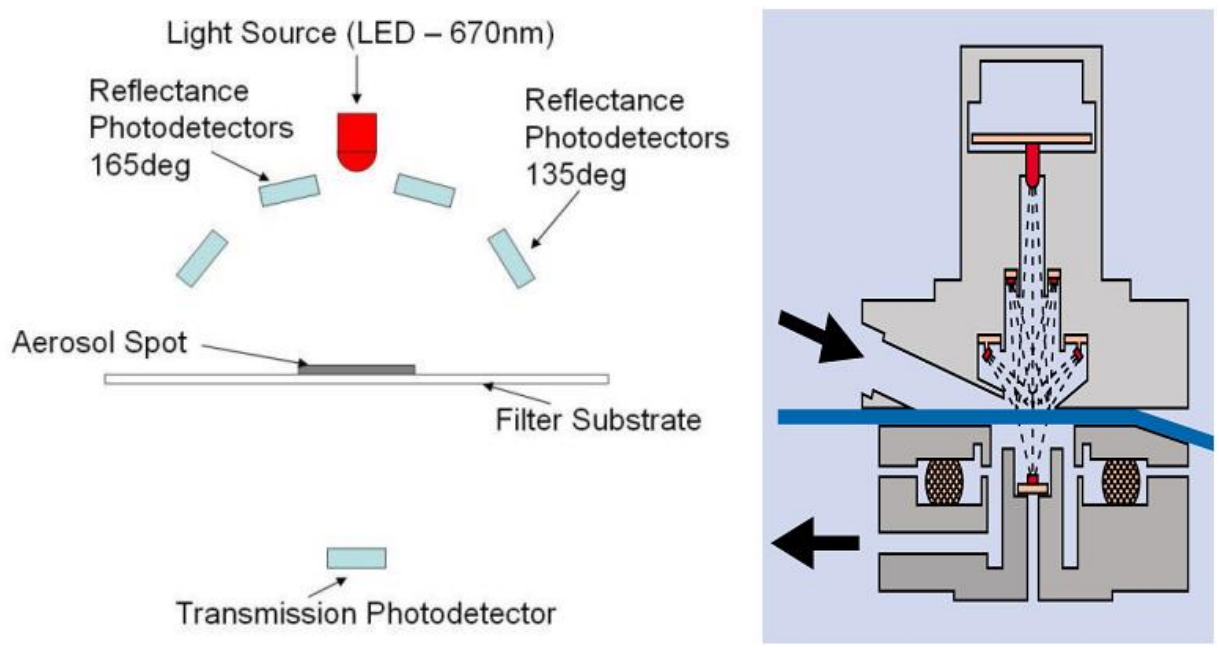

Figura 16 - Desenho esquemático do princípio de funcionamento do MAAP. Simultaneamente à medida de absorção em um filtro de fibra de vidro, o espalhamento ótico é determinado e descontado através de um algoritmo desenvolvido para o instrumento. 


\subsubsection{A medida da absorção espectral de aerossóis com Aetalômetro}

O Aetalômetro é um instrumento que estima a concentração de $\mathrm{BC}$ presente na atmosfera em tempo real. O seu princípio de funcionamento (Figura 17) consiste em medir a atenuação de um feixe de luz transmitida por um filtro que está continuamente coletando amostra de aerossol com resolução temporal de 1 minuto. A atenuação ótica (ATN) é definida como:

$$
A T N=100 \cdot \ln \frac{I_{0}}{I}
$$

onde $I_{0}$ representa a intensidade de luz transmitida pelo filtro limpo, e $I$ a intensidade de luz transmitida após a exposição do filtro. A atenuação ótica é função do comprimento de onda da luz incidente $(\lambda)$, de modo que a concentração de BC pode ser determinada para comprimentos de onda fixos:

$$
[B C]=\sigma_{a b s}(\lambda) / M A C
$$

A concentração em massa de BC é calculada a partir da mudança na atenuação ótica a $880 \mathrm{~nm}$ no intervalo de tempo selecionado utilizando o coeficiente mássico de absorção de 7,77 $\mathrm{m}^{2} / \mathrm{g}$ (Drinovec et al. 2015). Neste comprimento de onda, outras partículas de aerossóis (carbonáceos ou minerais) absorvem significativamente menos a radiação e, portanto, a absorção pode ser atribuída somente ao BC (Sandradewi et al. 2008; Fialho et al. 2006). As medidas em regiões espectrais distintas (370, 470, 520, 590, 660, 880 e $950 \mathrm{~nm}$ ) permitem a análise espectral dos dados. A análise da dependência da absorção com o comprimento de onda pode ser importante para a determinação da fonte emissora de BC ou a detecção de poeira mineral (Collaud Coen et al. 2004) a partir da dependência do albedo de espalhamento único com o comprimento de onda. 


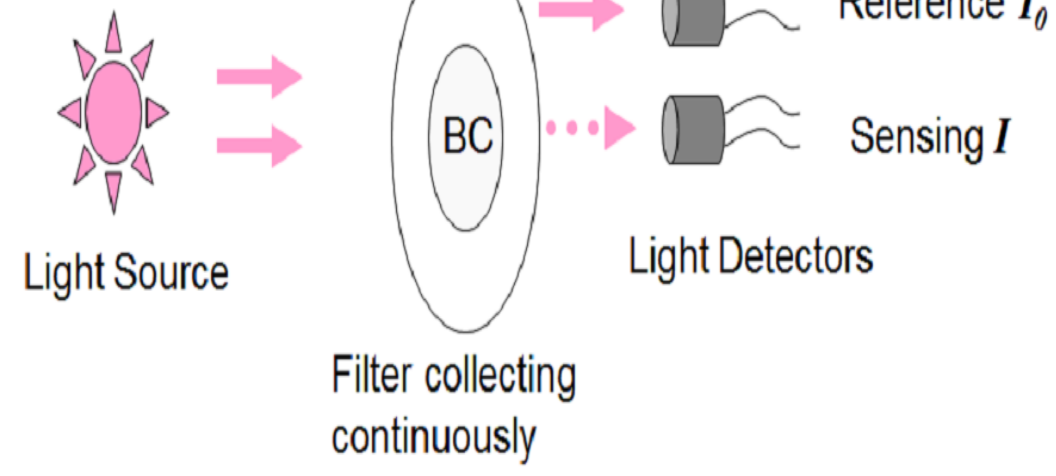

Figura 17 - Princípio de funcionamento do Aetalômetro modelo AE33, com dois feixes de referência de medidas para cálculos de correções para efeito de filter loading.

Nos experimentos que integram este trabalho, foram utilizados diversos modelos de Aetalômetros da Magee Scientific que mediram a dependência espectral do coeficiente de absorção em 7 comprimentos de onda. No ATTO foi utilizado um AE30 $(\lambda=370,470,520,590,660,880,950 \mathrm{~nm})$, na ZF2 foi utilizado o modelo AE33 com os mesmo comprimentos de onda do AE30 e, finalmente, no T3 foi utilizado o modelo $\operatorname{AE} 31(\lambda=370,430,470,565,700,880 \mathrm{~nm})$.

\subsubsection{A medida do espalhamento espectral com Nefelômetros}

O nefelômetro mede o coeficiente de espalhamento de luz devido à presença de partículas na atmosfera. Durante a operação deste instrumento, a amostra de ar é bombeada através do inlet para uma câmara volumétrica de análise, onde a amostra é iluminada sob uma faixa de $7^{\circ}$ a $170^{\circ}$ por uma lâmpada halogênica. $\mathrm{O}$ volume amostrado passa por uma série de obturadores ao longo do eixo principal do instrumento, sendo em seguida analisado por três tubos fotomultiplicadores (azul, verde e vermelho). O espalhamento de partículas é observado em um anteparo com alta eficiência de absorção de luz para minimizar a possibilidade de espalhamento pelas paredes internas do instrumento (Rizzo 2006). Periodicamente, uma válvula situada no inlet é acionada para drenar toda a amostra de aerossóis do interior do instrumento para que se possa medir o sinal de ar limpo do ambiente. Este sinal é subtraído do sinal original para que o espalhamento medido seja exclusivamente devido à presença de partículas de aerossol.

No desenvolvimento deste trabalho, foram utilizados os modelos Aurora Ecotech-3000 $(\lambda=450,525$ e $635 \mathrm{~nm})$ e o TSI-3563 $(\lambda=450,550$ e $700 \mathrm{~nm})$ que 
mediram o espalhamento de luz com resolução temporal de 1 minuto. A Figura 18 mostra o funcionamento de um nefelômetro TSI-3563.

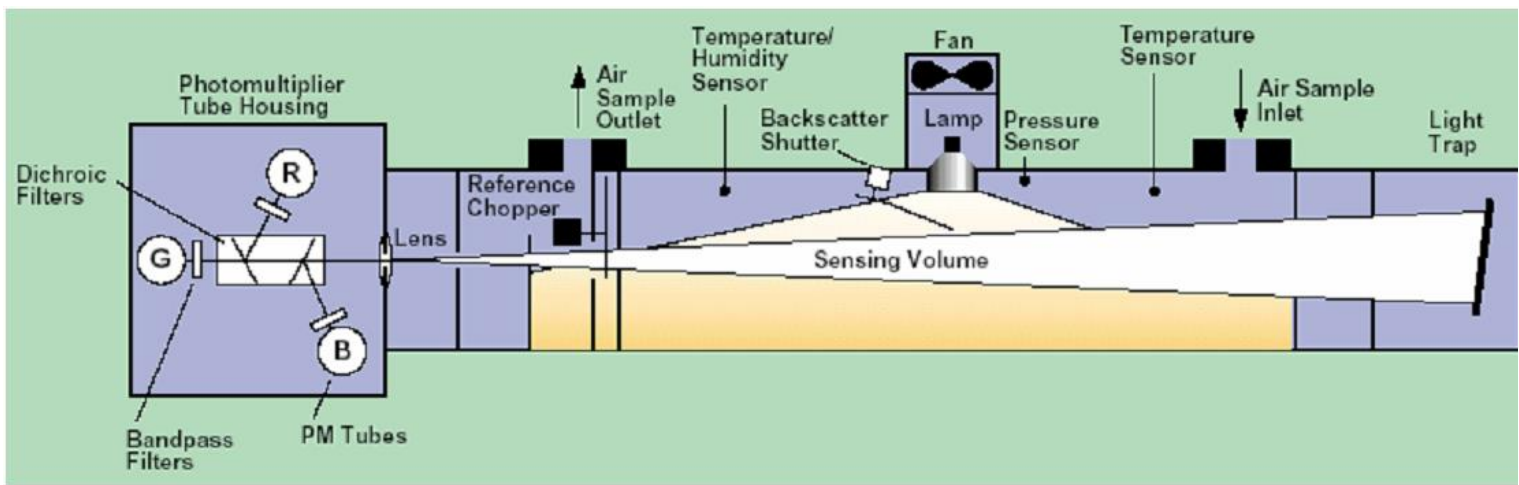

Figura 18 - Diagrama interno do nefelômetro TSI-3563. No canto direito da figura estão representados o inlet e o anteparo no qual é observado o espalhamento de luz devido à presença de partículas no interior da câmara volumétrica. No canto esquerdo estão representados os três tubos fotomultiplicadores (azul, verde, vermelho) (Rizzo 2006). 


\section{RESULTADOS E DISCUSSÃO}

Neste capítulo serão apresentados os principais resultados obtidos a partir de observações experimentais das propriedades óticas de aerossóis biogênicos, urbanos e de queimadas na Amazônia. A seção 5.1 apresenta uma caracterização das propriedades óticas integradas na coluna atmosférica em uma região fortemente impactada pela queima de biomassa, ao longo de 15 anos de medidas. Na seção 5.2 são mostrados os efeitos da poluição urbana de Manaus sobre a floresta tropical a partir de medidas conjuntas com fotômetros solares e instrumentos in-situ durante o experimento GoAmazon2014/5. Por fim, a seção 5.3 mostra o impacto dos aerossóis biogênicos naturais para a absorção da radiação solar em uma região de floresta preservada.

\subsection{MEDIDAS DAS PROPRIEDADES ÓTICAS DE AEROSSÓIS NA AMAZÔNIA ATRAVÉS DA REDE DE FOTÔMETROS SOLARES DA AERONET}

Muitos estudos têm se preocupado em entender como os eventos anuais de queima de biomassa interferem nas propriedades óticas dos aerossóis atmosféricos na região Amazônica e, consequentemente, no balanço radiativo terrestre. Para isto, medidas de propriedades óticas de aerossóis por sensoriamento remoto têm sido realizadas em várias localidades da Amazônia ao longo de 15 anos contínuos de medidas.

A profundidade ótica do aerossol está relacionada com a quantidade de partículas opticamente ativas na coluna atmosférica, sendo uma grandeza importante para o cálculo da forçante radiativa. A Figura 19 ilustra a série temporal da profundidade ótica obtida pelos fotômetros solares da AERONET em algumas localidades da bacia Amazônica. As principais regiões de interesse deste trabalho são: Alta Floresta, Manaus-EMBRAPA e Manacapuru, sendo que as duas últimas foram operadas dentro do escopo do experimento GoAmazon2014/5, cujos resultados serão discutidos na próxima seção. 


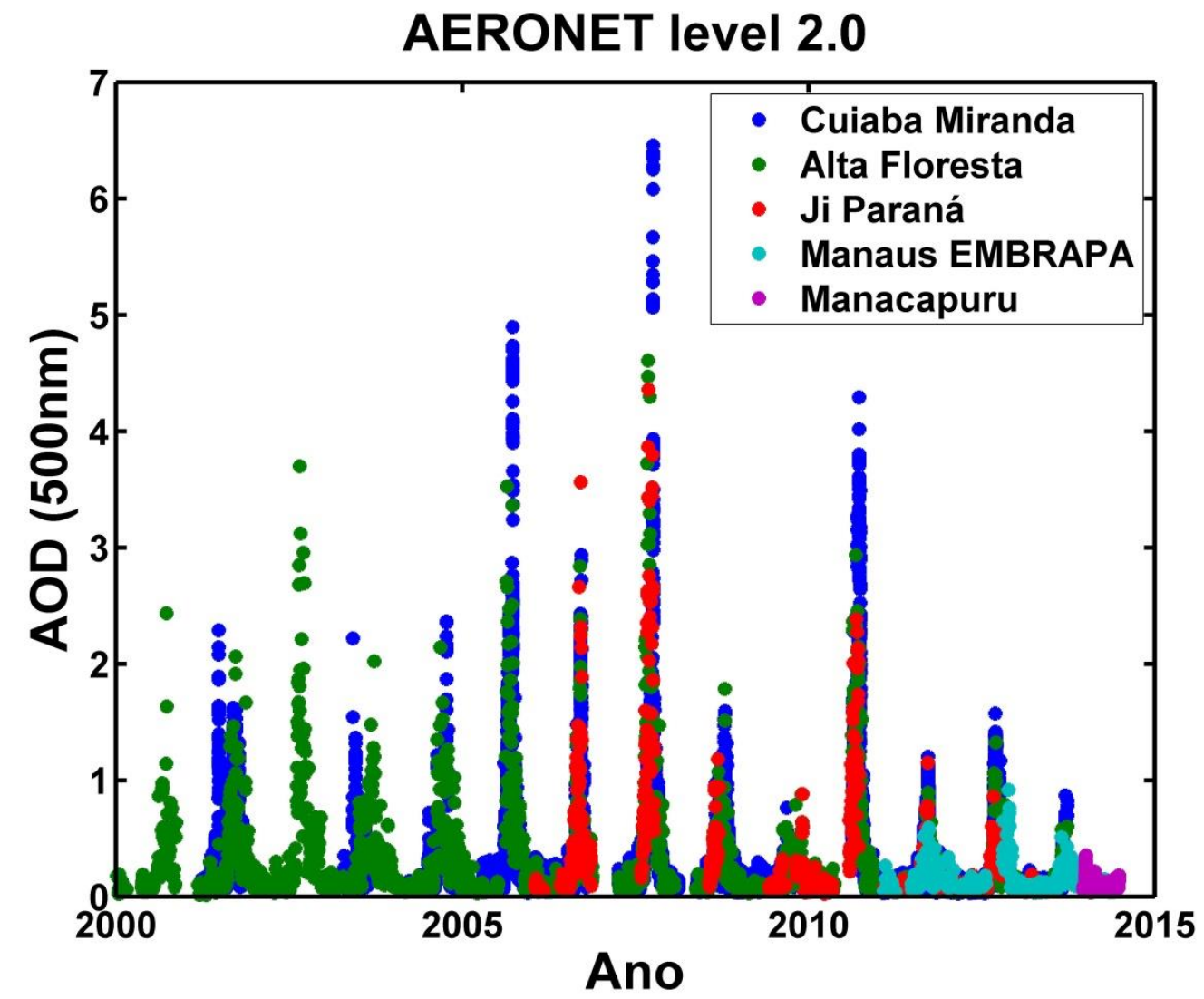

Figura 19 - Medidas da profundidade ótica em 500 nm para diferentes regiões da Amazônia desde 2000, utilizando os fotômetros solares da AERONET

Existe uma forte sazonalidade nas medidas de profundidade ótica para todos os sítios observados. Isso se deve às emissões de queimadas, que atingem seus valores máximos entre os meses de agosto e outubro. $\mathrm{O}$ restante do ano é caracterizado por baixos valores de AOD, tipicamente abaixo de 0,2 na faixa do visível. Também como indicado pela AOD, a intensidade das queimadas varia significativamente ao longo dos anos e também de uma região para outra. Uma das maiores cargas de aerossóis foi observada em Alta Floresta, que está localizada no arco do desflorestamento, região caracterizada por forte influência de queimadas e intensas atividades de mudanças de uso do solo. Os sítios menos impactados pela queima de biomassa foram a Embrapa e Manacapuru, localizados na Amazônia central. Além disso, os valores mais altos de AOD ocorreram nos anos de 2005, 2007 e 2010, quando também foram detectados os maiores números de focos de incêndios no Brasil (Figura 20), e foram os anos com secas mais severas na região Amazônica (Marengo et al. 2008; Ten Hoeve et al. 2012). 


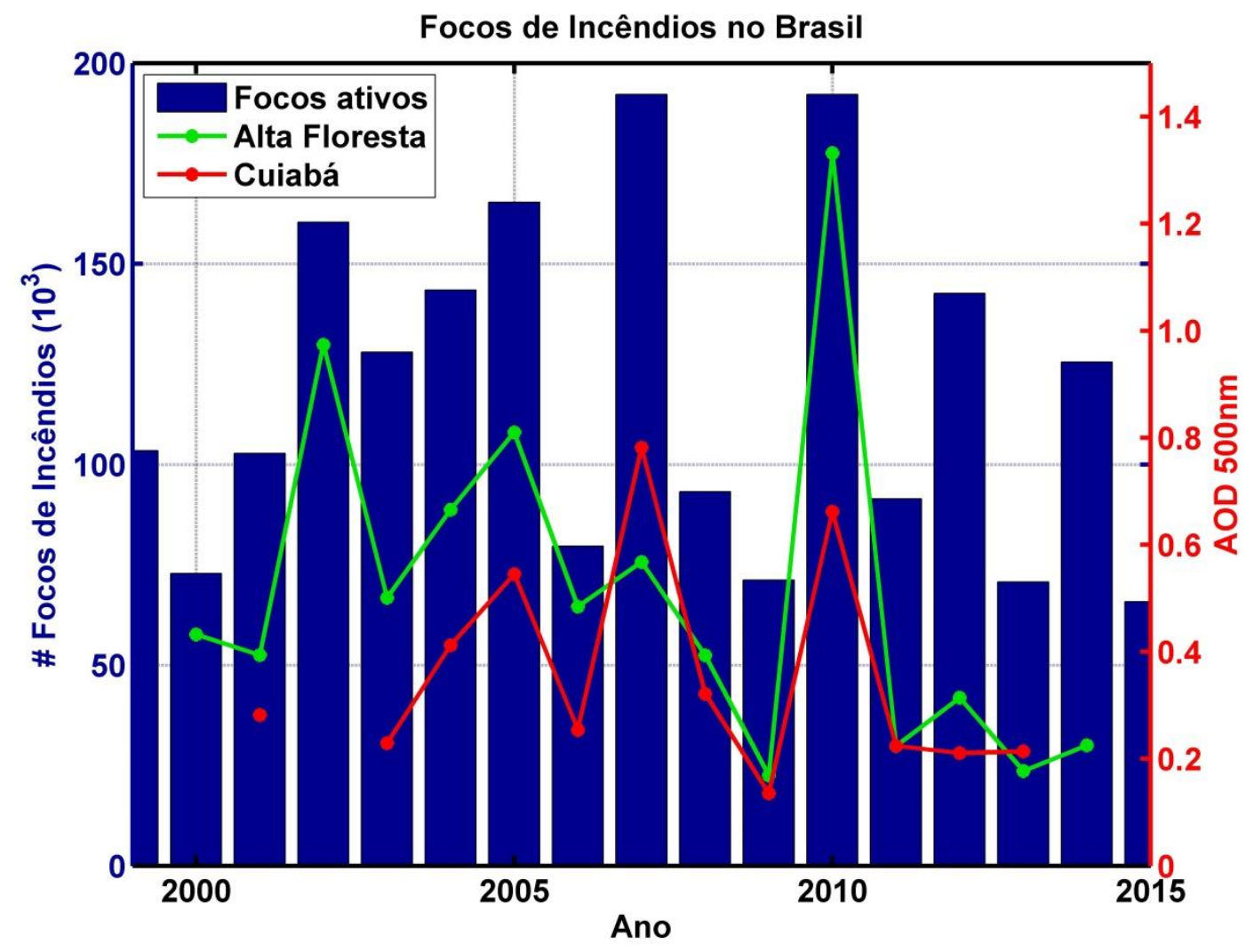

Figura 20 - Número de focos de incêndio detectados por imagens de satélite (INPE,2015). Os pontos verdes e vermelhos representam as médias da profundidade ótica de aerossóis em $500 \mathrm{~nm}$ calculadas durante a estação seca em Alta Floresta e Cuiabá, respectivamente, utilizando os fotômetros solares da AERONET.

Um dos produtos de inversão da AERONET fornece a profundidade ótica de absorção (AAOD) e de espalhamento (SAOD). A Figura 21 mostra a variabilidade interanual típica destas duas grandezas medidas no sítio de Alta Floresta, ilustrando o efeito da população de aerossóis na extinção da radiação ao longo do ano. Foram calculadas médias para cada dia do ano de todos os dados disponíveis de 2000 a 2014, período em que o instrumento funcionou ininterruptamente. É possível observar que o espalhamento é o efeito dominante na extinção da radiação nesta região. Durante a estação chuvosa (fevereiro-junho), a profundidade ótica de espalhamento média é de $0,04 \pm 0,01$, enquanto que a profundidade ótica de absorção média equivale a 0,007 \pm 0,006. Além disso, é observado um aumento em, aproximadamente, uma ordem de grandeza tanto da AOD de absorção quanto de espalhamento durante a estação de queimadas (agosto-outubro) devido à presença de aerossóis de queimadas. Estas partículas apresentam propriedades óticas bastante distintas dos aerossóis naturais emitidos pela floresta e devido às grandes concentrações, alteram significantemente a quantidade de radiação solar que é absorvida e espalhada na atmosfera. 


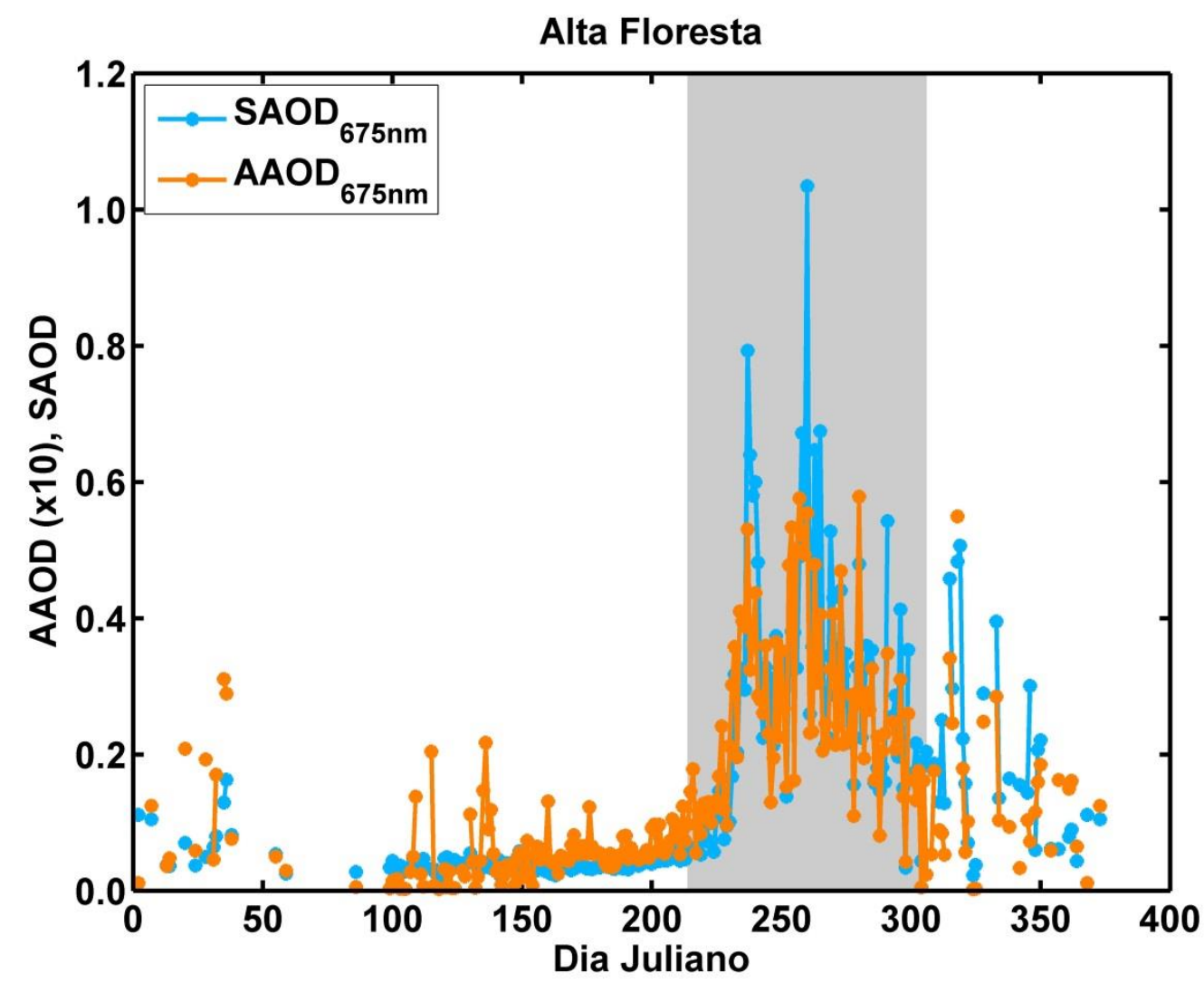

Figura 21 - Variação interanual típica da profundidade óptica de absorção e de espalhamento em Alta Floresta, representando a média diária de todos os dados obtidos ao longo de 15 anos de medidas (20002014). A banda sombreada representa a estação seca (agosto-outubro).

O forte aumento da concentração de aerossóis é acompanhado por uma alteração significativa na distribuição de tamanho das partículas, uma vez que a maioria das partículas emitidas durante eventos de queimadas pertence à moda fina (Schafer et al. 2008; Eck et al. 2010). A variação interanual típica da distribuição volumétrica de tamanho das partículas de aerossol bem como a fração da moda fina da $\mathrm{AOD}_{675 \mathrm{~nm}}$ estão apresentadas na Figura 22. A distribuição de tamanho é baseada em uma distribuição bimodal e apresenta um aumento considerável de partículas na moda fina (submicrométrica) na estação seca, com raio volumétrico médio de 0,15 $\mu \mathrm{m}$, em função da queima de biomassa. O particulado grosso corresponde, em grande parte, ao aerossol biogênico com raio volumétrico compatível com o medido por Schneider et al. (2011) ao nível do solo 1,6-5 $\mu \mathrm{m}$. 

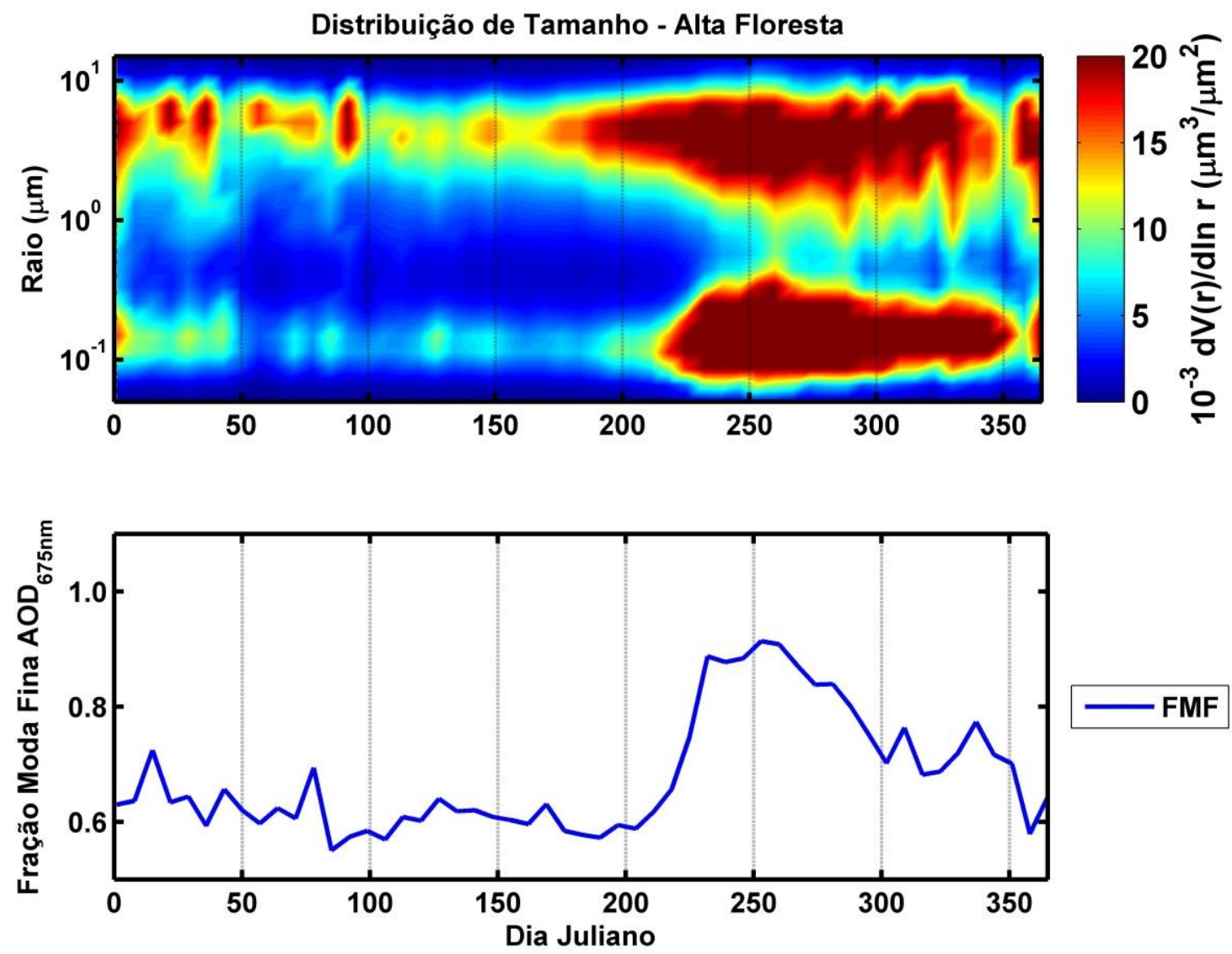

Figura 22 - (a) Distribuição volumétrica de tamanho para o sítio de Alta Floresta, representando a média semanal de todos os dados obtidos ao longo de 15 anos (2000-2014); (b) Fração da moda fina da $\mathrm{AOD}_{675 \mathrm{~nm}}(\mathrm{FMF})$ obtida pelo produto de inversão.

A fração de moda fina (FMF) da AOD representa a contribuição relativa desta moda para a profundidade ótica total do aerossol. Este parâmetro pode ser usado como um indicador geral da presença de aerossol antrópico, o qual é predominantemente encontrado na moda fina (Eck et al. 2010). A moda fina do aerossol natural na Amazônia é dominada por aerossóis secundários provenientes da oxidação de VOCs, e aparecem em baixas concentrações (Artaxo et al. 2013). Logo, no caso dos aerossóis da Amazônia, os valores mais elevados da FMF estão associados com as atividades de queima de biomassa. Em Alta Floresta, a contribuição da moda fina para a AOD (tal como indicado pela FMF) é dominante e representa aproximadamente $81 \%$ da AOD total na estação seca e $60 \%$ na estação chuvosa. Essencialmente, a extinção devido à moda grossa é opticamente minoritária para os maiores valores de AOD quando a fração fina dos aerossóis de queimadas domina completamente.

A Figura 23 mostra o espectro médio da profundidade ótica de absorção para diferentes intervalos da FMF em Alta Floresta. É interessante notar que a profundidade ótica de absorção aumenta significativamente com o aumento da fração da moda fina, 
ou seja, quando os aerossóis de queimadas são dominantes. O aumento da AOD de absorção é atribuído à presença de partículas absorvedoras nas emissões de queimadas e é consistente com os resultados obtidos por Rizzo et al. (2013) a partir de medidas insitu na ZF2. Rizzo et al. (2013) observou aumento do coeficiente de absorção em $637 \mathrm{~nm}$ de $0,5 \mathrm{Mm}^{-1}$ para $2,8 \mathrm{Mm}^{-1}$ da estação chuvosa para a estação seca, quando há a influência de aerossóis de queimadas.

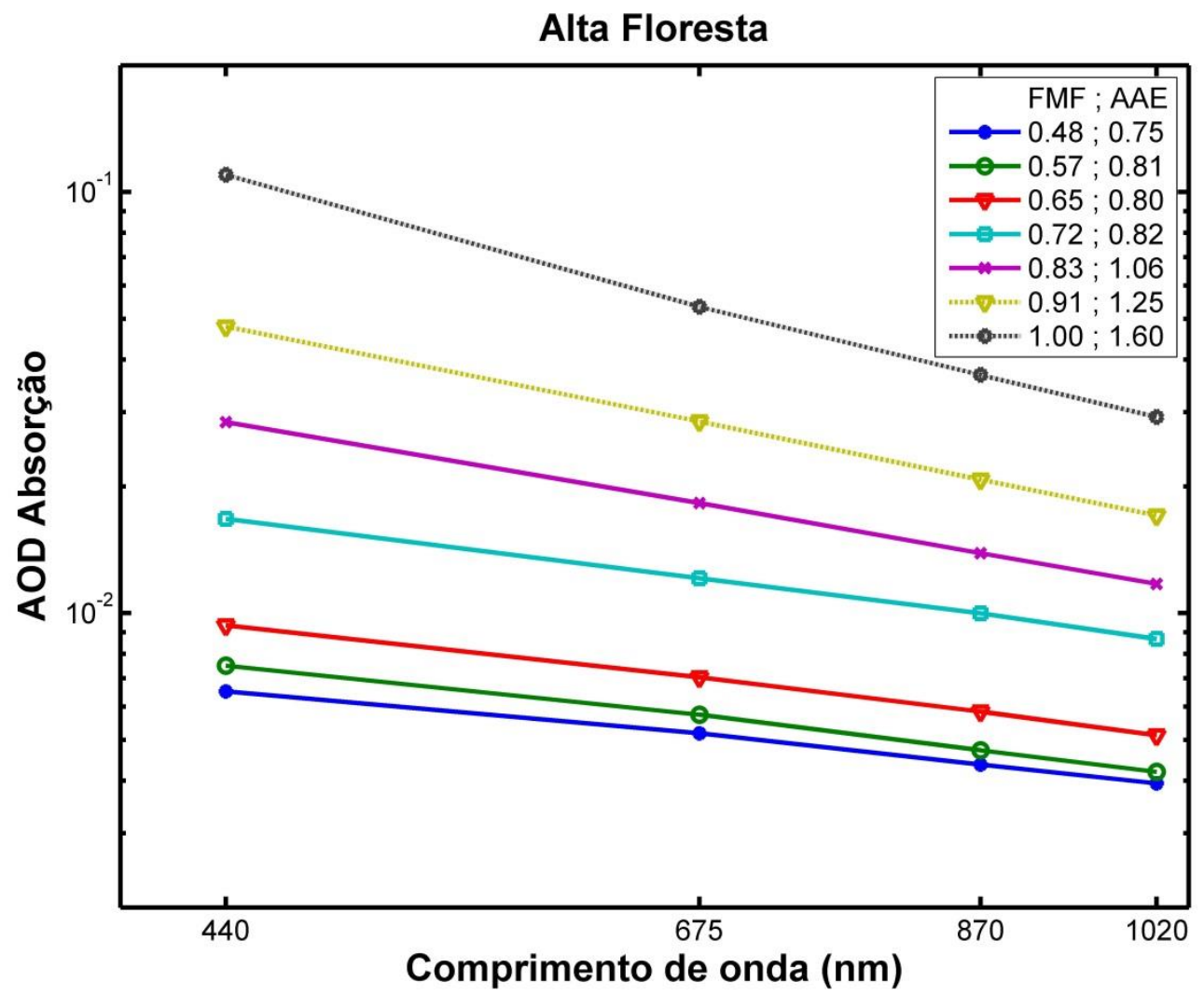

Figura 23 - Profundidade ótica de absorção espectral média em função do comprimento de onda em escala logarítmica para os intervalos da fração de moda fina da $\mathrm{AOD}_{675 \mathrm{~nm}}$ em Alta Floresta ao longo de 15 anos de medidas. Também está indicado o coeficiente Ångström de absorção (AAE) médio para cada intervalo de FMF.

O coeficiente Ångström de absorção (AAE) é normalmente utilizado para caracterizar a dependência espectral da AOD de absorção em uma determinada região. Em Alta Floresta, o AAE varia de 0,75 para as observações dominadas pelos aerossóis biogênicos na moda grossa $($ FMF < 0,48) e aumenta progressivamente até uma média de 1,60 para os casos dominados pelo aerossol de queimadas na moda fina (FMF > 0,91). Também é possível observar que a dependência da AAOD em função do comprimento de onda pode ser ajustada por uma reta em coordenadas logarítmicas. 
Muitos estudos recentes têm mostrado relações entre espécies absorvedoras de radiação e a dependência espectral de absorção (Bahadur et al. 2012; Bond et al. 2013; Cazorla et al. 2013). Alguns foram baseados em medições de sensoriamento remoto em locais com um forte tipo dominante, como desertos, áreas urbanas poluídas, regiões com incêndios florestais, etc. Neste estudo, foi feita uma estimativa dos tipos de aerossóis, utilizando suas propriedades óticas espectrais para a estação Alta Floresta da AERONET, que é dominada por aerossóis de queima de biomassa na estação seca e aerossóis biogênicos na estação chuvosa. $\mathrm{O}$ método utilizado foi o mesmo descrito por Cazorla et al. (2013), no qual utilizou o AAE como um indicador da composição química do aerossol e dividiu a região de um gráfico AAE vs. SAE (também chamado de matriz Ångström) em diferentes regiões. Cada região deste tipo de figura está associada a um diferente tipo de aerossol.

A dependência espectral do AAE pode ser relacionada com o tipo de aerossol de absorção dominante em uma mistura de aerossóis. O BC tipicamente segue uma dependência espectral $\lambda^{-1}$, obtendo-se uma AAE de 1 (Bergstrom et al. 2002), enquanto o carbono orgânico em aerossóis de queima de biomassa e poeiras minerais contribuem para a absorção de radiação no ultravioleta e regiões espectrais do azul, resultando em um AAE maior de que 1 (geralmente na faixa de 1 a 3) (Kirchstetter 2004). Por outro lado, a dependência espectral do coeficiente de espalhamento, o SAE, depende principalmente do tamanho dominante em uma mistura de aerossóis, variando de 0 a 3 , onde os maiores números estão associados a partículas pequenas (moda fina) e os números menores indicam a predominância de partículas grandes (moda grossa) (Bergstrom et al. 2007).

A grande vantagem desta classificação é separar as espécies absorvedoras de aerossóis em EC, OC, biogênicos e poeira mineral. Primeiramente, medidas que representam partículas biogênicas e poeira mineral são separadas ao longo do eixo SAE, uma vez que elas são encontradas principalmente na moda grossa em comparação com os aerossóis carbonáceos, que são encontrados principalmente na moda fina e ultrafina perto da fonte de emissão. Em segundo lugar, o EC é um absorvedor eficiente em todos os comprimentos de onda comparado ao OC, que absorve fortemente apenas com comprimentos de onda curtos, separando estas espécies ao longo do eixo AAE. Esta partição é baseada na repartição simplificada publicada por Bahadur et al (2012).

A fim de compreender melhor os tipos dominantes de aerossóis em Alta Floresta para as estações seca e chuvosa, a matriz Ångström foi aplicada para todos os dados de 
nível 2.0 disponíveis, conforme ilustrado na Figura 24. De fato, durante a estação chuvosa o aerossol atmosférico foi classificado majoritariamente como partículas biogênicas. Durante a estação seca, foi observada a predominância de EC e OC provenientes da queima de biomassa que se somam ao aerossol biogênico natural. Estas partículas são introduzidas na atmosfera alterando significativamente suas propriedades físicas. O EC emitido nos eventos de queimadas é o responsável pelo aumento da profundidade ótica de absorção que foi observada na Figura 21, enquanto que o OC é o responsável pelo aumento do espalhamento expresso pelos maiores valores de SAE.

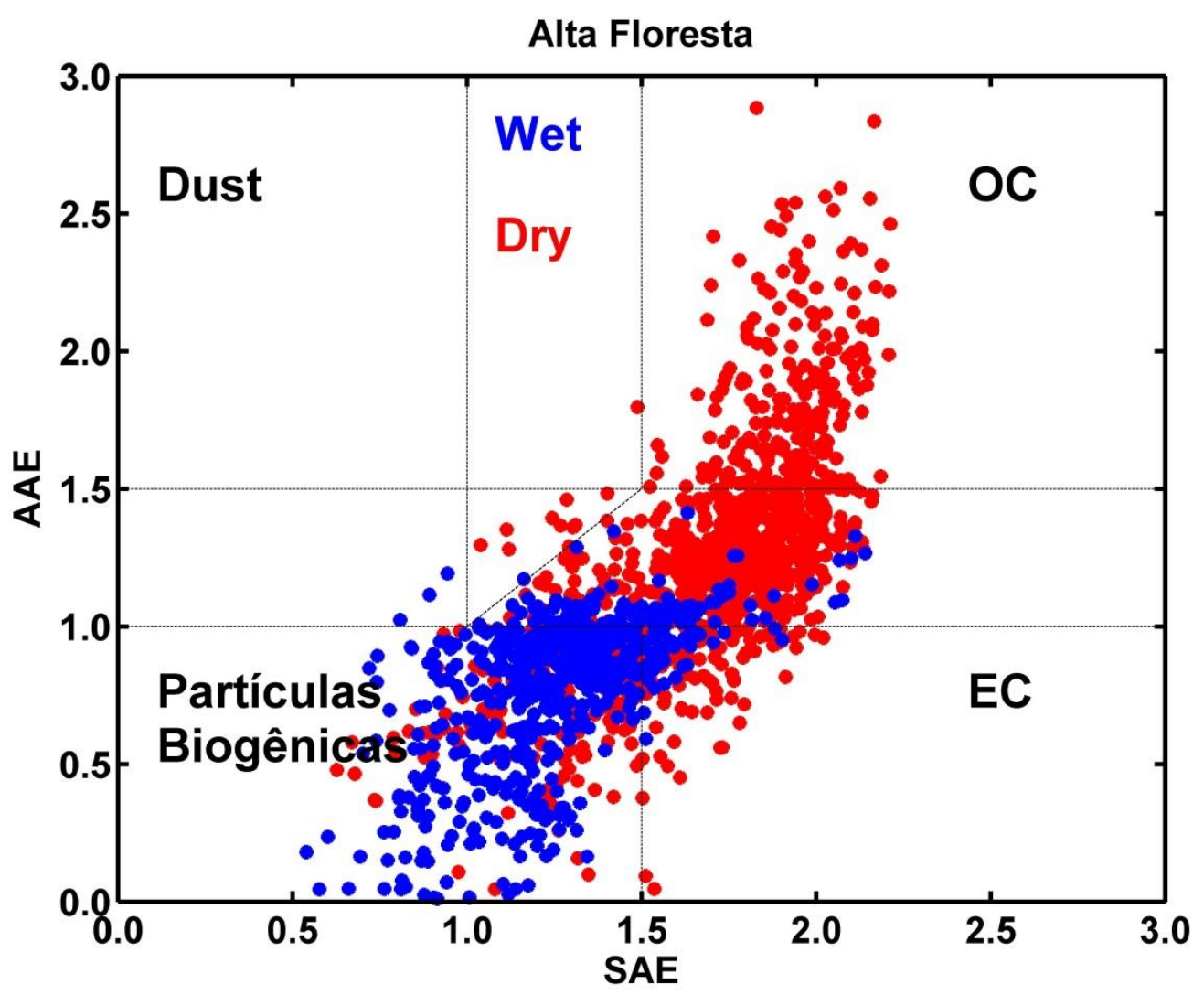

Figura 24 - Matriz Ångström com medidas de fotometria solar em Alta Floresta (dados com nível 2.0) para as estações seca e chuvosa.

Este resultado também deixa claro que o OC é a fração dominante na estação seca. Isso está de acordo com o que foi obtido por Mayol-Bracero (2002) na mesma região. A partir de análises de combustão térmica, o autor estimou que o carbono orgânico representa a fração dominante $(\sim 84 \%)$ do aerossol carbonáceo derivado da queima de biomassa (combustão lenta), e o EC representa cerca de $16 \%$ do carbono total. Medidas recentes de espectroscopia de massa mostram que o OC representa cerca de $82 \%$ do PM1 (Brito et al. 2014). 
Durante a estação chuvosa nenhuma medida do fotômetro foi classificada como puramente dust, ao contrário do que era esperado dado o conhecido transporte anual de poeira saariana no nordeste América do Sul durante esta época do ano. Isto pode ser devido às condições predominantes de céu nublado durante a estação chuvosa, limitado a disponibilidade de dias com condições adequadas para realização de medidas de qualidade no almucantar, resultando em um número relativamente baixo de medições bem-sucedidas $\mathrm{N}_{\text {wet }}=633$ (36\% do número total de medições $\mathrm{N}=1739$ ). Outro fator importante na identificação de soil dust é que as emissões do deserto do Saara atravessam o oceano Atlântico e cerca de $1500 \mathrm{~km}$ de floresta antes de ser observado na Amazônia. Isto acarreta misturas internas entre dust, aerossol biogênico e aerossol marinho, dificultando a identificação unívoca.

A significativa mudança na população de aerossóis que compõe a atmosfera Amazônica da estação úmida para a estação seca apresenta efeitos diretos no balanço radiativo. A Figura 25 mostra a matriz Ångström aplicada a todos os dados de Alta Floresta de 2000 a 2014 e as cores representam o valor da forçante radiativa instantânea no topo da atmosfera, que é um produto da AERONET. É interessante notar que as medidas classificadas como OC apresentam as forçantes radiativas mais negativas (-53 $\pm 17 \mathrm{~W} / \mathrm{m}^{2}$ ), mostrando que o OC é altamente espalhador e, quando presente na atmosfera, tem um efeito de resfriamento no topo da atmosfera. Por outro lado, o EC é altamente absorvedor e influencia a forçante radiativa positivamente $\left(-12 \pm 9 \mathrm{~W} / \mathrm{m}^{2}\right)$, atuando como uma espécie de gás de efeito estufa. Durante a estação chuvosa, a forçante radiativa instantânea no topo da atmosfera média é de $-3,9 \pm 2,6 \mathrm{~W} / \mathrm{m}^{2}$, enquanto que na estação seca este efeito é de resfriamento $\left(-27 \pm 21 \mathrm{~W} / \mathrm{m}^{2}\right)$. 


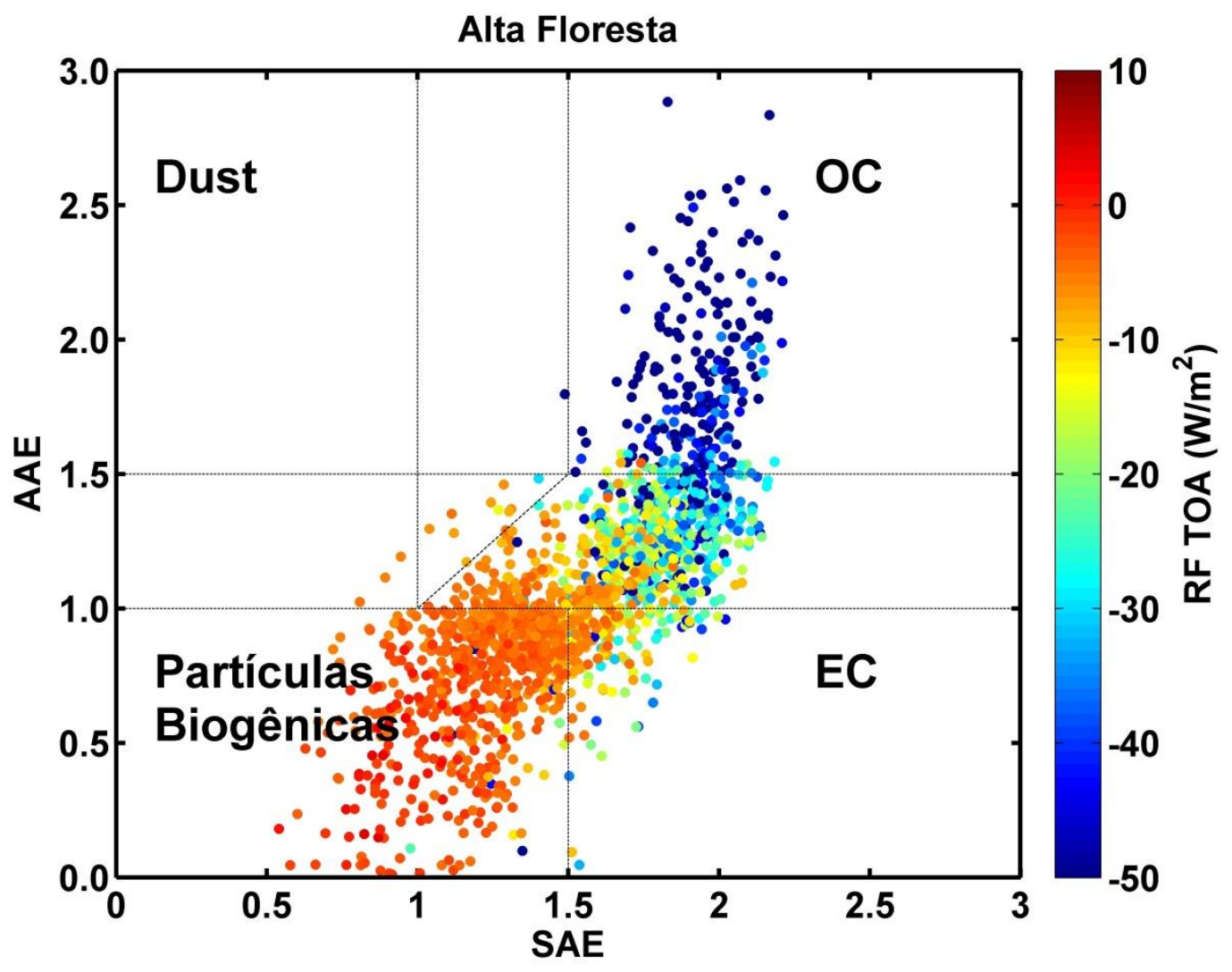

Figura 25 - Matriz Ångström com todas as medidas de Alta Floresta tomadas ao longo de 15 anos. As cores representam a forçante radiativa no topo da atmosfera.

Portanto, com base apenas nas propriedades óticas dos aerossóis, foi possível fazer uma análise qualitativa dos tipos de aerossóis dominantes durante a queima de biomassa na Amazônia, avaliando seus impactos no balanço radiativo regional. Foi observado que o espalhamento de luz é predominante nas partículas de queimadas devido a maior presença do carbono orgânico (OC). O carbono elementar (EC) também é emitido na queima de biomassa em grandes quantidades e absorve eficientemente a radiação solar em todo o espectro. Apesar de não ser a fração dominante na concentração total de aerossóis de queimadas, esta componente absorvedora apresenta um impacto significativo na forçante radiativa no topo da atmosfera, tornando essencial o seu estudo e monitoramento nesta região.

O código de transferência radiativa SBDART foi utilizado para expandir a forçante radiativa instantânea da AERONET em médias diárias. Os modelos de superfície utilizados neste código foram desenvolvidos baseados no albedo de superfície obtidas pelo sensor MODIS sobre a área estudada. Os modelos de aerossóis foram desenvolvidos a partir de medidas de propriedades ópticas de aerossóis obtidas pelos radiômetros solares da rede AERONET. A partir disto, a forçante radiativa direta média 
de 24h obtida para Alta Floresta durante a estação seca no período de 2000 a 2014 foi de $-11,5 \pm 0,3 \mathrm{~W} / \mathrm{m}^{2}$. Para fins de comparação, as médias das forçantes radiativas diretas de aerossóis para as estações de queimadas de 2000 a 2009 calculadas a partir de outras metodologias são reportadas na Tabela 3.

Tabela 3-Resultados de forçante radiativa direta de aerossóis de queimadas no TOA obtidos neste trabalho e em outras referências.

\begin{tabular}{cccc}
\hline Referência & Região & Período & SWARF-24h (W/m²) \\
\hline Este trabalho & Alta Floresta, MT & $2000-2014$ & $-11,5 \pm 0,3$ \\
Sena et al., 2013 & Amazônia & $2000-2009$ & $-8,2 \pm 2,1$ \\
Sena et al., 2015 & Amazônia & $2000-2009$ & $-5,2 \pm 2,6$ \\
Patadia et al., 2008 & Amazônia & $2000-2005$ & $-7,6 \pm 1,9$ \\
Procopio et al., 2004 & Amazônia & 2002 & $-5,6 \pm 0,6$ \\
Procopio et al., 2004 & Alta Floresta, MT & $1993-2002$ & $-8,3 \pm 2,0$ \\
Procopio et al., 2004 & Ji Paraná, RO & $1994-2002$ & $-8,4 \pm 2,2$ \\
\hline
\end{tabular}

Observa-se uma diferença significativa entre o valor da SWARF-24h obtida no presente trabalho e os valores obtidos em estudos anteriores. Esta diferença deve-se principalmente ao fato da AERONET reportar medidas apenas nas quais a AOD > 0,4, causando um viés nas medidas para condições poluídas.

Além das queimadas, outra importante fonte de compostos absorvedores de luz na região Amazônica é a poluição urbana da cidade de Manaus, que se soma às emissões naturais da floresta Amazônica e das queimadas regionais. O estudo detalhado dos efeitos da pluma urbana de Manaus sobre as propriedades óticas do aerossol e sobre o balanço radiativo é um dos objetivos do experimento GoAmazon2014/5, cujos resultados serão apresentados e discutidos a seguir. 


\subsection{INFLUÊNCIA DA PLUMA DE MANAUS SOBRE AS PROPRIEDADES ÓTICAS DO AEROSSOL NO CONTEXTO DO EXPERIMENTO GOAMAZON2014/5}

\subsubsection{Medidas por sensoriamento remoto durante o experimento GoAmazon2014/5}

Dentro do escopo do projeto GoAmazon2014/5, foi instalado um fotômetro CIMEL vento abaixo da cidade de Manaus, no sítio de amostragem chamado T3, próximo da cidade de Manacapuru. Com isto foi possível fazer uma comparação com outro fotômetro idêntico instalado no sítio da Embrapa (T0e), localizado vento acima da cidade de Manaus, em uma região com pouco impacto antrópico durante a estação chuvosa. A Figura 26 ilustra a série temporal da $\mathrm{AOD}_{675 \mathrm{~nm}}$ (profundidade ótica de aerossóis no comprimento de onda de $675 \mathrm{~nm}$ ) para as estações ARM-Manacapuru e Manaus-Embrapa da rede AERONET. É importante notar que os valores plotados para a estação chuvosa são mais escassos por causa da maior cobertura de nuvem que limita as medições remotas de aerossóis.

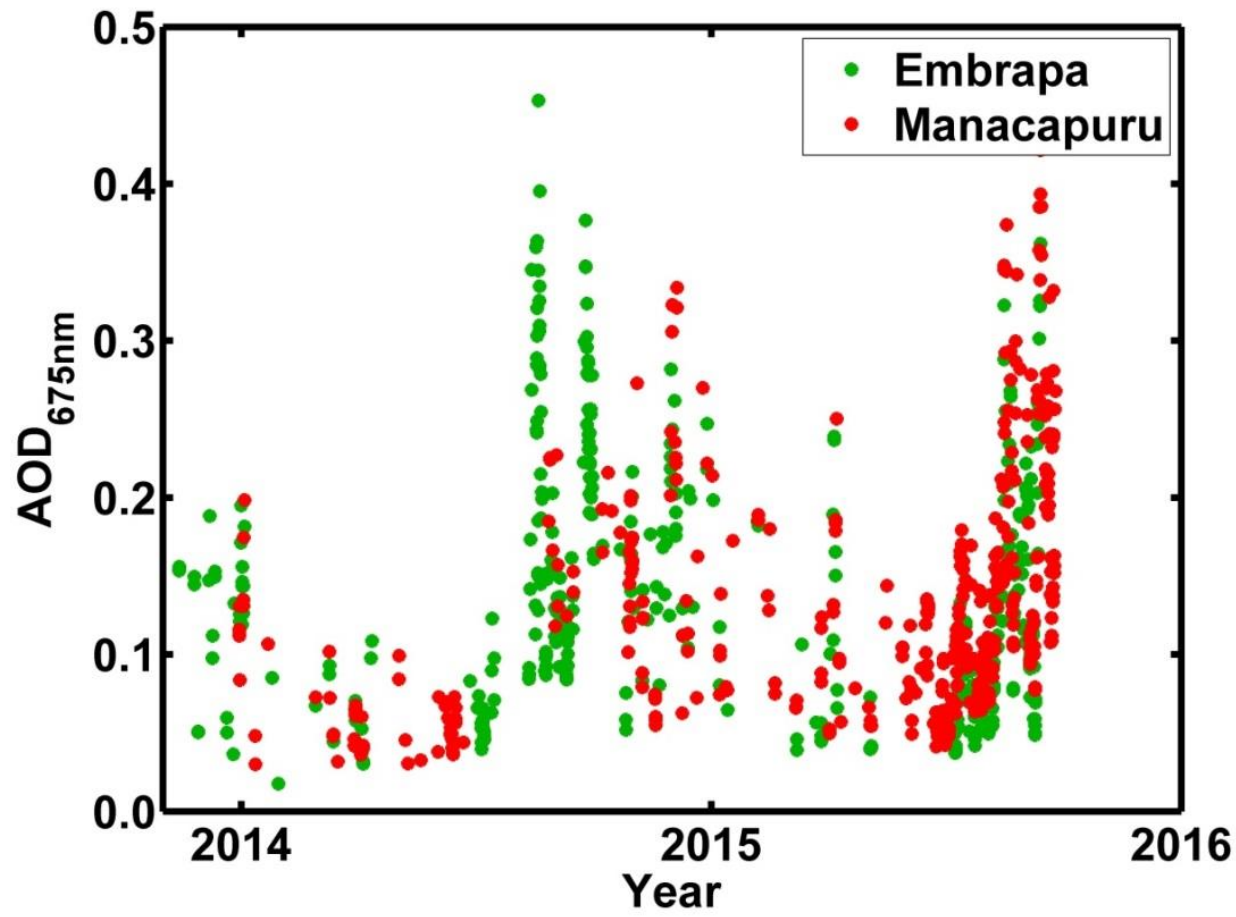

Figura 26 - Serie temporal da profundidade ótica das estações Manaus-Embrapa e ARM-Manacapuru da AERONET, localizadas vento acima e vento abaixo da cidade de Manaus, respectivamente. Os pontos representam médias horárias de todos os dados nível 1.5 disponíveis durante o experimento GoAmazon2014/5, no período de janeiro de 2014 a setembro de 2015. 
Dois aspectos são importantes na Figura 26: i) A sazonalidade bem definida da AOD nesta região, aumentando significativamente durante a estação seca e ii) a similaridade entre os valores de AOD vento acima (Embrapa) ou vento abaixo (Manacapuru) da cidade de Manaus. Como observado na seção anterior, a sazonalidade bem definida dos valores de AOD nesta região está diretamente relacionada com a queima de biomassa que ocorre anualmente na bacia Amazônica. Durante a estação úmida (fevereiro-junho), os altos índices de precipitação fazem com que a região apresente baixas concentrações de aerossóis, resultando em valores muito baixos $(0,10$ 0,15) para a profundidade ótica. A AOD média obtida em ARM-Manacapuru durante a estação chuvosa foi de $0,11 \pm 0,04$, valor estatisticamente indistinguível das medidas no site da Embrapa, onde a AOD média é de 0,10 \pm 0,05 (Figura 27). Com o início da estação seca (agosto-outubro) e redução do volume de chuvas, a AOD aumenta consideravelmente com médias de 0,24 \pm 0,12 em Manacapuru e de 0,24 $\pm 0,15$ na Embrapa. Novamente, também na estação seca, a AOD em ambos os sites é similar.

A similaridade entre os valores de AOD na Embrapa e Manacapuru mostram que, apesar das emissões urbanas significativas de Manaus, esta grandeza é representativa do transporte de larga escala, que impacta os dois sítios igualmente. Portanto, um estudo detalhado destes dois sítios experimentais se faz ideal para estudar o efeito da poluição urbana de Manaus em meio às emissões naturais da floresta Amazônica e das emissões regionais de queimadas. 


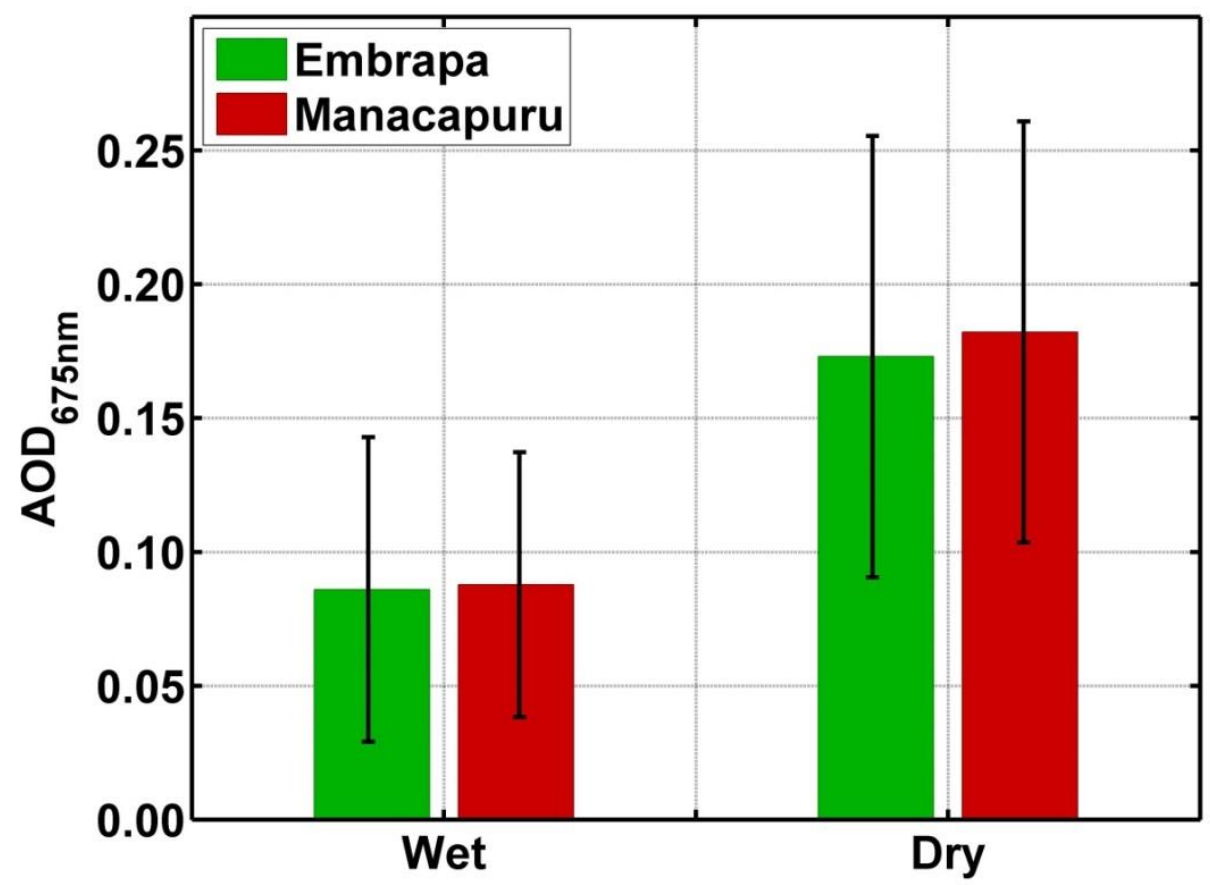

Figura 27 - Profundidade ótica média $\left(\mathrm{AOD}_{675 \mathrm{~nm}}\right)$ para as estações chuvosa e seca medidas com os fotômetros solares da AERONET nos sites Embrapa e Manacapuru durante o experimento GoAmazon2014/5 (medidas de janeiro de 2014 a setembro de 2015). Também está indicada a variabilidade da distribuição das medidas.
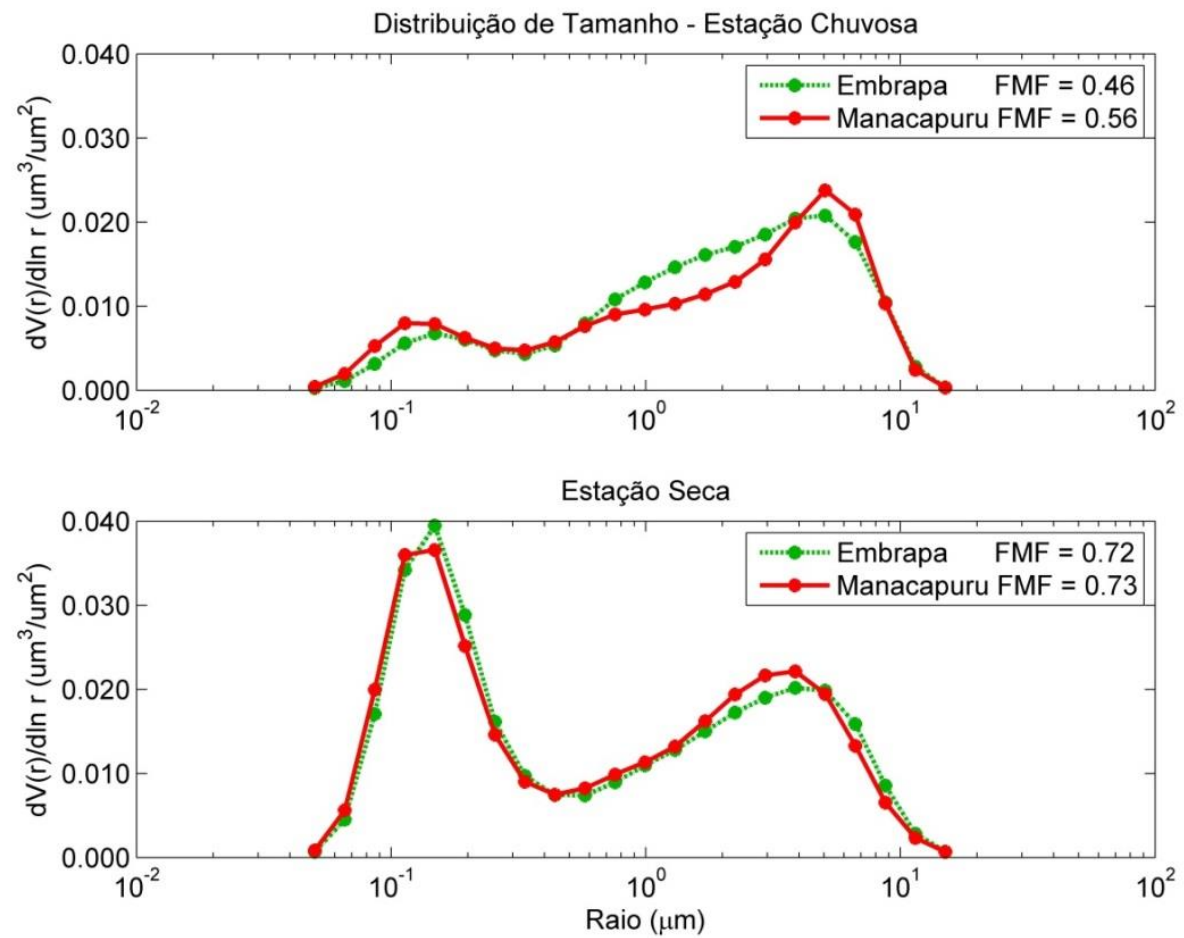

Figura 28 - Média das distribuições de tamanho volumétricas derivadas de observações durante a estação chuvosa (Fevereiro-Junho) e os meses de queimadas (Agosto-Outubro) nos sítios da Embrapa e Manacapuru. Também indicada está a fração da moda fina (FMF) para cada estação do ano e cada local. 
Observa-se também uma similaridade na distribuição de tamanho dos aerossóis entre os sítios experimentais da Embrapa e Manacapuru, derivada pela AERONET ao longo dos anos de 2014 e 2015. A Figura 28 mostra as distribuições volumétricas de tamanho típicas da estação chuvosa e da estação seca para os dois sítios de estudo.

Em Manacapuru, a contribuição da moda fina para a AOD (tal como indicado pela FMF) é dominante e representa aproximadamente $73 \%$ da AOD total na estação seca, valor semelhante ao observado na Embrapa nesta estação do ano (72\%). Na estação chuvosa, a moda fina representa 59 \% da AOD total em Manacapuru, superior aos $47 \%$ observados na Embrapa. Portanto observamos o impacto da pluma de Manaus no incremento da fração fina do aerossol em Manacapuru na estação chuvosa. Na estação seca, a dominância do aerossol de queimadas é tão forte que não permite distinguir o impacto das emissões da cidade de Manaus na distribuição de tamanho. A similaridade da distribuição de tamanho na estação seca entre sítios distantes apenas 100 km é notável. Isso demonstra a robustez dos produtos de inversão da AERONET e a qualidade da metodologia empregada neste estudo.

A Figura 29 mostra os valores de AAOD $_{675 n m}$ obtidos para os dois sítios experimentais. Ao contrário do que foi observado para a profundidade ótica de extinção (Figura 27), existe uma notável diferença na componente de absorção (AAOD $675 \mathrm{~nm}$ ) antes e depois da pluma, evidenciando a presença de aerossóis mais absorvedores em Manacapuru do que na Embrapa. 


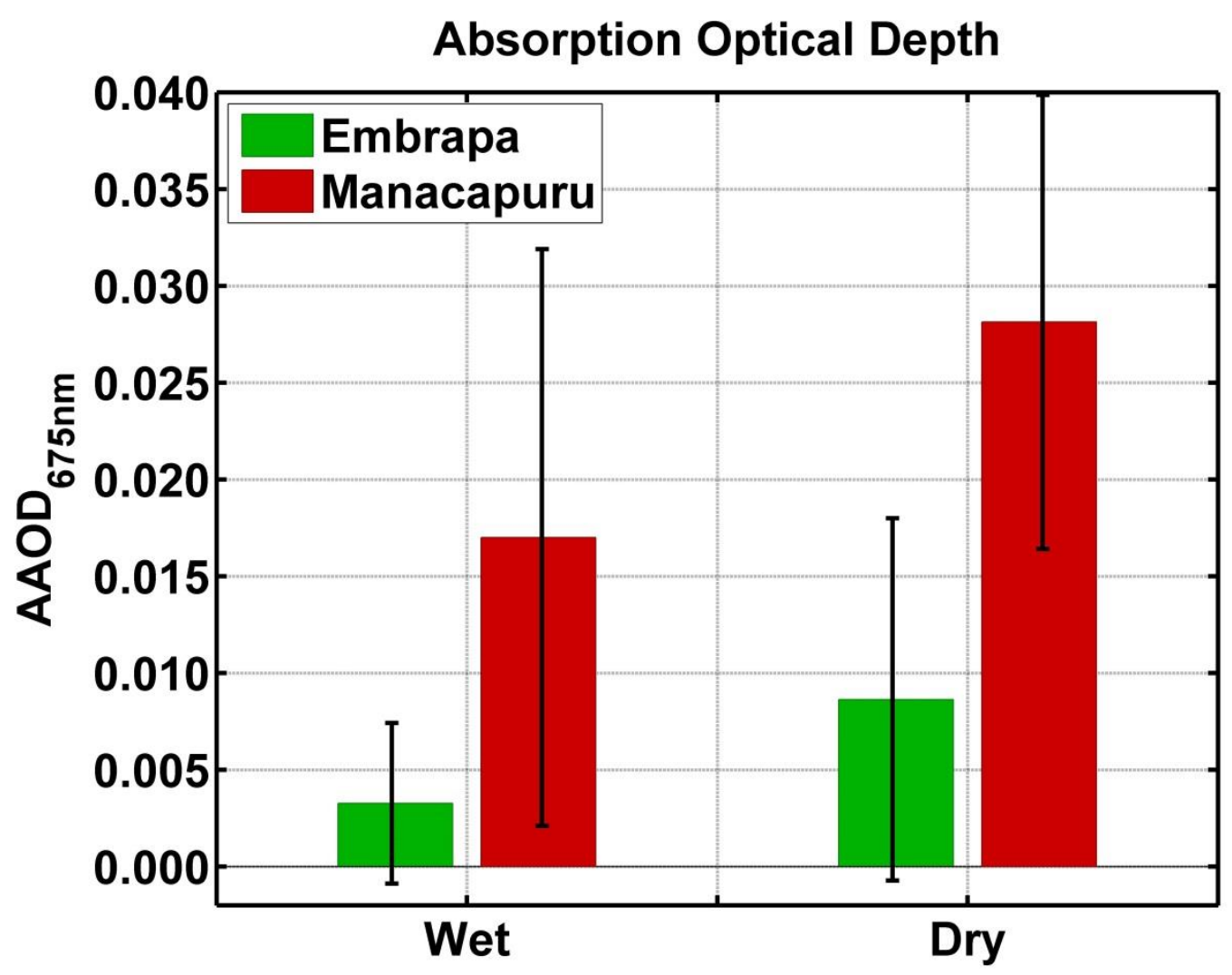

Figura 29 - Profundidade ótica de absorção média $(675 \mathrm{~nm})$ para as estações chuvosa e seca medidas com os fotômetros solares da AERONET nos sites Embrapa e Manacapuru durante o experimento GoAmazon2014/5. As barras de erro representam o desvio padrão.

A profundidade ótica de absorção média em ARM-Manacapuru durante a estação chuvosa é de $0,018 \pm 0,012$, seis vezes superior à da Embrapa, onde a AAOD média é de 0,003 $\pm 0,004$. Durante a estação seca, a AAOD aumenta em ambos os sítios, atingindo valores de 0,027 \pm 0,012 em Manacapuru e de 0,007 $\pm 0,009$ na Embrapa. Portanto mesmo na estação seca, a componente de absorção mostra claramente o impacto da poluição urbana de Manaus nas propriedades óticas dos aerossóis devido às emissões de $\mathrm{BC}$ da cidade de Manaus.

O aumento no valor da componente de absorção da profundidade ótica da estação chuvosa para a estação seca nos dois sítios é atribuído ao BC emitido na queima de biomassa. Entretanto, a maior componente de absorção observada em Manacapuru em relação à Embrapa é atribuída à presença de poluição urbana de Manaus e outras fontes locais. Isto mostra que parte do aerossol fino observado em Manacapuru provém da queima de combustíveis fósseis e outros tipos de combustão incompleta que libera grandes quantidades de $\mathrm{BC}$ para a atmosfera. 
A fim de avaliar o impacto que a poluição urbana tem sobre o clima da floresta tropical, as forçantes radiativas no topo da atmosfera na Embrapa e Manacapuru foram derivadas para as estações seca e chuvosa com as medidas dos fotômetros solares da rede AERONET. A Figura 30 apresenta a forçante radiativa no topo da atmosfera derivada pela AERONET para os dois sítios experimentais e para as estações seca e chuvosa. Apesar da AOD ser similar para os dois sítios, observa-se que a forçante radiativa é nitidamente diferente entre eles. Mesmo para a estação seca, onde a distribuição de tamanho é similar, observamos diferenças na forçante radiativa. A razão desta diferença é a quantidade de black carbon.

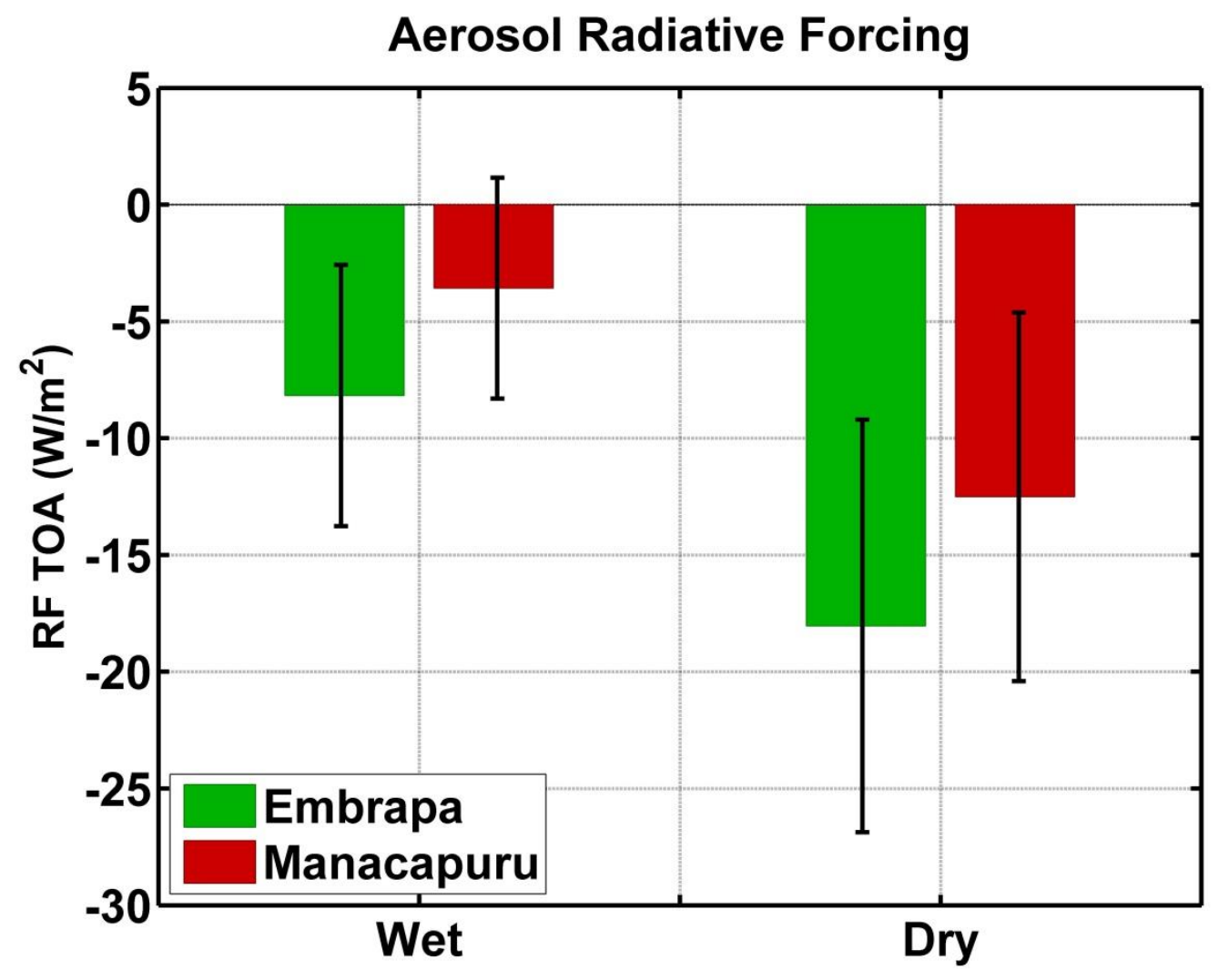

Figura 30 - Forçante radiativa no topo da atmosfera média para as estações chuvosa e seca medidas com os fotômetros solares da AERONET nos sites Embrapa e Manacapuru durante o experimento GoAmazon2014/5. O desvio padrão também está indicado na figura.

Como também observado na seção 5.1, os aerossóis provenientes da queima de biomassa têm efeito de resfriamento no clima, resultando em uma forçante mais negativa na estação seca em comparação com a estação chuvosa. Apesar de também conter concentrações elevadas de black carbon, o espalhamento de luz é predominante nas partículas de queimadas devido a maior presença do carbono orgânico (OC). $O$ efeito de dominante do aerossol é de resfriamento devido à presença forte ( $70-80 \%$ da 
composição) do OC no aerossol. Em média, para o sítio da Embrapa, a forçante radiativa no TOA diminuiu de $-7 \mathrm{~W} / \mathrm{m}^{2}$ para $-12 \mathrm{~W} / \mathrm{m}^{2}$ da estação chuvosa para a estação seca, o que é causado pelo aumento na concentração de aerossóis de queimadas. Em Manacapuru, esta redução na forçante foi de $-3 \mathrm{~W} / \mathrm{m}^{2}$ na estação chuvosa para $-6,5$ $\mathrm{W} / \mathrm{m}^{2}$ na estação seca. O efeito do BC na forçante radiativa é muito forte, causando uma alteração na estação chuvosa de $-7 \mathrm{~W} / \mathrm{m}^{2}$ para $-3 \mathrm{~W} / \mathrm{m}^{2}$ entre os dois sites. O efeito da absorção também é notável na estação seca, com redução da forçante radiativa no TOA de -12 para $-6,5 \mathrm{~W} / \mathrm{m}^{2}$ entre os dois sites. Isso ocorre mesmo quando a pluma de queimadas domina em ambos os sítios experimentais. Estas fortes alterações na forçante radiativa podem ser comparadas com o aquecimento devido ao $\mathrm{CO}_{2}$ de $+2,29 \mathrm{~W} / \mathrm{m}^{2}$. Isso mostra que as emissões urbanas de Manaus afetam significativamente o balanço radiativo atmosférico. Como os aerossóis tem forte impacto na razão entre radiação direta e difusa, e como esta razão influencia fortemente a taxa fotossintética, como demonstrado em vários trabalhos recentes (OLIVEIRA et al. 2007; Cirino et al. 2014; Rap et al. 2015; Pacifico et al. 2015), observamos que a pluma de Manaus está influenciando na taxa fotossintética responsável pela absorção de $\mathrm{CO}_{2}$ da atmosfera no entorno da cidade de Manaus.

\subsubsection{Medidas in-situ durante o experimento GoAmazon2014/5}

Durante o experimento GoAmazon2014/5, além de medidas por sensoriamento remoto, um grande conjunto de medidas in-situ incluindo absorção e espalhamento espectrais foram realizadas na Amazônia central. Nesta seção, serão utilizados dados de Manacapuru (T3), onde as medidas in-situ foram realizadas vento abaixo da pluma de Manaus, paralelamente ao fotômetro solar da AERONET. Também serão utilizados os dados da estação ATTO (T0a) que, assim como a estação Manaus-Embrapa da AERONET, está localizada vento acima da pluma, em uma região relativamente livre de emissões antrópicas.

A Figura 31 mostra a série temporal dos coeficientes de absorção e espalhamento obtidos em Manacapuru e no ATTO durante o experimento GoAmazon2014/5 (janeiro a dezembro de 2014). 

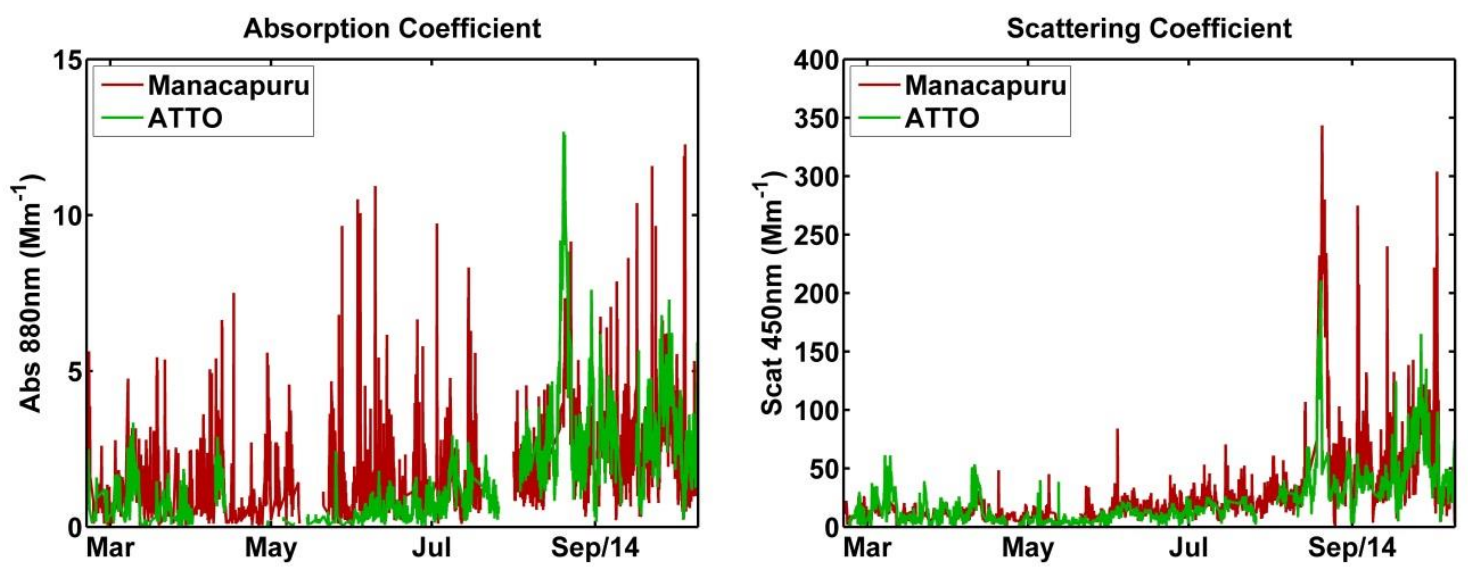

Figura 31 - Série temporal do coeficiente de absorção em $880 \mathrm{~nm}$ (à esquerda) e coeficiente de espalhamento em $450 \mathrm{~nm}$ (à direita) para os sítios TOa e T3 do GoAmazon2014/5. Foi utilizado corte de tamanho PM10 até 5 de maio de 2014 e a partir desta data foi utilizado corte PM1.

As medidas in-situ dos coeficientes de absorção e espalhamento também mostraram uma forte sazonalidade, apresentando valores máximos durante a estação de queimadas (agosto-outubro). Também pelas medidas in-situ, foi observado que o coeficiente de absorção medido em Manacapuru é consistentemente superior ao medido no ATTO, o que pode ser atribuído à absorção das partículas provenientes de poluição urbana. Esta diferença é mais evidente durante a estação chuvosa, quando a atmosfera apresenta baixas concentrações de aerossol de queimadas e é dominada por aerossóis biogênicos, ficando mais sensível às perturbações externas.

O albedo de espalhamento simples (SSA) representa a contribuição relativa do espalhamento para a extinção total da radiação, onde valores próximos de 1 são associados com aerossóis predominantemente espalhadores (e.g. sulfato de amônia) e valores baixos $(0,1-0,6)$ indicam a predominância de aerossóis absorvedores (e.g. black carbon). Foi observada uma diferença significativa nos valores de SSA (637nm) entre os dois sítios, obtidos a partir de medidas in-situ para as estações seca e chuvosa (Figura 32). No T3, o valor do albedo de espalhamento foi de $0,83 \pm 0,11$ na estação chuvosa, $10 \%$ inferior ao valor do albedo obtido na estação ATTO de 0,92 $\pm 0,06$. Na estação seca, o valor do SSA em Manacapuru de 0,80 \pm 0,09 também é inferior ( $5 \%$ ) ao valor obtido no ATTO de 0,83 $\pm 0,06$, indicando a presença da pluma urbana mesmo com a dominância de aerossóis de queimadas nesta época do ano. Neste sentido, a pluma de Manaus interfere na quantidade de radiação absorvida na atmosfera, sendo responsável pela significativa redução de aproximadamente 10\% do SSA em $637 \mathrm{~nm}$. Resultado similar também foi obtido por Rizzo et al (2013) analisando medidas in-situ na ZF2. Foi observado que o coeficiente de espalhamento aumenta por um fator de 2,5 em períodos 
com a presença de pluma, enquanto que a absorção aumenta por um fator de $5 \mathrm{em}$ relação aos valores obtidos em condições limpas, resultando em uma diminuição de 5\% no SSA.

\section{ESTAÇÃO CHUVOSA}
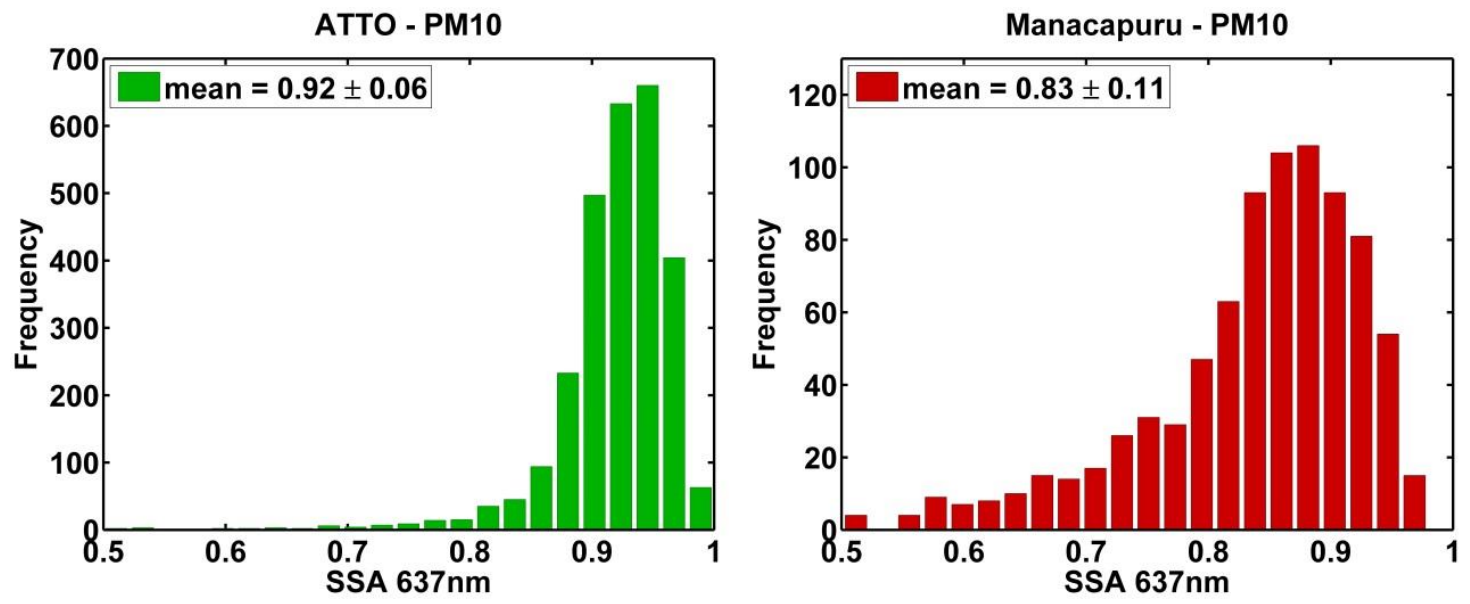

ESTAÇÃO SECA
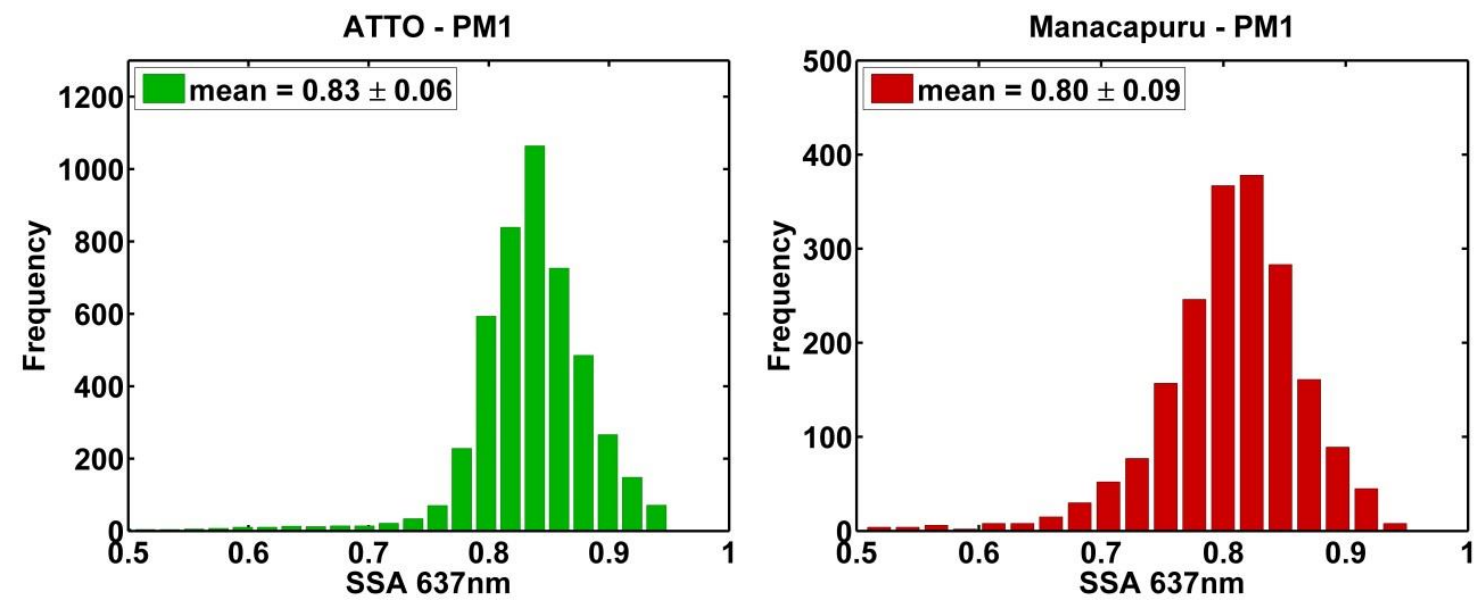

Figura 32 - Histograma dos valores de albedo simples obtidos para as estações ATTO (T0a) e Manacapuru (T3) a partir de medidas in-situ utilizando Aetalômetros e Nefelômetros durante a estação seca e chuvosa de 2014.

Portanto, foi observado que em regiões de background o albedo de espalhamento é superior (mais espalhador) ao obtido em regiões impactadas pela pluma urbana (mais absorvedor). As emissões veiculares, principalmente as de veículos a diesel, são dominadas por partículas pequenas e absorvedoras como o black carbon, enquanto que partículas biogênicas são majoritariamente encontradas nas frações grossas e espalham eficientemente a radiação por sua composição dominada por carbono orgânico.

Medidas com Aerosol Chemical Speciation Monitor (ACSM, Aerodyne Research Inc.) tanto no ATTO quanto em Manacaupru mostram a dominância forte de 
aerossóis orgânicos versus as demais componentes (BC, sulfato, nitrato etc.). A Figura 33 abaixo mostra a composição dos aerossóis na torre ATTO de março de 2014 a julho de 2015. Observam-se propriedades similares ao observado com medidas de sensoriamento remoto, com predominância de carbono orgânico espalhador. Na estação chuvosa de 2014, o carbono orgânico corresponde a 72\% da massa do PM1, sulfato e nitrato a $4 \%$ cada, enquanto o BC corresponde a $7 \%$ da massa. Isso mostra que a maior parte do aerossol biogênico natural é espalhador, compatível com SSA próximo a 0,90.
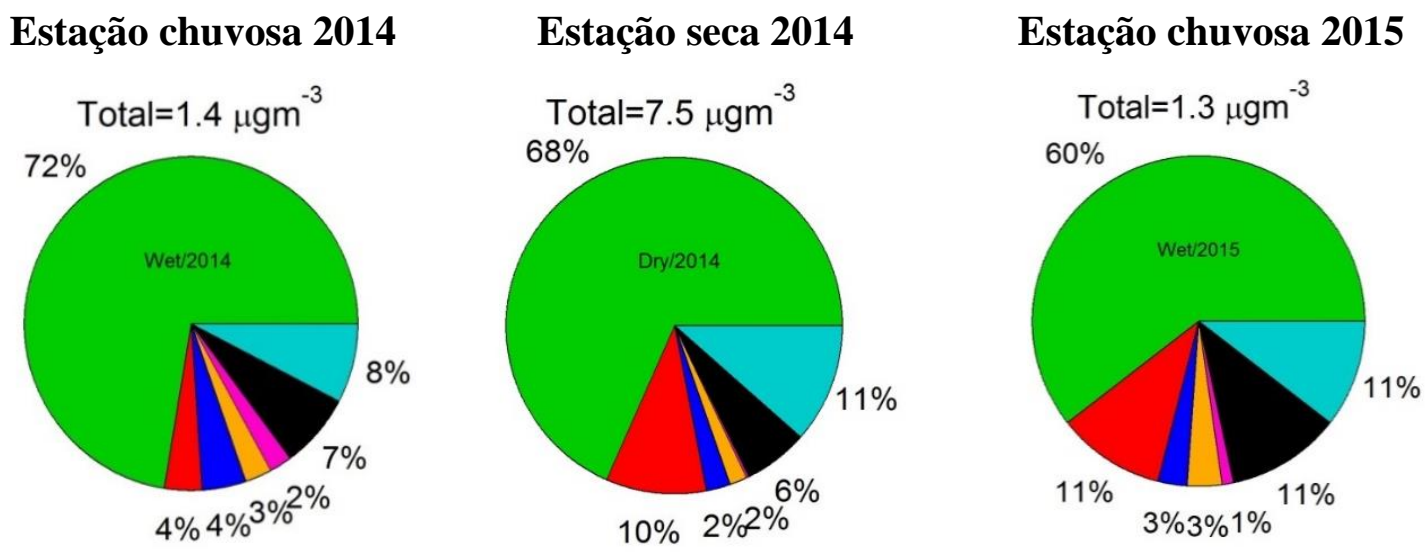

Organics sulfate nitrate Ammonium choride BCe water

Figura 33 - Composição química de aerossol fino na torre ATTO, para a estação chuvosa de 2014, estação seca de 2014 e estação chuvosa de 2015, respectivamente, medidos com o Aerosol Chemical Speciation Monitor (ACSM). Compilação de Samara Carbone, 2015.

Em Manacapuru, o albedo de espalhamento medido in-situ é consistente com o obtido pela AERONET na coluna atmosférica, mesmo considerando que em condições de umidade relativa ambiente, o SSA aumentaria entre 2-5\% (Anderson et al., 1999). O SSA médio obtido por sensoriamento remoto para as estações chuvosa foi de $0,84 \pm$ 0,13, muito similar ao 0,84 $\pm 0,07$ obtido na seca (Tabela 4). A surpreendente concordância de medidas integradas na coluna (AERONET) com medidas obtidas em solo nos mostra que a atmosfera amazônica é bem misturada verticalmente por causa da forte convecção. A mistura de emissões de superfície é eficiente e não altera as propriedades óticas dos aerossóis. 
Tabela 4- Estatísticas dos valores de albedo simples obtidos por medidas in-situ e pelos fotômetros solares da AERONET em Manacapuru durante as estações seca e chuvosa de 2014.

\begin{tabular}{ccccc}
\hline & \multicolumn{2}{c}{ T3 (Manacapuru) - Albedo de espalhamento simples (SSA) } \\
\hline & \multicolumn{2}{c}{ Estação Chuvosa } & \multicolumn{2}{c}{ Estação Seca } \\
In-situ* & AERONET** & In-situ* & AERONET** \\
Média & 0,86 & 0,84 & 0,87 & 0,84 \\
Desv. Pad. & 0,11 & 0,13 & 0,08 & 0,07 \\
Percentil 25 & 0,79 & 0,75 & 0,85 & 0,79 \\
Percentil 50 & 0,86 & 0,84 & 0,87 & 0,84 \\
Percentil 75 & 0,90 & 0,90 & 0,89 & 0,88 \\
\hline
\end{tabular}

*SSA (637 nm) corte de tamanho PM10

**SSA $(675 \mathrm{~nm})$

A Figura 34 e Figura 35 ilustram o ciclo diurno dos coeficientes Ångström de absorção (AAE) e de espalhamento (SAE) obtidos em Manacapuru durante o experimento GoAmazon2014/5. Estas grandezas são intensivas no sentindo de que não dependem da concentração de partículas e seu ciclo diurno evidencia a influência da pluma de Manaus no sítio experimental.

No caso da absorção de radiação por aerossóis, o chamado soot carbon tem uma dependência espectral (AAE) próximo de 1,0-1,2. Por outro lado, existem componentes que também absorvem radiação, mas com uma dependência espectral diferente, com um AAE da ordem de 1,8 a 2,0. Esta segunda componente é frequentemente chamada de brown carbon, em contraposição ao black carbon (BC) (Andreae \& Gelencsér 2006). Em nossas medidas in-situ apresentadas na Figura 34 com a variabilidade diurna em Manacapuru, observamos uma forte variação no AAE, indo de valores da ordem de 1,8, à noite, para 1,2 no período da tarde. Estes valores de $\mathrm{AAE}$ indicam que durante a noite há predomínio da componente de $\mathrm{BrC}$, enquanto que durante o dia temos uma componente de absorção mais característica de $\mathrm{BC}$ emitido em processos de combustão veiculares em áreas urbanas. 

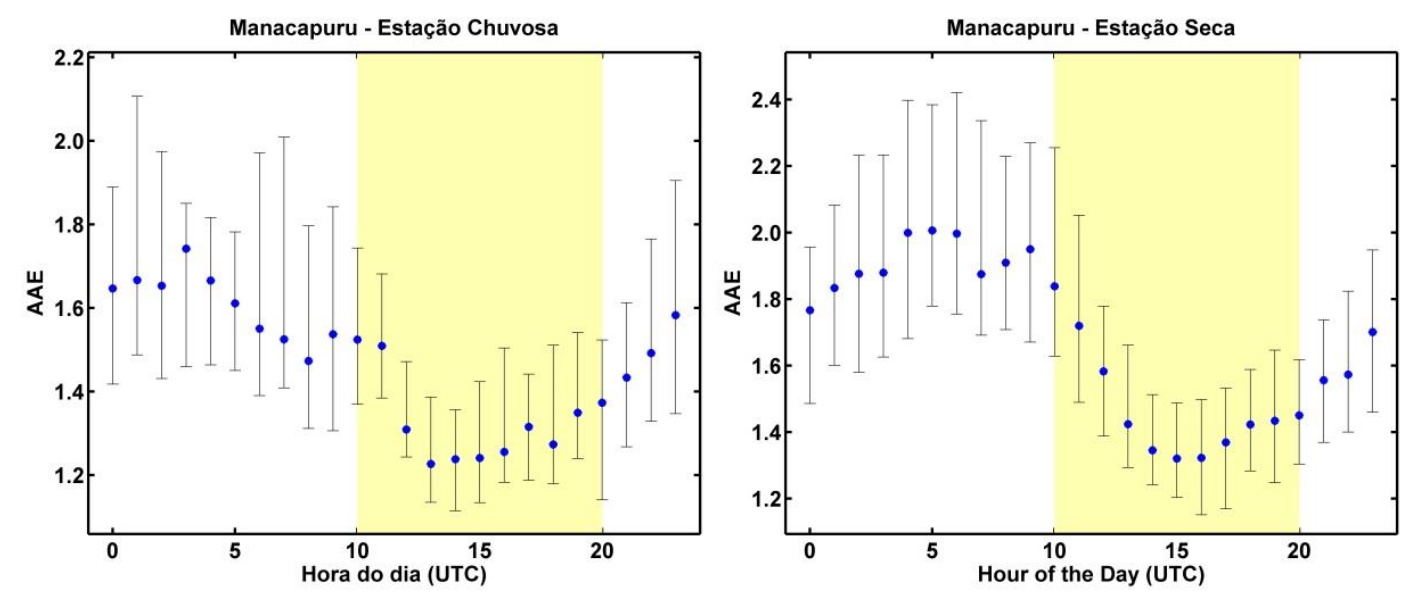

Figura 34 - Ciclo diurno médio do expoente Ångström de absorção calculado em Manacapuru para as estações chuvosa e seca de 2014. As barras inferiores e superiores representam o primeiro e terceiro quartis, respectivamente. A área sombreada representa o horário diurno.

Por outro lado, levando em conta agora a dependência espectral do espalhamento, foi observado que o ciclo diurno do SAE mostra uma significativa variação no tamanho médio das partículas de aerossol ao longo do dia. Os baixos valores de SAE $(0,8)$ durante a noite indicam a presença de partículas predominantemente na moda grossa, de origem biogênica. Ao longo do dia, devido a maior altura da camada limite que permite o transporte de poluentes, o tamanho médio das partículas de aerossol diminui com a chegada da pluma urbana, atingindo os maiores valores de $\operatorname{SAE}(1,2)$. O ciclo diurno pronunciado do SAE ocorre apenas durante a estação chuvosa. Na estação seca, a presença de aerossóis de queimadas na moda fina contribui para o aumento significativo do SAE $(1,6-1,8)$, que não apresenta um ciclo diurno definido. É interessante ressaltar que a influência da pluma de Manaus em Manacapuru é mais significativa durante o dia, período em que os fotômetros estão aptos a fazer medidas. 

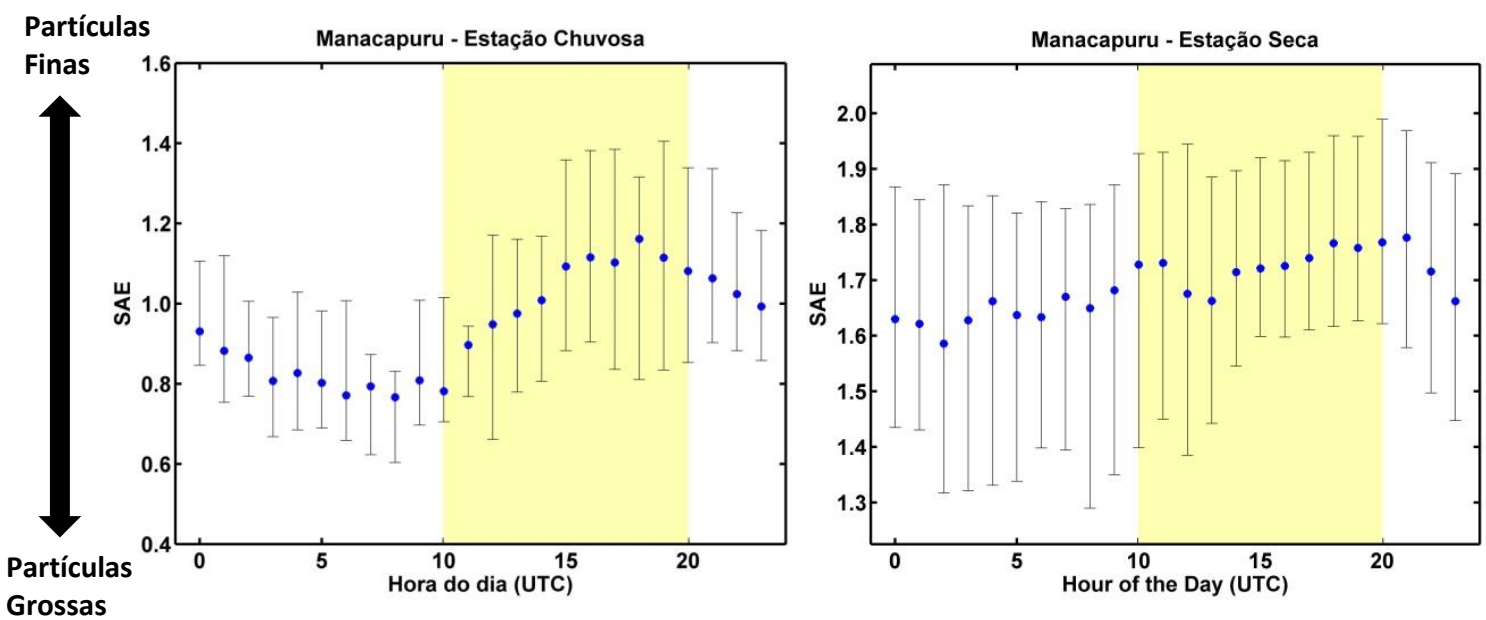

Figura 35 - Ciclo diurno médio do expoente Ångström de espalhamento calculado em Manacapuru para as estações chuvosa e seca de 2014. As barras inferiores e superiores representam o primeiro e terceiro quartis, respectivamente. A área sombreada representa o horário diurno.

Portanto, a partir das medidas in-situ foi possível observar que o impacto da pluma de Manaus sobre o T3 é mais significativo durante a estação chuvosa, quando há baixa concentração de aerossóis na atmosfera, tornando-a mais sensível a perturbações externas. Além disso, também foi observado maior efeito da pluma de Manaus no T3 no período diurno, quando os fotômetros da AERONET estão aptos a fazer medidas. Isso mostra que as emissões urbanas de Manaus afetam significativamente o balanço radiativo atmosférico. Outra componente presente abundantemente na região Amazônica são as partículas biogênicas naturais emitidas primariamente pela floresta. Um experimento especial foi desenhado para avaliar quantitativamente a absorção da radiação destas partículas na atmosfera. Os resultados deste experimento serão discutidos em detalhes na próxima seção. 


\subsection{CONTRIBUIÇÃO DE PARTÍCULAS BIOGÊNICAS NA MODA GROSSA PARA A ABSORÇÃO DE RADIAÇÃO NA AMAZÔNIA CENTRAL}

A influência de partículas biogênicas nas propriedades óticas do aerossol pode ser relativamente pequena em escala global, no entanto, em escalas regionais estas partículas podem ter uma influência relevante sobre o espalhamento e absorção de luz (Després et al. 2012; Rizzo et al. 2011). Na Amazônia, o aerossol biogênico compõe uma grande fração da massa total de aerossol, especialmente na moda grossa (Artaxo et al. 1988; Artaxo et al. 1998). Utilizando análises termo óticas, (Guyon et al. 2004) estimou-se que até $66 \%$ de massa de aerossol e até $47 \%$ da absorção de luz na atmosfera amazônica foram atribuídos a partículas biogênicas durante a estação chuvosa.

Nesta parte do trabalho, será discutido um experimento que foi desenvolvido em uma região de floresta preservada especialmente para avaliar a contribuição das partículas biogênicas naturais para a absorção da radiação. Como visto na seção anterior, estas partículas estão presentes em grandes quantidades na bacia Amazônica, portanto o estudo detalhado de suas propriedades óticas é essencial para avaliar seu impacto no clima e diminuir as incertezas nas estimativas da forçante radiativa.

As medidas tiveram início no dia 8 de maio de 2014 na reserva ecológica ZF2, localizada a $55 \mathrm{~km}$ ao norte de Manaus, em condições geralmente limpas, e foram continuadas até o final de agosto, quando a estação seca já tinha começado e o site passou a receber aerossóis de queimadas transportados de longas distâncias.

Quatro equipamentos foram utilizados para medir o coeficiente de absorção de luz a partir de métodos óticos. Um conjunto composto por um Aetalômetro e um MAAP coletou partículas de aerossol com corte de tamanho de $10 \mu \mathrm{m}$, sendo que outro conjunto com os mesmos instrumentos coletou ao mesmo tempo partículas com corte de 2,5 $\mu \mathrm{m}$. A ideia é termos dois instrumentos medindo frações diferentes de tamanho do aerossol, permitindo a separação da absorção causada pela fração grossa. O aerossol atmosférico foi amostrado abaixo do dossel da floresta com resolução temporal de 1 minuto, e depois pós-processado para 30 minutos. As medidas foram tomadas após o aerossol passar por um processo de secagem, utilizando o sistema de difusão com sílica gel, que reduziu a umidade relativa para valores abaixo de $40 \%$. No experimento, também foi utilizado um optical particle counter (OPC, Grimm) para medir a concentração numérica de partículas com diâmetros variando de 0,3 a $32 \mu \mathrm{m}$. O desenho esquemático do arranjo experimental está mostrado na Figura 36. 


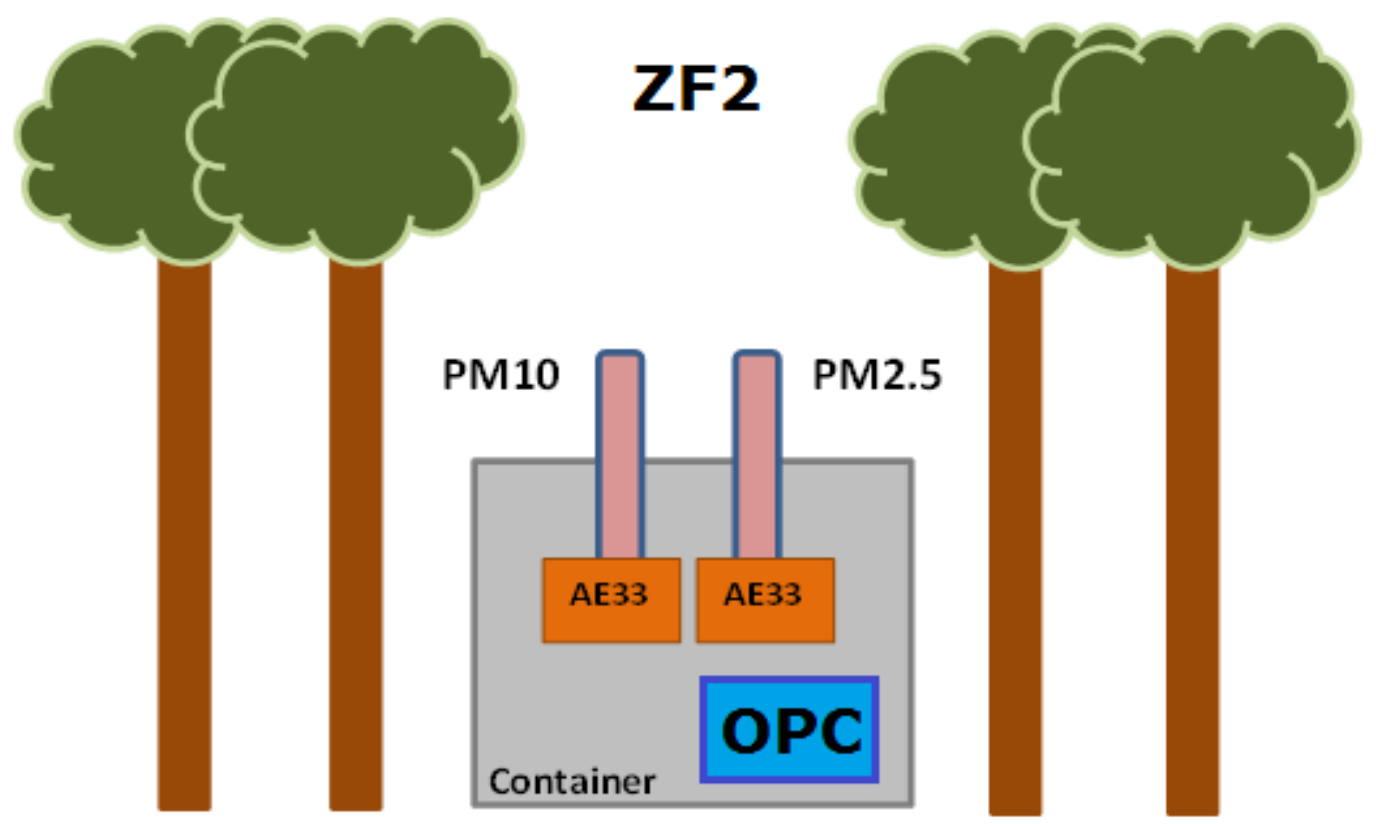

Figura 36 - Desenho esquemático do arranjo experimental na reserva ecológica ZF2.

As medidas de absorção realizadas pelos Aetalômetros foram corrigidas para efeitos de espalhamento múltiplo, de acordo com algoritmos utilizados por Rizzo et al., 2011. A medida de absorção pelo MAAP já contempla estas correções que são feitas internamente no instrumento (Petzold et al. 2005). Os dois MAAPs funcionaram paralelamente aos dois AE33 com os mesmos cortes de tamanho (PM10 ou PM2.5).

A comparação entre as medidas em paralelo mostradas na Figura 37 apontam para uma excelente concordância entre os instrumentos de medida para as diferentes frações de tamanho do aerossol. Isso ocorreu apesar dos dois instrumentos utilizarem princípios diferentes para a medida da absorção. Para PM2.5, a razão entre os instrumentos foi de $1,093 \pm 0,002$. Para a fração de aerossóis menores que 10 mícron (PM10) esta razão foi de $0,991 \pm 0,004$. 

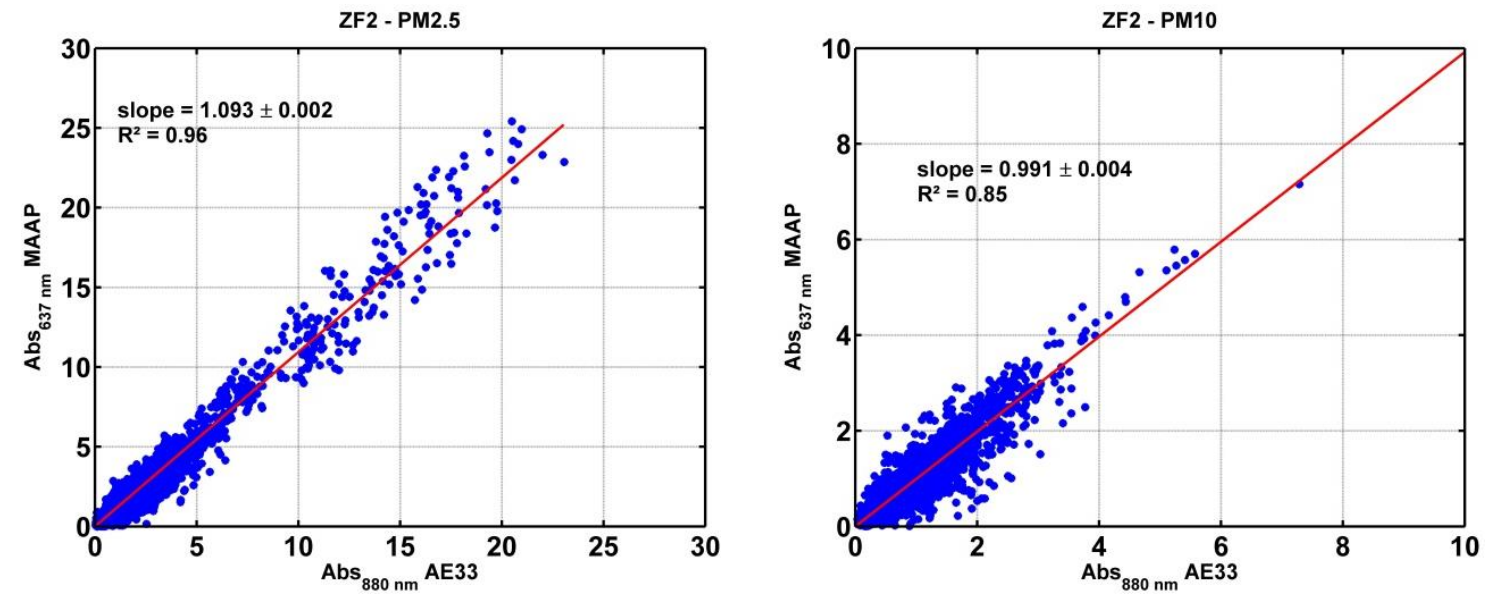

Figura 37 - Comparação entre os coeficientes de absorção medidos pelo AE33 e MAAP no sítio experimental da ZF2, para os cortes de tamanho $\mathrm{PM}_{10}$ e $\mathrm{PM}_{2.5}$.

A série temporal do coeficiente de absorção está mostrada na Figura 38 e indica que os instrumentos apresentaram comportamento bem semelhante durante todo o experimento. Os coeficientes de absorção em 880nm obtidos pelos Aetalômetros apresentaram uma média de 0,5 $\pm 0,4 \mathrm{Mm}^{-1}$ nos dias mais limpos, atingindo valores próximos a $10 \mathrm{Mm}^{-1}$ nos dias mais afetados por emissões de queimadas na estação seca.

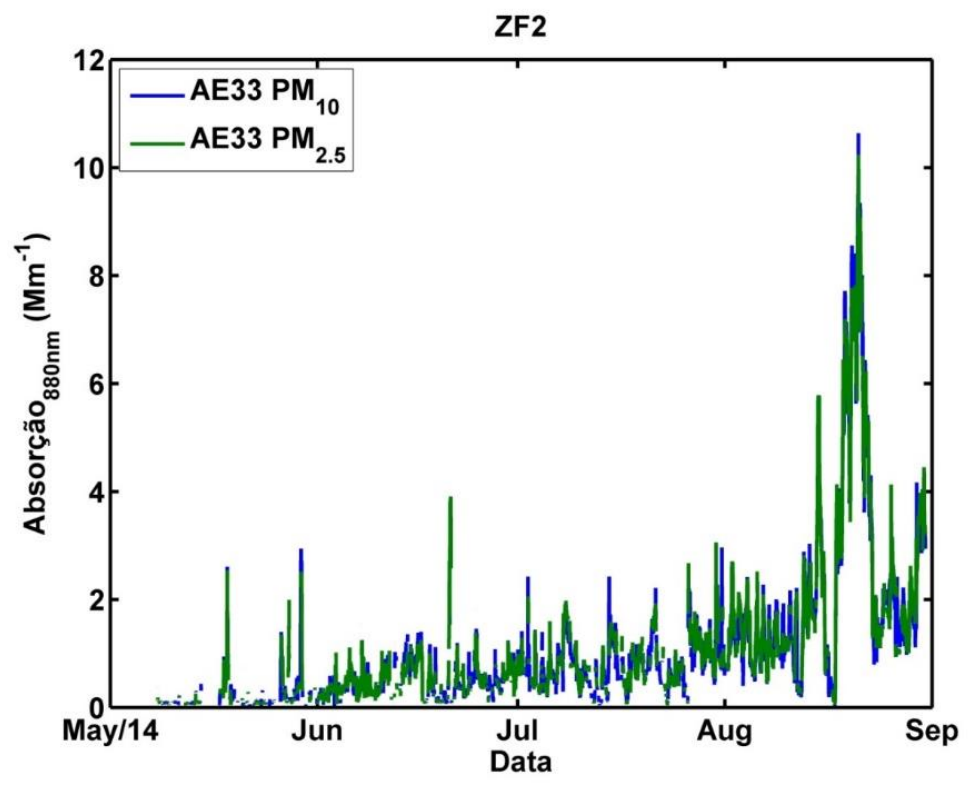

Figura 38 - Série temporal dos coeficientes de absorção do particulado $P M_{10}$ e $P M_{2.5}$, medidos pelo Aetalômetro AE33 no sítio experimental da ZF2

A Figura 39 exibe o perfil diário para as concentrações numéricas de partículas nas modas fina $(0,25$ a $2,5 \mu \mathrm{m})$ e grossa $(2,5$ a $10 \mu \mathrm{m})$ medidas pelo OPC na ZF2. É observado que as partículas finas apresentam um comportamento completamente diferente das partículas grossas, aumentando significativamente ao longo do dia (de 5 
parts $/ \mathrm{cm}^{3}$ para 9 parts $/ \mathrm{cm}^{3}$, aproximadamente). Este aumento pode estar relacionado à três processos: 1) a processos fotoquímico de sua formação; 2) a processos de advecção que são favorecidos pelo aumento da camada limite planetária; e 3) à condensação dos compostos orgânicos voláteis emitidos predominantemente durante o dia em aerossóis submicrométricos, causando o aumento destas partículas a tamanhos detectáveis pelo OPC.

Por outro lado, as máximas concentrações obtidas para as partículas grossas (aproximadamente 0,07 parts $/ \mathrm{cm}^{3}$ ) ocorrem durante a noite, coincidindo com a pronunciada atividade biológica noturna da floresta, onde há um aumento das taxas de liberação de partículas biogênicas primárias consistindo de leveduras, pequenos fungos, bactérias, pólens e outras partículas biogênicas (Martin et al. 2010). Esta mesma característica também foi determinada na ZF2 por outras técnicas (Pöhlker et al. 2012). No meio do dia, a população de partículas grossas também é influenciada pela evolução da camada limite planetária. A camada limite planetária é a região da atmosfera cujos campos de ventos estão sob a influência da superfície terrestre. Sob a camada limite, ocorre a dispersão de poluentes pelo fenômeno de difusão turbulenta, determinada por fatores térmicos (temperatura da superfície, fluxo de calor a partir do solo) e mecânicos (rugosidade, velocidade do vento na superfície).
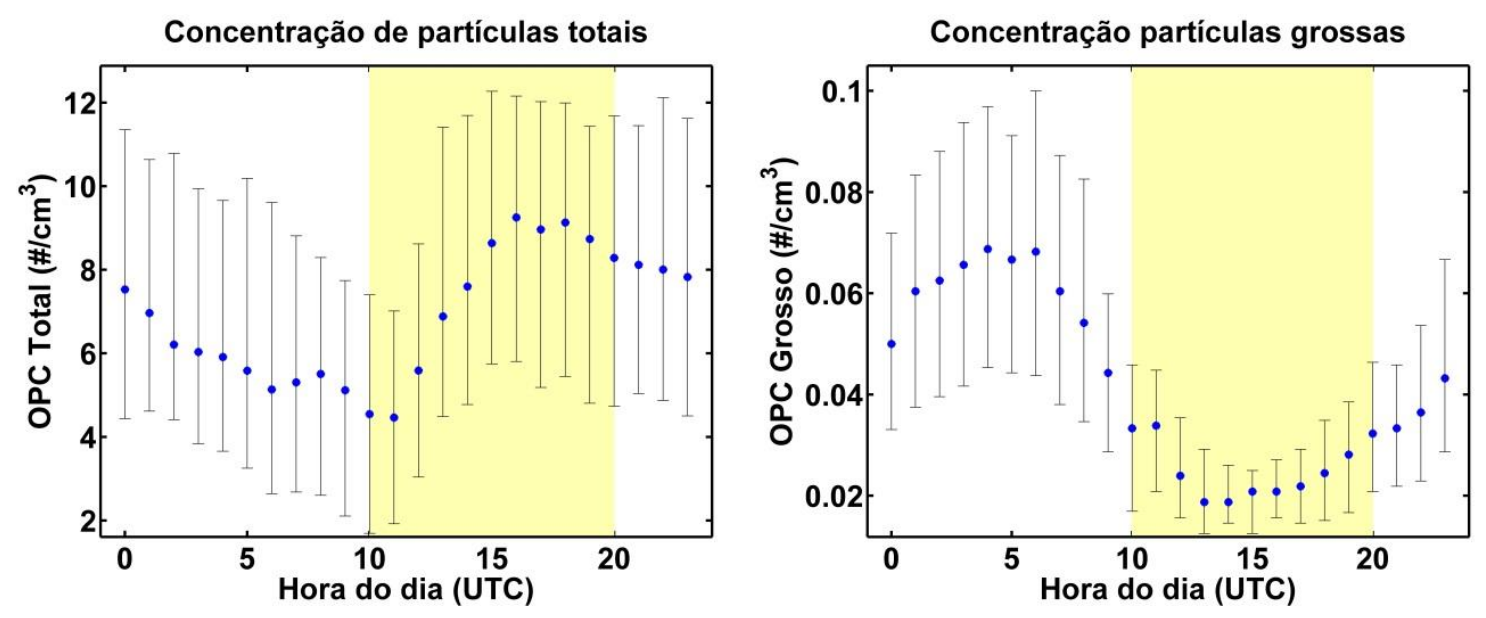

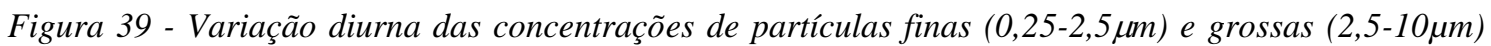
medidas pelo OPC Grimm na reserva ecológica $Z F 2$ durante o experimento. A área sombreada representa o horário diurno.

Foi feita uma comparação direta entre os coeficientes de absorção em $880 \mathrm{~nm}$ (comprimento de onda no qual o instrumento é calibrado) entre o particulado fino e grosso medidos pelos dois AE33 operados em paralelo. Esta comparação está ilustrada na Figura 40. 


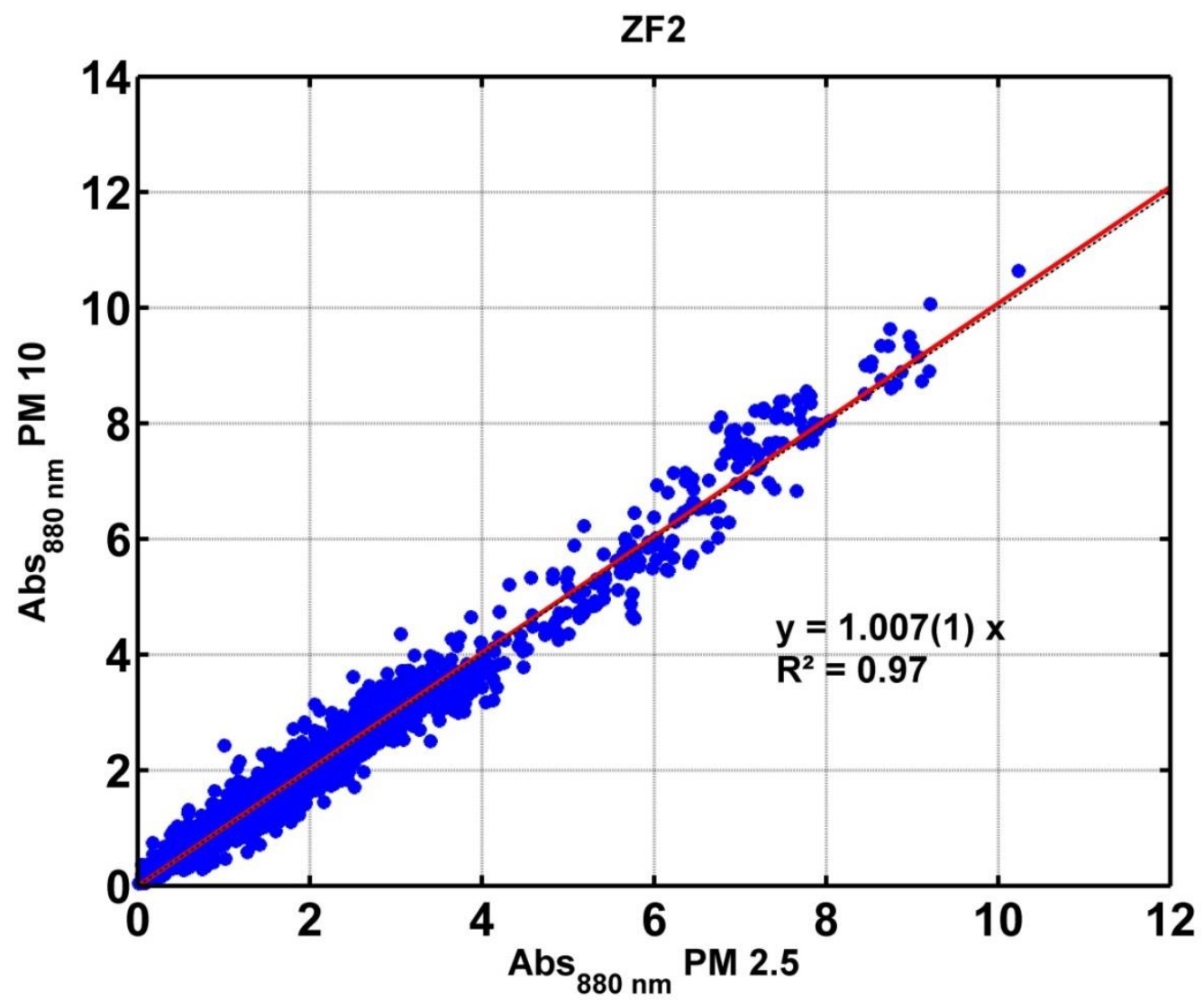

Figura 40 - Regressão linear entre os coeficientes de absorção dos particulados PM10 e PM2.5, medidos pelo AE33 na ZF2.

A regressão da Figura 40 apresentou um slope de 1,007 e mostrou alto coeficiente de correlação entre $\mathrm{PM}_{10}$ e $\mathrm{PM}_{2.5}\left(\mathrm{R}^{2}=0,97\right)$. O resultado desta regressão é determinado pelos maiores valores de absorção que ocorrem no mês de julho e agosto, quando o site passou a receber aerossóis de queimadas transportados por longas distâncias. Para observarmos o efeito da absorção por partículas grossas biogênicas é necessário estudarmos esta regressão para baixos valores de absorção, característicos dos efeitos do aerossol biogênico. Baseado neste procedimento, estas regressões lineares foram refeitas aplicando um limite superior para os valores de absorção. Os limites de cada regressão foram sendo reduzidos para analisarmos o impacto do aerossol biogênico para decrescentes valores de absorção. Valores acima dos limites estipulados não foram considerados nestas regressões. 


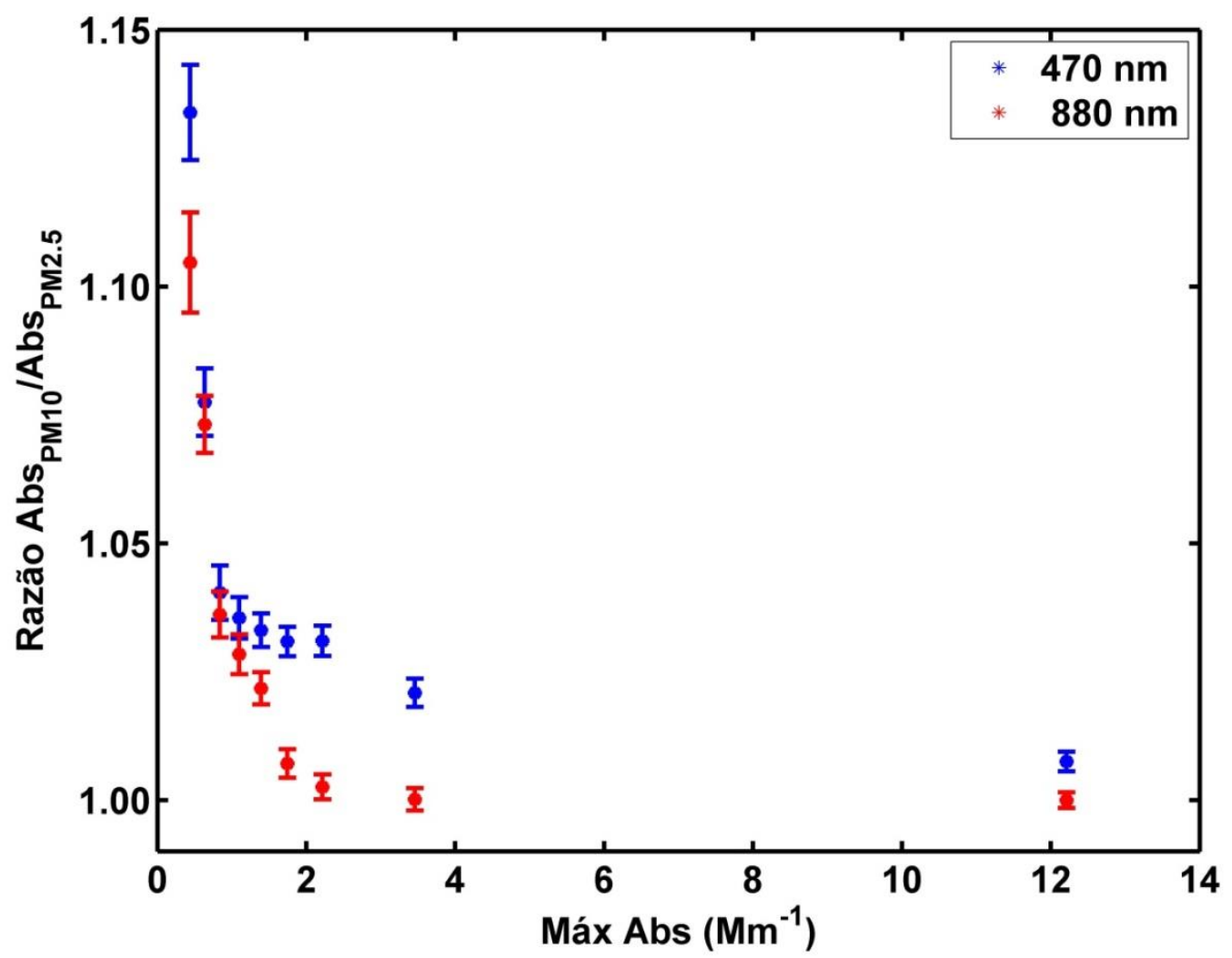

Figura 41 - Razão entre os coeficientes de absorção do $\mathrm{PM}_{10}$ e $\mathrm{PM}_{2.5}$ medidos pelo AE33 como função do valor máximo de absorção utilizado na regressão para os comprimentos de onda 470 e $880 \mathrm{~nm}$.

Esta análise mostra que a contribuição para a absorção do $\mathrm{PM}_{10}$ em relação ao $\mathrm{PM}_{2.5}$ aumenta em condições mais limpas, ou seja, para valores menores de absorção, como mostrado na Figura 41. Este aumento da absorção $(880 \mathrm{~nm})$ do particulado grosso em relação ao fino chega a $11 \%$. Portanto, é possível estabelecer um limiar $\left(\sim 2 \mathrm{Mm}^{-1}\right)$ abaixo do qual as partículas grossas (relacionadas com aerossol biogênico primário) começaram a desempenhar um papel significante na absorção de luz. Acima desse valor, nenhuma contribuição significativa para absorção da moda grossa foi observada, sendo dominado pela fração fina. Ao efetuar a mesma análise em 470nm, mais sensível à absorção de aerossóis orgânicos, observa-se uma diferença maior para valores de absorção mais altos, funcionando como indicativo da natureza biogênica dos aerossóis da moda grossa, ou seja, o chamado brown carbon.

Este experimento demonstrou que as partículas grossas biogênicas têm um papel na absorção de radiação, mesmo não sendo provenientes de queima de combustíveis fósseis ou de queimadas de florestas. Observamos também que as partículas biogênicas são emitidas preferencialmente à noite, através de processos biológicos. 


\section{CONCLUSÕES}

Este trabalho fez um extenso estudo de propriedades de absorção de radiação no espectro solar para os diferentes tipos de aerossóis predominantes na Amazônia (biogênicos, urbanos e de queimadas). Propriedades como o espalhamento de radiação e sua dependência espectral também foram estudadas para as várias componentes. Observou-se uma grande sazonalidade dos coeficientes de espalhamento e absorção devido aos eventos anuais de queimadas e ao transporte de poluentes da pluma de Manaus no sítio T3. Foi observado no sítio T3 grande variação diurna do coeficiente Ångström de espalhamento, associado à produção de aerossóis secundários (SOA) na atmosfera amazônica no período da tarde, evidenciando a presença de processos fotoquímicos na formação de SOA. A altura da camada limite também afeta a distribuição de tamanho dos aerossóis facilitando processos de transportes regionais.

Pela primeira vez foi realizada a aplicação da técnica desenvolvida por Cazorla et al., (2013) para separar tipos de aerossóis na Amazônia. Esta técnica utiliza uma análise conjunta dos coeficientes de Ångström de espalhamento e absorção, separando as componentes de poeira, EC, OC e biogênicos, que possuem propriedades óticas muito diferentes. Observamos grande variabilidade do AAE e SAE associados com os vários tipos de partículas presentes no aerossol amazônico. Valores de AAE da ordem de $\sim 2,0$ foram observados na estação de queimadas, e refletem a presença de brown carbon. Emissões urbanas da cidade de Manaus mostraram um AAE próximo a 1,0, valores típicos de emissão de veículos a diesel. No espalhamento foi observado um aumento do SAE da estação chuvosa para a estação seca, em consequência do aumento da moda de acumulação sobre a moda grossa, que também foi observado na variação interanual da distribuição volumétrica de tamanho medida pela AERONET. Este método proposto por Cazorla et al., (2013) mostrou-se uma boa aproximação para separar as várias componentes de aerossóis com frações diferentes de absorção e espalhamento na Amazônia.

A partir da separação clara entre as componentes de aerossóis da Amazônia, foi possível avaliar seu impacto no balanço radiativo terrestre. As medidas classificadas como OC apresentaram as forçantes radiativas mais negativas $\left(-53 \pm 17 \mathrm{~W} / \mathrm{m}^{2}\right)$, mostrando que o OC é altamente espalhador e, quando presente na atmosfera, tem um efeito de resfriamento no topo da atmosfera. Por outro lado, o EC é altamente absorvedor e influencia a forçante radiativa positivamente, aquecendo a atmosfera, levando uma forçante altamente negativa para valores mais próximos de zero, com uma 
média de $-12 \pm 9 \mathrm{~W} / \mathrm{m}^{2}$. Durante a estação chuvosa, a forçante radiativa média no topo da atmosfera foi de $-3,9 \pm 2,6 \mathrm{~W} / \mathrm{m}^{2}$, que é um valor alto se comparado com a forçante radiativa do $\mathrm{CO}_{2}$, atualmente estimado $\mathrm{em}+2,3 \mathrm{~W} / \mathrm{m}^{2}$ (IPCC, 2013). Na estação seca, a média da forçante radiativa foi de $-27 \pm 21 \mathrm{~W} / \mathrm{m}^{2}$, valor extremamente alto mostrando a importância do efeito direto dos aerossóis no clima da Amazônia.

No contexto do experimento GoAmazon2014/5, as duas regiões vento acima e vento abaixo da cidade de Manaus monitoradas pelos radiômetros CIMEL da AERONET mostraram grande similaridade na espessura ótica de aerossóis e na distribuição de tamanho. Apesar da extinção de luz ser similar nos dois sites, uma significativa diferença foi observada na componente de absorção da AOD. A presença da pluma de Manaus é responsável pelo aumento da absorção da luz solar em Manacapuru, devido à maior concentração de partículas de black carbon emitidas principalmente por veículos a diesel, e isto apresenta impactos diretos no balanço radiativo. $\mathrm{O}$ efeito do $\mathrm{BC}$ na forçante radiativa é muito forte, causando uma alteração na estação chuvosa de $-7 \mathrm{~W} / \mathrm{m}^{2}$ na região vento acima para $-3 \mathrm{~W} / \mathrm{m}^{2}$ no sítio vento abaixo da pluma. O efeito da absorção também é notável na estação seca, com aumento da forçante radiativa no TOA de -12 para $-6,5 \mathrm{~W} / \mathrm{m}^{2}$ entre os dois sites. Isso ocorre mesmo quando a pluma de queimadas domina em ambos os sítios experimentais. Medidas insitu realizadas paralelamente ao fotômetro solar mostraram que a pluma urbana atinge Manacapuru principalmente durante o dia.

Neste trabalho, também foi constatado que as partículas biogênicas emitidas primariamente pela floresta na fração grossa apresentam significativa absorção de radiação no espectro visível. Em condições de atmosfera Amazônica natural, a absorção em $880 \mathrm{~nm}$ do $\mathrm{PM}_{10}$ é cerca de $10 \%$ superior à absorção do $\mathrm{PM}_{2.5}$ no mesmo comprimento de onda. Esta porcentagem aumenta para comprimentos de onda menores. Para $440 \mathrm{~nm}$, a diferença na absorção entre $\mathrm{PM}_{10}$ e $\mathrm{PM}_{2.5}$ chega a $15 \%$. Importante lembrar que enquanto temos cerca de 300 partículas por $\mathrm{cm}^{3}$ na moda fina, temos 3 partículas por $\mathrm{cm}^{3}$ na moda grossa, evidenciando que a eficiência da absorção das partículas grossas não pode ser desprezada. Estas medidas foram realizadas utilizando Aetalômetros que amostraram o aerossol abaixo do dossel da floresta, que é dominado por emissões biogênicas naturais. Este experimento permitiu quantificar a absorção da radiação por partículas grossas, e é a primeira medida deste tipo já realizada.

É importante que medidas de mais longo prazo das propriedades óticas de aerossóis com os fotômetros solares sejam realizadas na Amazônia central, uma vez que 
as medidas por sensoriamento remoto são afetadas pela alta cobertura de nuvens na Amazônia, especialmente na estação chuvosa. Além disso, o perfil vertical da distribuição de partículas e de suas propriedades óticas poderia ser mais bem estudado através de instrumentos como LIDAR e medidas de perfis verticais em aviões. A forçante radiativa de aerossóis deve ser estimada com métodos adicionais, tais como Raman Lidar, MODIS e CERES, além de uma componente de modelamento acoplada. As determinações de fotômetros solares da rede AERONET devem ser validadas por métodos independentes e com medidas de piranômetros em solo, preferencialmente com separação espectral. 


\section{Referências Bibliográficas}

Albrecht, B. a, 1989. Aerosols, Cloud Microphysics, and Fractional Cloudiness. Science, (4), pp.1227-1230.

Allan, J.D. et al., 2014. Airborne observations of IEPOX-derived isoprene SOA in the Amazon during SAMBBA. Atmospheric Chemistry and Physics, 14(20), pp.11393-11407. Available at: http://www.atmos-chem-phys.net/14/11393/2014/.

Andreae, M.O., 2002. Biogeochemical cycling of carbon, water, energy, trace gases, and aerosols in Amazonia: The LBA-EUSTACH experiments. Journal of Geophysical Research, 107(D20), p.8066. Available at: http://doi.wiley.com/10.1029/2001JD000524.

Andreae, M.O. et al., 2012. Carbon monoxide and related trace gases and aerosols over the Amazon Basin during the wet and dry seasons. Atmospheric Chemistry and Physics, 12(13), pp.6041-6065. Available at: http://www.atmos-chem-phys.net/12/6041/2012/.

Andreae, M.O. et al., 2004. Smoking rain clouds over the Amazon. Science (New York, N.Y.), 303(5662), pp.1337-1342.

Andreae, M.O. et al., 2015. The Amazon Tall Tower Observatory (ATTO) in the remote Amazon Basin: overview of first results from ecosystem ecology, meteorology, trace gas, and aerosol measurements. Atmospheric Chemistry and Physics Discussions, 15(8), pp.11599-11726. Available at: http://www.atmos-chem-phys-discuss.net/15/11599/2015/.

Andreae, M.O. \& Gelencsér, a., 2006. Black carbon or brown carbon? The nature of lightabsorbing carbonaceous aerosols. Atmospheric Chemistry and Physics Discussions, 6(3), pp.3419-3463.

Andreae, M.O. \& Merlet, P., 2001. Emission of trace gases and aerosols from biomass burning. Global Biogeochemical Cycles, 15(4), pp.955-966.

Andreae, M.O. \& Rosenfeld, D., 2008. Aerosol-cloud-precipitation interactions. Part 1. The nature and sources of cloud-active aerosols. Earth-Science Reviews, 89(1-2), pp.13-41. Available at: http://linkinghub.elsevier.com/retrieve/pii/S0012825208000317.

Araújo, A.C., 2002. Comparative measurements of carbon dioxide fluxes from two nearby towers in a central Amazonian rainforest: The Manaus LBA site. Journal of Geophysical Research, 107(D20), p.8090. Available at: http://doi.wiley.com/10.1029/2001JD000676.

Artaxo, P. et al., 2013. Atmospheric aerosols in Amazonia and land use change: from natural biogenic to biomass burning conditions. Faraday Discussions, 165(0), pp.203-235. Available at: http://dx.doi.org/10.1039/C3FD00052D.

Artaxo, P. et al., 1988. Composition and sources of aerosols from the Amazon Basin. Journal of Geophysical Research, 93(D2), p.1605. Available at: http://doi.wiley.com/10.1029/JD093iD02p01605.

Artaxo, P. et al., 1998. Large-scale aerosol source apportionment in Amazonia. Journal of Geophysical Research, 103(D24), p.31837. Available at: http://doi.wiley.com/10.1029/98JD02346. 
Artaxo, P., 2001. The Atmospheric Component of Biogeochemical Cycles in the Amazon Basin. In Biogeochemistry of the Amazon Basin. pp. 42-52.

Baars, H. et al., 2011. Further evidence for significant smoke transport from Africa to Amazonia. Geophysical Research Letters, 38(20), p.n/a-n/a. Available at: http://doi.wiley.com/10.1029/2011GL049200.

Bahadur, R. et al., 2012. Solar absorption by elemental and brown carbon determined from spectral observations. Proceedings of the National Academy of Sciences, 109(43), pp.17366-17371. Available at: http://www.pnas.org/cgi/doi/10.1073/pnas.1205910109.

Barbosa, H.M.J. et al., 2014. A permanent Raman lidar station in the Amazon: description, characterization, and first results. Atmospheric Measurement Techniques, 7(6), pp.17451762. Available at: http://www.atmos-meas-tech.net/7/1745/2014/.

Barth, M. et al., 2005. Coupling between Land Ecosystems and the Atmospheric Hydrologic Cycle through Biogenic Aerosol Pathways. Bams, 86(December), pp.1738-1742. Available at: http://journals.ametsoc.org/doi/abs/10.1175/BAMS-86-12-1738.

Becker, B.K., 2001. Síntese do Processo de Ocupação da Amazônia - Lições do passado e desafios do presente. Em: Causas e Dinâmica do Desmatamento na Amazônia, 5-28, Ministério do Meio Ambiente, Brasília.

Bergstrom, R.W. et al., 2007. Spectral absorption properties of atmospheric aerosols. Atmospheric Chemistry and Physics, 7(23), pp.5937-5943. Available at: http://www.atmos-chem-phys.net/7/5937/2007/.

Bergstrom, R.W., Russell, P.B. \& Hignett, P., 2002. Wavelength Dependence of the Absorption of Black Carbon Particles: Predictions and Results from the TARFOX Experiment and Implications for the Aerosol Single Scattering Albedo. Journal of atmospheric Sciences, pp.567-577.

Boers, N. et al., 2014. Prediction of extreme floods in the eastern Central Andes based on a complex networks approach. Nature Communications, 5, p.5199. Available at: http://www.nature.com/doifinder/10.1038/ncomms6199.

Bond, T.C. et al., 2013. Bounding the role of black carbon in the climate system: A scientific assessment. Journal of Geophysical Research: Atmospheres, 118(11), pp.5380-5552. Available at: http://doi.wiley.com/10.1002/jgrd.50171.

Bond, T.C. \& Bergstrom, R.W., 2006. Light Absorption by Carbonaceous Particles: An Investigative Review. Aerosol Science and Technology, 40(1), pp.27-67. Available at: http://www.tandfonline.com/doi/abs/10.1080/02786820500421521.

Boucher, O., D. Randall, P. Artaxo, C. Bretherton, G. Feingold, P. Forster, V.-M. Kerminen, Y. Kondo, H. Liao, U. \& Lohmann, P. Rasch, S.K. Satheesh, S. Sherwood, B.S. and X.Y.Z., 2013. Clouds and Aerosols. Supplementary Material. In: Climate Change 2013: The Physical Science Basis. Contribution of Working Group I to the Fifth Assessment Report of the Intergovernmental Panel on Climate Change [Stocker, T.F., D. Qin, G.-K. Plattner, M. Tignor, S.K. Allen, J. , pp.1-4. 
Brito, J. et al., 2014. Ground-based aerosol characterization during the South American Biomass Burning Analysis (SAMBBA) field experiment. Atmospheric Chemistry and Physics, 14(22), pp.12069-12083. Available at: http://www.atmos-chem-phys.net/14/12069/2014/.

Cazorla, A. et al., 2013. Relating aerosol absorption due to soot, organic carbon, and dust to emission sources determined from in-situ chemical measurements. Atmospheric Chemistry and Physics, 13(18), pp.9337-9350. Available at: http://www.atmos-chemphys.net/13/9337/2013/.

Chang, D. et al., 2015. Comprehensive mapping and characteristic regimes of aerosol effects on the formation and evolution of pyro-convective clouds. , (October 2015), pp.10325-10348.

Charlson, R.J. et al., 1992. Antlropogenic Aerosols Anthropogenic Perturbation of Tropospheric. Science, 255(January), pp.423- 430.

Charlson, R. J. and Heintzenberg, J., 1995. Aerosol forcing of climate. In Wiley.

Chen, Q. et al., 2015. Submicron particle mass concentrations and sources in the Amazonian wet season (AMAZE-08). Atmospheric Chemistry and Physics, 15(7), pp.3687-3701. Available at: http://www.atmos-chem-phys.net/15/3687/2015/.

Cirino, G.G. et al., 2014. The effect of atmospheric aerosol particles and clouds on net ecosystem exchange in the Amazon. Atmospheric Chemistry and Physics, 14(13), pp.6523-6543. Available at: http://www.atmos-chem-phys.net/14/6523/2014/.

Collaud Coen, M. et al., 2004. Saharan dust events at the Jungfraujoch: detection by wavelength dependence of the single scattering albedo and first climatology analysis. Atmospheric Chemistry and Physics, 4(11/12), pp.2465-2480. Available at: http://www.atmos-chemphys.net/4/2465/2004/.

Davidson, E. a. et al., 2012. The Amazon basin in transition. Nature, 481(7381), pp.321-328.

Davidson, E. a. \& Artaxo, P., 2004. Globally significant changes in biological processes of the Amazon Basin: Results of the large-scale Biosphere-Atmosphere Experiment. Global Change Biology, 10, pp.519-529.

Després, V.R. et al., 2012. Primary biological aerosol particles in the atmosphere: a review. Tellus B, 64(0). Available at: http://www.tellusb.net/index.php/tellusb/article/view/15598.

Drinovec, L. et al., 2015. The "dual-spot" Aethalometer: an improved measurement of aerosol black carbon with real-time loading compensation. Atmospheric Measurement Techniques, 8(5), pp.1965-1979. Available at: http://www.atmos-meas-tech.net/8/1965/2015/.

Dubovik, O. et al., 2006. Application of spheroid models to account for aerosol particle nonsphericity in remote sensing of desert dust. Journal of Geophysical Research, 111(D11), p.D11208. Available at: http://doi.wiley.com/10.1029/2005JD006619.

Dubovik, O. et al., 2002. Non-spherical aerosol retrieval method employing light scattering by spheroids. Geophysical Research Letters, 29(10), pp.54-1-54-4. Available at: http://doi.wiley.com/10.1029/2001GL014506. 
Dubovik, O. et al., 2002. Variability of Absorption and Optical Properties of Key Aerosol Types Observed in Worldwide Locations. Journal of the Atmospheric Sciences, 59(3), pp.590608.

Dubuisson, P., Buriez, J.C. \& Fouquart, Y., 1996. High spectral resolution solar radiative transfer in absorbing and scattering media: Application to the satellite simulation. Journal of Quantitative Spectroscopy and Radiative Transfer, 55(1), pp.103-126. Available at: http://linkinghub.elsevier.com/retrieve/pii/0022407395001344.

Eck, T.F. et al., 2010. Climatological aspects of the optical properties of fine/coarse mode aerosol mixtures. Journal of Geophysical Research: Atmospheres, 115(19), pp.1-20.

Eck, T.F. et al., 2003. High aerosol optical depth biomass burning events: A comparison of optical properties for different source regions. Geophysical Research Letters, 30(20), p.2035. Available at: http://www.agu.org/pubs/crossref/2003/2003GL017861.shtml.

Fialho, P. et al., 2006. The Aethalometer calibration and determination of iron concentration in dust aerosols. Journal of Aerosol Science, 37(11), pp.1497-1506. Available at: http://linkinghub.elsevier.com/retrieve/pii/S0021850206000474.

Forster, P., V. Ramaswamy, P. Artaxo, T. Berntsen, R. Betts, D.W. Fahey, J. Haywood, J. Lean, D.C. Lowe, G. Myhre, J. Nganga, R.P. \& G. Raga, M.S. and R.V.D., 2007. Changes in Atmospheric Constituents and in Radiative Forcing. Change, 30(22), pp.129-234. Available at: http://en.scientificcommons.org/23467316.

Gallagher, M.W. et al., 2002. Measurements and parameterizations of small aerosol deposition velocities to grassland, arable crops, and forest: Influence of surface roughness length on deposition. Journal of Geophysical Research, 107(D12), p.549. Available at: http://nora.nerc.ac.uk/3644/.

García, O.E. et al., 2012. Shortwave radiative forcing and efficiency of key aerosol types using AERONET data. Atmospheric Chemistry and Physics, 12(11), pp.5129-5145. Available at: http://www.atmos-chem-phys.net/12/5129/2012/.

Gatti, L. V. et al., 2014. Drought sensitivity of Amazonian carbon balance revealed by atmospheric measurements. Nature, 506(7486), pp.76-80. Available at: http://www.nature.com/doifinder/10.1038/nature12957.

Guyon, P. et al., 2004. ARTICLE IN PRESS Sources of optically active aerosol particles over the Amazon forest. Atmospheric Environment, 38, pp.1039-1051.

Heald, C.L. et al., 2010. A simplified description of the evolution of organic aerosol composition in the atmosphere. Geophysical Research Letters, 37(8), p.L08803. Available at: http://doi.wiley.com/10.1029/2010GL042737.

Ten Hoeve, J.E. et al., 2012. Recent shift from forest to savanna burning in the Amazon Basin observed by satellite. Environmental Research Letters, 7(2), p.024020. Available at: http://stacks.iop.org/1748-

9326/7/i=2/a=024020?key=crossref.4097861c2b92ff70ec552dc953c8218a. 
Holben, B.N. et al., 1998. AERONET - A Federated Instrument Network and Data Archive for Aerosol Characterization. Remote Sensing of Environment, 66(1), pp.1-16. Available at: http://www.sciencedirect.com/science/article/pii/S0034425798000315.

Gash J. H. C. et al., 1996. Amazonian Deforestation and Climate. ohn Wiley and Sons, pp.173174.

Kaufman, Y.J. et al., 2005. The effect of smoke, dust, and pollution aerosol on shallow cloud development over the Atlantic Ocean. Proceedings of the National Academy of Sciences of the United States of America, 102(32), pp.11207-12. Available at: http://www.pnas.org/content/102/32/11207.abstract.

Kiehl, J.T. \& Briegleb, B.P., 1993. The relative roles of sulfate aerosols and greenhouse gases in climate forcing. Science, 260(5106), pp.311-314.

Kiehl, J.T. \& Trenberth, K.E., 1997. Earth's Annual Global Mean Energy Budget. Bulletin of the American Meteorological Society, 78(2), pp.197-208.

Kirchstetter, T.W., 2004. Evidence that the spectral dependence of light absorption by aerosols is affected by organic carbon. Journal of Geophysical Research, 109(D21), p.D21208. Available at: http://doi.wiley.com/10.1029/2004JD004999.

Kuhn, U. et al., 2010. Impact of Manaus City on the Amazon Green Ocean atmosphere: ozone production, precursor sensitivity and aerosol load. Atmospheric Chemistry and Physics, 10(19), pp.9251-9282. Available at: http://www.atmos-chem-phys.net/10/9251/2010/.

Kulmala, M. et al., 2013. Direct observations of atmospheric aerosol nucleation. Science (New York, N.Y.), 339(6122), pp.943-6. Available at: http://www.ncbi.nlm.nih.gov/pubmed/23430652.

Laakso, L., 2003. Ultrafine particle scavenging coefficients calculated from 6 years field measurements. Atmospheric Environment, 37(25), pp.3605-3613. Available at: http://linkinghub.elsevier.com/retrieve/pii/S1352231003003261.

Marengo, J. a. et al., 2008. The Drought of Amazonia in 2005. Journal of Climate, 21(3), pp.495-516. Available at: http://journals.ametsoc.org/doi/abs/10.1175/2007JCLI1600.1.

Martin, S.T. et al., 2010. Sources and properties of Amazonian aerosol particles. Reviews of Geophysics, 48(2), p.RG2002. Available at: http://doi.wiley.com/10.1029/2008RG000280.

Mayol-Bracero, O.L., 2002. Water-soluble organic compounds in biomass burning aerosols over Amazonia 2. Apportionment of the chemical composition and importance of the polyacidic fraction. Journal of Geophysical Research, 107(D20), p.8091. Available at: http://doi.wiley.com/10.1029/2001JD000522.

Müller, T. et al., 2011. Characterization and intercomparison of aerosol absorption photometers: result of two intercomparison workshops. Atmospheric Measurement Techniques, 4(2), pp.245-268. Available at: http://www.atmos-meas-tech.net/4/245/2011/.

Myhre, G. et al., 2013. 2013: Anthropogenic and Natural Radiative Forcing. Climate Change 2013: The Physical Science Basis. Contribution of Working Group I to the Fifth Assessment Report of the Intergovernmental Panel on Climate Change, pp.659-740. 
Nakajima, T. \& Tanaka, M., 1988. Algorithms for radiative intensity calculations in moderately thick atmospheres using a truncation approximation. Journal of Quantitative Spectroscopy and Radiative Transfer, 40(1), pp.51-69. Available at: http://linkinghub.elsevier.com/retrieve/pii/0022407388900313.

Oliveira, P.H.F. et al., 2007. The effects of biomass burning aerosols and clouds on the CO 2 flux in Amazonia. Tellus $B$, 59(3), pp.338-349. Available at: http://www.tellusb.net/index.php/tellusb/article/view/16994.

Pacifico, F. et al., 2015. Biomass burning related ozone damage on vegetation over the Amazon forest: a model sensitivity study. Atmospheric Chemistry and Physics, 15(5), pp.27912804. Available at: http://www.atmos-chem-phys.net/15/2791/2015/.

Pandis, S.N. et al., 1992. Secondary organic aerosol formation and transport. Atmospheric Environment. Part A. General Topics, 26(13), pp.2269-2282. Available at: http://linkinghub.elsevier.com/retrieve/pii/096016869290358R.

Petzold, A. et al., 2005. Evaluation of Multiangle Absorption Photometry for Measuring Aerosol Light Absorption. Aerosol Science and Technology, 39(1), pp.40-51. Available at: http://www.tandfonline.com/doi/abs/10.1080/027868290901945.

Petzold, A. et al., 2013. Recommendations for reporting "black carbon" measurements. Atmospheric Chemistry and Physics, 13(16), pp.8365-8379. Available at: http://www.atmos-chem-phys.net/13/8365/2013/.

Pöhlker, C. et al., 2012. Biogenic potassium salt particles as seeds for secondary organic aerosol in the Amazon. Science (New York, N.Y.), 337(6098), pp.1075-8. Available at: http://www.ncbi.nlm.nih.gov/pubmed/22936773.

Ramanathan, V. et al., 2001. Indian Ocean Experiment: An integrated analysis of the climate forcing and effects of the great Indo-Asian haze. Journal of Geophysical Research, 106(D22), p.28371.

Rap, A. et al., 2015. Fires increase Amazon forest productivity through increases in diffuse radiation. Geophysical Research Letters, 42(11), pp.4654-4662. Available at: http://doi.wiley.com/10.1002/2015GL063719.

Rizzo, L. V., 2006. Os fluxos turbulentos de partículas e de compostos orgânicos voláteis, e a distribuição vertical de aerossóis na baixa troposfera da Amazônia.

Rizzo, L. V. et al., 2011. Spectral dependence of aerosol light absorption over the Amazon Basin. Atmospheric Chemistry and Physics, 11(17), pp.8899-8912.

Russell, P.B. et al., 2010. Absorption Angstrom Exponent in AERONET and related data as an indicator of aerosol composition. Atmospheric Chemistry and Physics, 10(3), pp.11551169. Available at: http://www.atmos-chem-phys.net/10/1155/2010/.

Sandradewi, J. et al., 2008. A study of wood burning and traffic aerosols in an Alpine valley using a multi-wavelength Aethalometer. Atmospheric Environment, 42(1), pp.101-112. 
Schafer, J.S. et al., 2008. Characterization of the optical properties of atmospheric aerosols in Amazônia from long-term AERONET monitoring (1993-1995 and 1999-2006). Journal of Geophysical Research, 113(D4), pp.1-16. Available at: http://www.agu.org/pubs/crossref/2008/2007JD009319.shtml.

Schnaiter, M., C. Linke, O. Mohler, K.-H. Naumann, H. Saathoff, R. Wagner, U. Schurath, and B.W., 2005. Absorption amplification of black carbon internally mixed with secondary organic aerosol. Journal of Geophysical Research, 110(D19), p.D19204. Available at: http://doi.wiley.com/10.1029/2005JD006046.

Schneider, J. et al., 2011. Mass-spectrometric identification of primary biological particle markers: indication for low abundance of primary biological material in the pristine submicron aerosol of Amazonia. Atmospheric Chemistry and Physics Discussions, 11(7), pp.19143-19178. Available at: http://www.atmos-chem-phys-discuss.net/11/19143/2011/.

Schuster, G.L., Dubovik, O. \& Holben, B.N., 2006. Angstrom exponent and bimodal aerosol size distributions. Journal of Geophysical Research, 111(D7), p.D07207. Available at: http://doi.wiley.com/10.1029/2005JD006328.

Seinfeld, J.H. \& Pandis, S.N., 2006. ATMOSPHERIC From Air Pollution to Climate Change SECOND EDITION,

Sena, E.T., 2013. Variabilidade espacial e temporal da forçante radiativa direta de aerossóis de queimadas e os efeitos da mudança de uso do solo na Amazônia.

Sena, E.T. \& Artaxo, P., 2015. A novel methodology for large-scale daily assessment of the direct radiative forcing of smoke aerosols. Atmospheric Chemistry and Physics, 15, pp.5471-5483. Available at: http://www.atmos-chem-phys.net/15/5471/2015/.

Sena, E.T., Artaxo, P. \& Correia, a. L., 2013. Spatial variability of the direct radiative forcing of biomass burning aerosols and the effects of land use change in Amazonia. Atmospheric Chemistry and Physics, 13(3), pp.1261-1275. Available at: http://www.atmos-chemphys.net/13/1261/2013/.

De Souza, D.O. \& dos Santos Alvalá, R.C., 2014. Observational evidence of the urban heat island of Manaus City, Brazil. Meteorological Applications, 21(2), pp.186-193. Available at: http://doi.wiley.com/10.1002/met.1340.

Steffen, W. et al., 2015. Planetary boundaries: Guiding human development on a changing planet. Science, 347(6223), pp.1259855-1259855. Available at: http://www.sciencemag.org/cgi/doi/10.1126/science.1259855.

Soares-Filho, B., Alencar, A., Nepstad, D., Cerqueira, G., Del Carmen Vera Diaz, M., Rivero, S., Solórzano, L. and Voll, E., 2004. Simulating the response of land-cover changes to road paving and governance along a major Amazon highway: The Santarém-Cuiabá corridor, Glob. Chang. Biol., 10(5), 745-764, doi:10.1111/j.1529-8817.2003.00769.x.

Surratt, J.D. et al., 2010. Reactive intermediates revealed in secondary organic aerosol formation from isoprene. Proceedings of the National Academy of Sciences, 107(15), pp.6640-6645. Available at: http://www.pnas.org/cgi/doi/10.1073/pnas.0911114107. 
Talbot, R. W., M. O. Andreae, H. Berresheim, P. Artaxo, M. Garstang, R. C. Harriss, K. M. Beecher, and S.M.L., 1990. Aerosol chemistry during the wet season in central Amazonia: The influence of long-range transport. Journal of Geophysical Research, 95(D10), pp.16955-16969.

Trenberth, K.E., Fasullo, J.T. \& Kiehl, J., 2009. Earth's Global Energy Budget. Bulletin of the American Meteorological Society, 90(3), pp.311-323. Available at: http://journals.ametsoc.org/doi/abs/10.1175/2008BAMS2634.1.

Twomey, S., 1974. Pollution and the Planetary Albedo. Atmospheric Environment, 41(SUPPL.), pp.120-125.

Twomey, S., 1977. The Influence of Pollution on the Shortwave Albedo of Clouds. Journal of the Atmospheric Sciences, 34(7), pp.1149-1152.

Wesely, M.L. \& Hicks, B.B., 2000. A review of the current status of knowledge on dry deposition. Atmospheric Environment, 34(12-14), pp.2261-2282.

Wexler, A.S., Lurmann, F.W. \& Seinfeld, J.H., 1994. Modelling Urban and Regional Aerosols I. Model Development. Atmospheric Environment, 28(3), pp.531-546.

Wild, M. et al., 2013. The global energy balance from a surface perspective. Climate Dynamics, 40(11-12), pp.3107-3134.

Williams, M.R., Fisher, T.R. \& Melack, J.M., 1997. Chemical composition and deposition of rain in the central Amazon, Brazil. Atmospheric Environment, 31(2), pp.207-217. 


\section{Apêndice A - RESUMOS PUBLICADOS EM ANAIS DE CONGRESSOS}

1) Holanda, Bruna Amorim; Paulo Artaxo; Brent N. Holben. LONG-TERM AERONET REMOTE SENSING OBSERVATIONS IN AMAZONIA; 13th IGAC (International Global Atmospheric Chemistry) Science Conference, 22-26 Setembro de 2014, Natal, Brasil.

2) Paulo Artaxo, Henrique M Barbosa, Joel Ferreira De Brito, Florian Wurm, Bruna Amorim Holanda, Samara Carbone, Andrea Arana, Glauber G. Cirino, Rodrigo Souza, Luciana Varanda Rizzo, Scot T. Martin, Meinrat O. Andreae, Brent N. Holben and Joel Schafer. Aerosol Physical and Chemical Properties Before and After the Manaus Plume in the GoAmazon2014 Experiment. American Geophysical Union Fall meeting, San Francisco, USA, 15-19 Dezembro de 2014.

3) Holanda, Bruna Amorim, Paulo Artaxo, Joel F. Brito, Henrique Barbosa, Meinrat O. Andreae, Jorge Saturno, Christopher Pöhlker, Brent Holben, Joel Schafer. Light Absorption of Biogenic Aerosol Particles in Amazonia. American Geophysical Union Fall meeting, San Francisco, USA, 15-19 Dezembro de 2014.

2015

4) Artaxo, P., Henrique M. J. Barbosa, Elisa T. Sena, Boris Barja, Joel F. Brito, Bruna A. Holanda. Aerosol radiative forcing and optical properties of aerosols over Amazonia using Lidar, AERONET and other tools. VIII Workshop Lidar Measurements in Latin America (WLMLA) em Cayo Coco, Cuba, 6-10 Abril de 2015.

5) Barbosa, H. M. J., Boris Barja, Diego Alves Gouveia, Eduardo Landulfo, Paulo Almeida, Bruna A. Holanda, Theotônio Pauliquevis, Paulo Artaxo, Scot Martin Disentangling the Manaus pollution plume from the biomass burning plume during the second GoAmazon 2014/5 Intensive Operating Period (IOP2). VIII Workshop Lidar Measurements in Latin America (WLMLA) em Cayo Coco, Cuba, 6-10 Abril de 2015.

6) Artaxo, P., H. M. J. Barbosa, S. Carbone, J. F. Brito, B. A. Holanda, G. Cirino, R. A. F. Souza, L. V. Rizzo, S. Martin, M. O. Andreae. Aerosol Physical and Chemical Properties in Amazonia Investigated in the GoAmazon 2014/15 Experiment. SAMBBA Workshop on Data Analysis, University of Reading, 22-24 Abril de 2015.

7) B.A. Holanda, J.F. Brito, H. Barbosa, S. Carbone, G. Cirino, L.V. Rizzo, M.O. Andreae, J. Saturno, C. Pöhlker, S. Martin, B. Holben, P. Artaxo. Light Absorption by Aerosol Particles in Amazonia. Latin American and Caribbean Aerosol Measurements School: From measurements technologies to applications em La Paz, Bolivia, 22-27 Junho de 2015 .

8) P. Artaxo, H.M.J. Barbosa, J.F. Brito, S. Carbone, E.T. Sena, B. Holanda, M.A.F. Silva Dias, G. Cirino, L.V. Rizzo, R. Souza, S. Martin, M.O. Andreae, C. Pöhlker, and J. Saturno, Aerosols in Amazonia: Urban impacts on a pristine atmosphere at GoAmazon 2014-15. Paper 15AAP_O014, European Aerosol Conference - EAC, Milano, Itália, 6-11 Setembro de 2015.

9) S. Carbone, J.F. Brito, L.V. Rizzo, B.A. Holanda, J. Saturno, C. Pöhlker, H.M.J. Barbosa, M.O. Andreae, and P. Artaxo, Chemical characterization of submicron aerosol particles during the dry and wet seasons in the Amazon forest - ATTO station. Paper 
15AAP_O015. European Aerosol Conference - EAC, Milano, Itália, 6-11 Setembro de 2015.

10) J. Brito, G. Cirino, L.V. Rizzo, B.A. Holanda, S. Carbone, H. Barbosa, F. Ditas, C. Pöhlker, X. Chi, M.L. Krüger, D. Moran, J. Saturno, M.O. Andreae, S.S. de Sá, Y.J. Liu, S.T. Martin, R. Souza, J. Wang, B.B. Palm, J.L. Jimenez, and P. Artaxo. Paper 41AAP_O042. European Aerosol Conference - EAC, Milano, Itália, 6-11 Setembro de 2015.

11) B.A. Holanda, J.F. Brito, H. Barbosa, S. Carbone, G. Cirino, L.V. Rizzo, M.O. Andreae, J. Saturno, C. Pöhlker, S. Martin, B. Holben, and P. Artaxo. Light absorption by aerosol particles in Amazonia. Paper 2AAP_P079. European Aerosol Conference - EAC, Milano, Itália, 6-11 Setembro de 2015.

12) P. Artaxo, H.M.J. Barbosa, J. F. Brito, S. Carbone, B.A. Holanda, G. G. Cirino, L. V. Rizzo, S. Martin, M. O. Andreae, C. Pöhlker. The biogeochemistry of aerosols and trace gases in Amazonia in the GoAmazon 2014-15 experiment. International Society for Environmental Biogeochemistry (ISEB)", Piran, Slovenia, September 28 - October 2, 2015.

13) B.A. Holanda, J.F. Brito, S. Carbone, H. Barbosa, L.V. Rizzo, G. Cirino, M.O. Andreae, J. Saturno, C. Pöhlker, S. Martin, B. Holben, J. Schafer, P. Artaxo. Spectral Light Absorption and Scattering by Aerosol Particles in Central Amazonia. AGU Fall Meeting, San Francisco, 14-18 December 2015.

14) Joel F. De Brito, Glauber G. Cirino, Luciana V. Rizzo, Bruna A. Holanda, Samara Carbone, Henrique M Barbosa, Florian Ditas, Christopher Pöhlker, Xuguang Chi, Mira L. Krüger, Daniel Moran, Jorge Saturno, Meinrat O Andreae, Suzane S de Sá, Yingjun Liu, Scot T Martin, Rodrigo Souza, Jian Wang, Brett B Palm, Jose L Jimenez and Paulo Artaxo. The impact of anthropogenic emissions on the otherwise pristine Amazonian rainforest: Insights on aerosol dynamics as observed during GoAmazon2014/5. AGU Fall Meeting, San Francisco, 14-18 December 2015. 